\title{
L'INFRACTION COLLECTIVE (APPROCHES PSYCHO-SOCIO-CRIMINOLOGIQUES ET SA STRUCTURE JURIDIQUE EN FRANCE)
}

\author{
Par Sami SELÇUK \\ Docteur en droit \\ Agrégé de droit et procédure pénale \\ Conseiller à la Cour de cassation
}

Sommaire: I - Introduction, II - Terminologie, III - Approches psycho-socio-criminologiques: A - Théorie de Sighele, B - Théorie de Tarde, C - Théorie de Le Bon, D - Théorie de Mac Dougall, E - Théorie de Freud, F - Théorie de Gustav Jung, G - Théorie d'Adler, $\mathrm{H}$ - Théorie d'Espinas, I - Théorie de Reiwald, J - Théories sociologiques, $\mathrm{K}$ - Théorie de M.M. Robert et Lascoumes, IV - Les aspects particuliers et la structure juridique de l'infraction collective en France, $\mathrm{A}-$ Pensée criminelle collective et répréhensible, B - La tentative et l'infraction collective, $\mathrm{C}$ - Désistement et infraction collective, $\mathrm{D}-$ Prescription et infraction collective, $\mathrm{E}-$ Collectivisation de la responsabilité pénale au point de vue du fait matériel, a) La culpabilité et la participation au fait collectif, b) L'appartenance à un grupe, aa) L'appartenance à un groupe constitue une infraction spéciale dans certains cas: 1. Le complot, 2. La formation de bandes armées, 3 . Organisation de mouvements insurrectionnels, 4. Participation à l'attroupement, 5. Coalition de functionnaires, 6. Association de malfaiteurs, bb) La participation à une activité collective constitue une circonstance aggravante dans certains cas: 1. Rébellion, 2. Mendicité, 3. Viol, 4. Vol, 5. Pillage, cc) L'appartenance active à un groupe entraîne une responsabilité des agissements colllectifs dans certains cas: 1. La participation présumée: Crimes de guerre, 2. L'assimilation entre l'appartenance au groupe et la participation: a - Crimes et délits commis en bande, b-Actions commises en groupe (loi "anti-casseurs"), aa - Infractions, aaa Violences ou dommages matériels commis en groupe lors d'actions à force ouverte, bbb - Violences ou dommages matériels commis au cours de rassemblements illicites ou interdits, ccc - Répression des actions de provocateurs, $\mathrm{bb}$ ) Les modalités de la répression, aaa - Les pénalités, bbb Tentative, ccc - Complicité, ddd - Circonstances atténuantes et sursis, eee - Cumul d'infractions, fff - Excuse absolutoire, ggg - Procédure de flagrant délit, cc) Dispositions communes: responsabilité civile et solidarité: 
aaa - Responsabilité civile, bbb - Limitation de la réparation, ccc - Atténuation facultative de la règle de la solidarité, c - Solutions jurisprudentielles, $F$ - Les effets de l'atténuation du critère de la participation, G Faute, imputation et infraction collective, $\mathrm{H}-$ Psychologie du délinquant et infraction collective, $\mathrm{V}-$ Conclusion.

\section{INTRODUCTION}

Nous savons bien que la criminalité est un phénomène social. De plus, d'après DURKHEIM, elle est un phénomène social normal. ${ }^{2}$ En effet, l'histoire prouve aisément que la criminalité est inséparable de toute vie en

${ }_{1}^{1}$ Durkheim, Les règles de la méthode sociologique, Paris, 1960, pp. 65-72. En effet non seulement le crime, selon le grand sociologue français, est normal, mais il est facile de prouver qu'il a bien des utilités: "Contrairement aux idèes courantes, le criminel n'apparait plus comme un être radicalement insociable, comme une sorte d'élément parasite, de corps étranger et inassimilable, introduit au sein de la société; c'est un agent régulier de la vie səciale. Le crime, de son coté, ne doit plus être conçu comme un mal qui ne saurait être contenu dans de trop étroites limites; mais, bien loin qu'il y ait lieu de se féliciter quand il lui arrive de descendre trop sensiblementau dessous du niveau ordinaire, on peut ètre certain que ce progrès apparent est à la fois contemprorain et solidaire de quelque perturbation sociale. C'est ainsi que jama:s le chiffre des coups et blessures ne tombe aussi bas qu'en temps de disette. (...) (D'ailleurs, de ce que le crime est un fait de sociologie normale, il ne suit pas qu'il ne faille pas le hair. La douleur, elle non plus, n'a rien de désirable, l'individu la hait comme la société hait le crime, et pouriant elle relève de la physiologie normale. Non seulement elle dérive nécessairement ae la constitution même de tout être vivant, mais elle joue un rôle utile dans $l_{a}$ vie et pour lequel elle ne peut etre remplacée. Ce serait donc denaturer singulièrement notre pensée que de la présenter comme une apologie du crimel. En mème temps et par contrecoup, la théorie de la peine se retrouve renouvelée ou, plutôt, à renouveler. Si. en effet, le crime est une maladie, la peine en est le remède et ne peut être conçue autrement, aussi toutes lej discussions qu'elle soulève portent-elles sur le point de savoir ce qu'elle doit être pour remplir son rôle de remède. Mais, si le crime n'a rien de morbide, la peine ne saurait avoir pour objet de le guérir et sa vraie fonction doit être cherchee ailleurs." (op. cit., p. 72). D'autre part, il nous parait qu'a ce sujet, Karl Marx avait précedé Durkheim. En effet, il avait écrit ces phrases: "Un criminel produit la criminalité. Mais, si les liens entre cette branche soi-disant criminelle de la production et toute l'activité productrice de la société sont examinés de plus près, nous sommes forcés d'abandonner un certain nombre de préjugés. Le criminel produit non seulement la criminalité, mais aussi la loi criminelle; i) produit le professeur qui donne des cours au sujet de la loi criminelle et de la criminalité, et nême l'inévitable livre de base dans lequel le professeur présente ses idées et qui est une marchandise sur le marché.(...) De plus le criminel produit tout l'appareil policier ainsi que de l'administration de la justice, detectives, juges, jurys, etc., et toutes ces professions différentes, qui constituent autant de 
société ${ }^{2}$ et se trouve régulièrement dans toutes les sociétés. Si elle est un des aspects constants de cette vie en société ainsi qu'une maladie, ${ }^{3}$ il est superflu de dire que le phénomène délictuel est vieux comme le monde. Depuis les premiers temps de l'histoire, la criminalité n'a jamais cessé de se manifester dans toutes les civilisations et clans tous les lieux de la terre. C'est pourquoi, à toutes les époques et dans toutes les sociétés, toute action qui trouble la paix sociale, qui porte atteinte aux biens, est sanctionnée selon les règles de droit et les châtiments qui conviennent et varient avec l'état politique et économique, les traditions culturelles, les autres besoins de la communauté ${ }^{4}$. D'ailleurs, la réaction sociale est un réflexe de défense de la société contre les actes qui la perturbent.

catégories dans la division sociale du travail, développent des habilités diverses au sujet de l'esprit humain. créent de nouveaux besoins et de nouveaux moyeng de les satisfaire. La tourture elle-même a permis l'invention de techniques fort ingénieuses, employant une foule d'honnêtes travailleurs dans la production de ces instruments. Le criminel produit (...) aussi l'art, la littérature, les romans et les drames tragiques dont le thème est la criminalité, (...). Le criminel interrompt la monotonie et la sécurité de la vie bourgeoise. Il la protège ainsi contre la stagnation et fait émerger cette tension à fleur de peau, cette mobilité de l'esprit sans lesquelles le stimulus de la compétition elle-même serait fort mince. Il donne ainsi une nouvelle impulsion aux forces productrices. Lo crime enlève du marché du travail une portion excédentaire de la population. diminue la compétition entre travailleurs, et jusqu' à une certáine limite met un frein à la diminution des salaires, et la guerre contre le crime, de son côte, absorbe une autre partie de cette même population. Le criminel apparait ainsi comme une de ces "forces équilibrantes" naturelles qui établissent une juste balance et ouvrent la porte à plusieurs occupations soi-disant "utiles". L'influence du criminel sur le développement des forces productrices peut être détaillée. Est-ce que le métier de serrurier aurait atteint un tel degré de perfection s'il n'y avait pas eu de voleurs? Est-ce que la fabrication des chèques bancaires aurait atteint un tel degré-d'excellence s'il n'y avait pas eu d'escrocs? Est-ce que le microscope aurait pénétré avec autant d'efficacité le monde commercial de tous les jours s'il n'y avait eu de faux-monnayeurs? Le développernent de la chimie appliquée n'est-il pas dù autant à la falsification des marchandises et aux tentatives pour y remédier, qu'aux efforts productifs honnêtes? Le crime, par le développement sans fin de nouveaux moyens d'attaquer la propriété, a forcé l'invention de nouveaux moyens de défense, et ses effets productifs sont aussi grands que ceux des grèves par rapport l'invention des machines industrielles. Laissant le domaine du crime privé, y aurait-il un marché mondial, est-ce que les nations mème existeraient s'il $n$ y avait pas eu de crimes nationaux. Laarbre du mal n'est-il pas aussi l'arbre du savoir depuis le temps d'Adam? Le jour où le Mal disparaitra, la Société en serait gâtée, si même elle "ne disparait pas!" (Cité par Szabo. Déviance et Criminalite, textes, Paris, 1970, pp. 84-85).

2 Imbert-Levasseur, Le pouvoir, les juges et les bourreaux, Paris, 1972, p. 9.

3 Pinatel, La Société criminogène, Paris, 1971, p. 12.

- Antolisei, Manuale di diritto penale, parte speciale, Milano, 1977, I., pp. 4-5; 
Malgré cette réaction, souvent très sévère, de nos jours, ce fléau délictuel arrive aux larges dimensions, aux grands volumes et aux nouveaux modèles. Des dernières années, on parle beaucoup, dans tout le monde, du défi de la criminalités, et des formes nouvelles dongereuses de délinquance. En particulier, les délits collectifs, qui déclenchent une rếaction émotionnelle, se multiplient de plus en plus rapidement dans le monde moderne. Face à cet aspect de la criminalité actuelle sans cesse croissante, d'une part, malgré les progrès scientifiques en matière de recherche, on ne peut pas trouver une solution satisfaisante; en effet, "les sociétés industrielles se demandent si le taux croissant de la criminalité est un aspect endémique à leur essor, les sociétés moins avancés se demandent si c'est le prix qu'elles aussi doivent payer pour réaliser les progrès auxquels elles aspirent" ${ }^{\prime}$; d'autre part, la conscience collective des peuples désire que tous les actes délictuels de cette sorte, socialement intolérables, soient frappés de peines très sévères. D'ailleurs, la criminalité collective n'est pas une nouveauté. A notre époque, la délinquance en groupe dispose de moyens d'action plus puissants. De plus, cette délinquance a un caractère plus alarmant et se répand dans toutes les catégories criminelles?: bandes de jeunes délinquants, bandes de gangsters, commandos ou milices de délinquants politiques etc...

Bettiol - Pettoello Mantovani, Diritto penale, parte generale, Padova, 1986, p. 13 et s.; Léauté, Criminologie et science pénitentiaire, Paris, 1972, p. 10, Mantovani, Diritto penale, parte generale. Padova, 1979 , p. 5 et s.; Merle-Vitu, Traité de droit criminel, Droit pénal spécial, par André Vitu, Paris, 1982, I, pp. 13-15; Nuvolone, Il sistema di diritto penale, parte generale, Padova, 1975, pp. 11, 12; Pagliaro, Principi di diritto penale, parte generale, Milano, p. 211 et s.; Pradel, Droit pénal, Paris, 1984, p. 21 et s.; Ranieri, Manuale di diritto penale, Padova, 1968 , p. 9; Rodriguez Devesa, (Por Alfonso Serrano Gomez), Derecho penil espanol, parte especial, Madrid, 1987, p. $4_{i}$ Manzini, (Pisapia), Trattato di diritto penale italiano, Torino, 1981, I, p. 22 et s.; Hafızoğullian, Ceza normu, Ankara, 1987, p. 25 et s.; Içel-Donay, Karşllaştırmalı ve uygulamalı ceza hukuku, Istanbul, 1987, p. 6; Yüce, Ceza Hukukunun Temel Kavramları, Ankara, 1985, p. 2; Waquet, Les valeurs pénales, étude criminologique, Revue internationale dẹ droit penal, 1952, pp. 347-374.

${ }^{5}$ Lopez-Rey, Les jeunes et la criminalité dans la société contemporaine et liz société future, Revue de science criminelle et de droit pénal comparé, 198.), n. 4, p. 906; Ancel, La défense sociale nouvelle, un mouvement de politiqu.; criminelle humaniste, Paris, 1981, p. 6; Picca, Pour une politique du crime, Paris, 1966, p. 25 et s.; Brown, La prévention de la criminalité à la recherche de concepts et de stratégies, Rev. Sc. Crim., 1980, p. 943; Nuvolone, La criminalité de Lombroso à nos jours, Rev. Sc. Crim., 1979, n. 4, p. 749; Pinatel, la société criminogène, Paris, 1971, p. 7; Selçuk, Systeme de la justice penale totale et humaniste, Revue pénitantiaire et de droit pénal, 1980, n. 3., pp. 421-425.

6 Brown, étude précitée, p. 943.

${ }^{7}$ On peut consulter pour plus de détails: Alpaslan, Kriminoloji ve hukuk açısır:- 
On peut voir facilement que le délit est, spécialement dans ses formes les plus graves, les plus frappantes et les plus constantes, un fait social en relief, un indice proprement dit de: déficiences et de déséquilibres dans la structure de la société. Cette situation constitue la motivation juste des dernières lois que l'on a adoptées dans la plupart des pays civilisés aux cours des dernières années. ${ }^{8}$ Cependant, pour bien connaître et bien juger une action humaine, il faut en considérer non seulement l'aspect extérieur et l'effet physique, mais aussi l'élément psychique et intérieur: la volonté, l'intention, la conscience. ${ }^{9}$ Car, la mission sociale de la justice criminelle donne au droit pénal, avant tout, une éminente fonction de protection sociale, où doivent s'équilibrer les garanties de l'homme et celles de la collectivité et de la communautén ${ }^{10}$. Aussi, nous semble-t-il important d'aborder l'étude des groupes au sens le plus large du mot, pour bien connaître le délit de groupes, en d'autres termes, l'infraction collective et surtout pour bien savoir si des groupes ont un caractère criminogène. Car, cette nouvelle forme de délinquance, qui résulte quelquefois des agissements d'une foule, attire de plus en plus, l'attention des criminologues, des pénalistes et même des psychologues.

\section{TERMINOLOGIE}

En examinant les délits collectifs, nous désignerons tous les mots: réunion, rassemblement, regroupement, masse, foule et bande, au sens le plus large du terme, sous le vocable "groupe".

dan tedhiş̧̧ilik, Istanbul, 1983; Bassiouni, Perspectives en matière de terrorisme, Mélanges en l'honneur du Doyen Pierre Bouzat, 1980, pp. 471-487; Léauté, op. cit., p. 588 et s.; : Pinatel, Criminologie, (Traité de droit pénal de MM. Bouzat et Pinatel, III), Paris, 1970, pp. 447-460; Réponses à la violence, (Rapport Peyrefitte) Paris, 1977, I, II; Plantey, Réponses européennes au terrorisme international, Reuve de science criminelle et de droit comparé, 1983, pp. 379-394; Stéfani, Levasseur, Jambu-Merlin, Criminologie et science pénitentiaire, Paris, 1963, $\mathrm{n}^{\text {os }}$ 61, 224, 225; Sutherland, Principes de criminologie, Paris, 1966; Szabo, Criminologie, Montréal, 1970, p. 249 et s.

a A titre d'exemple, en France, le législateur a adopté en 1970 une "loi tendant à réprimer certaines formes nouvelles de délinquance" qui risque d'instituer la responsabilité collective. Elle est plus connue sous le nom de la "Loi-anticasseures" dans le public, abrogée le 23 décembre 1981, Bouloc, Chronique législative, Revue de science criminelle et de droit comparé, 1982, pp. 373-378. Dans le mème pays, le législateur a adopté une loi (n. 86-1620, 9 Septembre, 1986) concernant les infractions de terrorisme, Bouloc, Chronique lègislative. Revue de science criminelle et de droit comparé, 1987, pp. 247-251, 260-262.. De même en Italie, "Decreto-Legge, n. 625-15.12.1979, Misure urgenti per la tutela dell'ordinamento democratico e della sicureza pubblica. D.L. 8.2.1980, n. 15 . Conversione in legge, con modificazioni del D.L. 15.12.1979, n. 625.

9 Del Vecchio, La justice, la vérité, Paris, 1955, p. 142.

10 Ancel, La défense sociale nouvelle, Paris, 1981, p. 339. 
Selon le dictionnaire Robert, le groupe est "une réunion de plusieurs personnes dans un même lieu". La plupart du temps, les groupes de cette sorte constituent des rassemblements accidentels, spontanés, inorganisés. En ce qui concerne la bande, elle est un "groupe d'hommes qui combattent ensemble, rangés sous une même bannière, un même chef $(. .$.$) , un groupe$ associé pour quelque dessein, ou par quelque affinité"11. En d'autres termes, la bande est un groupe organisé bien que d'une façon irrégulière et occasionnelle ${ }^{12}$.

Cependant, ce sujet vaut d'être examiné autant au point de vue pénal que psychologique. En effet, pour faire la discrimination entre les bandes et les groupes, la plupart des écrivains ont déjà essayé de multiples définitions de chacun, en tenant compte de ses structures normatives, de ses buts, de ses jugements de valeur. Mais, il faut accepter que les formes courantes se trouvent toujours mixtes.

Certains écrivains distinguent entre les groupes à support institutionnel, les groupes spontanés, les quasi-groupes et les bandes, tout en montrant qu'on passe d'une catégorie à l'autre par glissement et non par rupture. Par exemple, les groupes scolaires ont un caractère de groupes à support institutionnel. A côté de cela, il y a des groupes spontanés à but précis: chorales, ateliers de bricoleurs. Ces groupes ne se moulent pas dans une structure préformée. Mais, il est difficile de les distinguer. Quant aux quasi-groupes, ils ne présentent pas de différences ou d'opposition radicales avec les bandes. Ces quasi-groupes eux-mêmes sont divisés en sous-groupes par rapport à leur stabilité. Par exemple, les groupes d'amitié sont stables, mais, les groupes délinquantiels, au contraire, transitoires quoique mieux organisés. Tandis que les bandes sont des regrouppements plus petits, mieux organisés, comme nous l'avons déjà dit. Elles ont des caractères localisés, des noyaux, des memibres, des leaders, des hostilités envers le milieu.

Selon la diversité des observations et des appellations, il est difficile de fixer une frontière objective entre les bandes et d'autres groupes. Par exemple, certains auteurs ont examiné particulièrement le mouvement hippie, d'autres également le mouvoment beatriick. Au cours de ces analyses typologiques et de maintes études monographiques que l'on a faites, d'une part, on a constaté la multiplication, depuis quelques années, de très vastes rassemblements regroupant jusqu'à des milliers de jeunes; d'autre part,

11 Dictionnaire Robert, Paris, 1973; Colliard, Libertés publiques, Paris, 1972, p. 597.

12 Garçon, Code pínal annoté, Paris, 1952, art. 440; Garraud, Traité thcorique et pratique du droit pénal français. 1916, Paris, IV, n. 2694; Léauté, op. cit., p. 588 €t s.; Vitu, op. cit., I, n. 147: Delmas-Marty, Les chemins de la répression, Paris, 1980 , p. 43. 
on a vu des parentés, des similitudes au point de vue de l'homogéneité d'âge, de sexe, de milieu social (scolaire, professionnel, familial), de collégialité du pouvoir, de but, etc... ${ }^{13}$.

Cependant, à notre avis, ces études ne sont pas arrivées à nier la meilleure organisation des bandes par rapport aux autres groupes. On ne doit pas oublier cet aspect, sinon la forêt sera masquée par l'arbre.

\section{APPROCHES PSYCIO-SOCIO-CRIMINOLOGIQUES:}

Le point de départ de la psychologie, même de la psychologie des groupes, est sans doute l'individu. Il s'agit icı d'étudier non pas les groupes, les masses à proprement parler, mais les modifications que subit le psychisme particulier de l'individu lorsqu' il se trouve entouré d'une multitude d'autres individus. Pourtant, ceci ne signifie nullement que la psyhologie des groupes doive être assimilée, en fin de compte, à la psychologie de l'individu. C'est pourquoi, il y a longtemps que de nombreux écrivains ont assez profondément examiné les groupes, au sens le plus large du terme, au point de vue de la criminalité, de la responsabilité délictuelle et de la culpabilité. Maintenant, nous alions examiner brièvement les théories principales.

\section{A. Théorie de SIGHELE:}

SIGHELE, psychologue, sociologue et criminaliste italien, a publié deux livres sur ce sujet à la fin du siècle dernier: "La foule criminelle" et "La psychologie des sectes"14.

Selon lui,

"La sociologie dicte ses lois parallèles à celles de la psychologio individuelle pour les agrégats homogènes et organiques: la psychologie collective devrait dicter ses lois pour les agnégats non homogènes et inorganiques. La foule constitue, en effet, d'un point de vue statique, un agrégat hétérogène par excellence, puisqu'il est composé d'individus de tous les àges, ses deux sexes, de toutes les classes et de toutes les conditıons sociales, de tous les degré de moralité et de culture; et inorganique par excellence, puisqu'il se forme sans accord préalable, soudainement, à l'improviste".

SIGHELE souligne, notamment, les caractères essentiels des groupes ou bien des masses qui découlent de leurs compositions. La masse est formée d'éléments tout à fait hétérogènes, inconnus les uns des autres et

13 Robert-Lascoumes, Les bandes d'adolescents, Paris, 1974; Robert, Les Bandes d'adolescents, Paris, 1966.

14 Sighele, La foule criminelle, Paris, 1938; Psychologie des sectes, Paris, 1908. 
leur organisation subite, provoquée par une étincelle de passion qui, jaillie de l'un d'eux, électrise ce pêle-mêle, en sorte qu'il agit comme un seul être. Cependant, la secte est une foule triée et permanente; la foule est une secte transitoire et qui n'a pas choisi ses membres. La sects est la forme chronique de la foule; la foule est la forme aiguë de la secte. En résumé; on peut considérer la foule comme l'élément primaire indéterminé qui engendre la secte.

Eu égard au phénomène de la délinquance concernant les groupes, les masses, SIGHELE s'est contenté de signaler les problèmes qui se rattachent au processus d'imitation, de contagion morale et de suggestion dans les groupes. Car cette suggestion a son effet le plus puissant et passe au crime endémique; puisque la foule, l'unité de temps et de lieu et le rapport immédiat entre les individus portent aux dernières limites du possible la rapidité de la contagion des émotions. Cette contagion agit presque uniquement dans un sens défavorable. Car SIGHELE croit à l'existence d'une disposition homicide innés. Comme a dit autrefois CARLYLE: "la civilisation n'est qu'une écorce au-dessous de laquelle peut brûler de son feu infernal la passion sauvage de l'homme".

SIGHELE relève des facteurs qui agissent dans le même sens et qui jouent un rôle déterminant dans le comportement criminel des groupes, des foules, l'instinct homicide inné, la présence d'éléments criminels et le nombre de ces éléments. L'état d'excitation psychologique de la foule est caractérisé par le fait que les événements les plus minimes prennent des proportions énormes et que la moindre provocation peut conduire au crime.

Nous trouvons chez SIGHELE, qui juge ainsi sans indulgence le niveau moral de la masse, une analyse intéressante de la responsabilité des membres de la foule: dans la grande majorité des cas, non seulement les meneurs existent, mais, il est facile de les voir et de les atteindre. Parfois même, on les punit trop sévèrement et on croit pouvoir attribuer à eux seuls la cause des crimes de la foule. Une telle remarque mérite d'être développée. Souvent, en effet, le chef fait figure de victime, de bouc Émissaire sur lequel la collectivité entière se décharge de la responsabilité de sa faute.

L'opinion de SIGHELE sur ce point, claire et définitive à la fois, est qu'une foule ne se forme pas sans raison. Les individus ne se réunissent pas sans but. Mais ce but, s'il existe toujours, n'est jamais connu que d'un petit nombre d'individus; le plus grand nombre s'agglomère autour du groupe initial par la simple force de la persuasion. Il cite à ce propos l'exemple célèbre du lynchage "les lyncheurs savent, avant de commettre 
le crime, qu'ils vont le commettre; ils ont prémédité la substance du crime. Il ne pourra donc y avoir qu'une très faible excuse en leur faveur".

En ce qui concerne la réaction de la société aux crimes collectifs, voici ce qu'il dit:

"Souvent une audience d'assises, ayant pour objet un crime sensationnel, surtout un crime collectif, présente des caractères typiques du phénomène de foule, auquel même les juges peuvent succomber".

\section{B. Théorie de TARDE:}

TARDE, sociologue et criminaliste français, parmi les autẹurs qui ont attiré l'attention sur la psychologie collective, écrit plusieurs ouvrages dont les deux suivants sont très intéressants: "Les lois de l'imitation" et "L'opinion et la foule"15.

Il est hors de doute que TARDE, grâce à ses connaissances étendues et profondes, aux vastes perspectives qu'il ouvre devant nous, grâce, en particulier, à sa vive imagination, a donné à la psychologie collective une base psychologique plus ample que :2e l'a fait SIGHELE.

D'après TARDE, c'est l'imitation qui est le principal facteur de cohésion et de continuité de la société, de la communauté. Il donne sur ce sujet la définition suivante:

"Une collection d'êtres en tant qu'ils sont en train de s'imiter entre eux ou en tant que, sans s'imiter actuellement, ils se ressemblent et que leurs traits communs sont des copies anciennes d'un même modele".

Dans sa préface à la deuxième édition, TARDE prévient le reproche d'une trop grande simplification dans les termes suivants:

"Il y a deux manières d'imiter, en effet, : fäire exactement comme soll modèle ou faire exactement le contraire".

Dans ses ouvrages qui ont trait à la force motrice affective de l'imitation, on peut trouver facilement et clairement la génèse de celle-ci. D'ailleurs, c'est justement cette analyse qui fait de TARDE autant un grand psychologue qu'un criminaliste. Cette génèse. est d'une importance considérable pour la psychologie des masses.

Cependant, TARDE a limité la portée de la définition de l'imitation. En effet, il a précisé qu'il n'entendait pas expliquer ce qu'est la société, mais, ce qui conditionne la cohésion. Il employait le mot "sociabilité" au lieu du mot "imitativité". Or, selon lui, "sociabilité" signifie "imitativité", c'est-à-dire la tendance à imiter.

15 Tarde, Les lois de l'imitation, Paris, 1907: L'opinion et la foule, Paris, 1909. 
Nous pouvons trouver également dans la doctrine de TARDE une analyse circonstancielle des relations existant entre la foule et le public qu'il caractérise tous les deux. Selon cette doctrine, les foules se ressemblent toutes, les unes aux autres par certains aspects, certains traits: leur intolérance prodigieuse, leur orgueil grotesque, leur susceptibilité maladive, le sentiment affolant de leur irresponsabilité née de l'illusion de leur toute puissance et enfin la perte totale du sentiment de la mesure qui tient à l'outrance de leurs émotions mutuellement exaltées. Partant de cela, à notre avis, il a relevé la caractéristique criminogène de la masse. En effet, TARDE a attiré ici l'attention sur ce point qui est très important pour notre exposé. Il a dit à ce sujet:

"Entre l'exécration et l'adoration, entre l'horreur et l'enthousiasme, entre les cris "vive" et "àmort"; il n'y a pas de milieu pour une foule... "vive" signifie "vive à jamais", il y a là un souhait d'immortalité divine. un commencement d'apothéose. Il suffit d'un rien pour changer la divinisation en damnation éternelle".

Pourtant, il faut faire ici une digression. TARDE signale aussi l'existence de "foules d'amour", de "foules de fêtes", en opposition aux "foules de haine". Il nous explique, avec du talent, comment elles ont contribué à tisser ou resserrer les liens sociaux. C'est qu'en fait, le rôle que jouent ces foules d'amour a une signification d'une autre nature profonde. On peut facilement constater que TARDE a examiné le caractère barbare et primitif de la foule, de groupe qui, au sens le plus large du terme, n'est nullement son attribut unique, mais simplement un des aspects parmi d'autres.

\section{Théorie de LE BON:}

LE BON, ainsi que TARDE, est ur des savants français mondialement connus. Il a publié un grand nombre d'oeuvres sur la psychologie des peuples et des foules et sur la sociologie à la fois. En particulier, son ouvrage "Psychologie des foules", parmi bien d'autres, a exercé une influence durable et profonde ${ }^{16}$.

Selon le thème qu'a développé LE BON dans l'introduction de son ouvrage, il insiste catégoriquement sur le fait que seule la connaissance du problème des foules et des peuples nous permet de comprendre l'évolution politique, sociale et culturelle de l'époque moderne.

En effet, selon notre écrivain:

“... l'àge où nous entrons sera véritablement l'ére des foules. Ce n'est pas dans les conseils des princes mais. dans l'àme des foules que sa

16 Le Bon, Psychologie des foules, Paris, 1895. 
préparent les destinées des nations. Il importe de savoir, qu' aujourd'hui, les revendications des foules deviennent de plus en plus nettes et no visent pas à moins qu'à détruire de fond en comble la société acuelle. pour la ramener à ce communisme primitif qui fut l'état normal de tous les groupes humains avant l'aurore de la civilisation".

Cependant, toutes les recherches de LE BON, qui nous ouvrent de vastes perspectives, au fond, portent sur la foule à côté de la critique des classes ouvrières.

$\mathrm{Au}$ fond, chez LE BON, au lieu de trouver l'analyse d'une âme et d'un esprit collectifs différents du psychisme particulier des individus qui composent la foule, nous voyons l'examen des individus dont le comportement, selon lui, est modifié dès qu'ils s'intègrent à une foule.

"Les caractères principaux de l'individu en foule ce sont: évanouissement de la personnalite consciente, orientation par voie de suggestion et de contagion des sentiments et des idées dans un mème sens, tendance à transformer en actes les idées suggérées... il n'est plus lui même. il est devenu un automate que sa volonté ne guide plus".

L'individu est englobé dans la foule. Ainsi, LE BON poursuit, sur l'inconscience qui se produit:

“...les observations particulières prouvent que l'individu plongé depurs quelques temps au sein d'une foule agissante se trouve bientôt placé... dans un état particulier qui se rapproche beaucoup de l'état de fascination où se trouve l'hypnotise, dans les mains de son hyphotiseur. La parsonnalité consciente est entièrement évanouie, la volonté et le discernement sont perdus".

On voit que, désormais, cette prédominance de l'inconscient engendre une transformation radicale de la personnalité de l'individu:

"Aussi, par le fait seul qu'il fait partie d'une foule organisée, l'homme descend de plusieurs degrés sur l'échelle de la civilisation. isole, c'était. peut-être un individu cultivé, en foule, c'est un barbare, c'est-à-dire un instinctif".

On arrive ainsi à une grave régression. L'homme de la foule retourne à l'état primitif, comme, dans le passé, chez le sauvage, et dans la première enfance chez l'homme civilisé. In résumé, le potentiel iritellectuel des différents individus ne joue aucun rôle. Sur ce point, nous pouvons citer ce passage: .

"Dès que quelques individus sont réunis, ils constituent une foule et alors même qu'ils seraient des savants distingués, ils prennent tous les caractères des foules pour ce qui est en dehors de leur spécialits. La faculté d'observation et l'esprit critique possédés par chacun d'eux s'évanouissent aussitót. (...) L'individu voit les choses en bloc et ne connait pas les transitions. (...) Il peut supporter la contradiction et 
la discussion. Mais la foule ne les supporte jamais: En bref, l'individu normal est différent selon qu'il se trouve isolé au sein d'une foule".

A la suite de ses recherches, LE BON a introduit l'expression "la foule psychologique". Selon lui:

“... le fait le plus frappant que présente une foule psychologique est jy suivant: quels que soient les individus qui la composent, quelques semblables ou dissemblables que soient leur genre de vie, leurs occu pations, leur caractère ou leur intelligence, par le fait seul qu'ils sont transformés en foule, ils possèdent une sorte d'áme collective qui les fait sentir, penser et agir d'une façon tout à fait différente de celle dont sentirait, penserait et agirait chacun d'eux isolément. Il y a des idées, des sentiments qui ne surgissent ou ne se transforment en acto que chez les individus en foule". En consequence, on peut dire que "la foule psychologique" est un ètrè provisoire, formé d'éléments' hétérogènes qui, pour un instant, se sont soudés, absolument comme les cellules qui constituent un corps vivant, forment par leur réunion un être nouveau, manifestant des caractères fort différents de ceux que chacune de ceq cellules possèdent. L'orientation de tous les sentiments et pensées de la collectivité se produit dans une mème direction. C'est ce qu'on appelte "la loi psychologique de l'unité mentale des foules".

Dans une foule, tout sentiment, tout acte est contagieux, en ce sens que l'individu sacrifie très facilement son intérêt personnel à l'intérêt collectif. Cela va, notamment, jusqu'à l'abandon de l'instinct de conservation. A savoir que, trois élements, le sentiment de toutepuissance, la contagion et la suggestibilité se manifestent dans la foule. L'origine de la suggestibilité dérive (provient) des membres de la foule qui s'influencent réciproquement.

LE BON conclut que, sur le plan intellectuel, le comportement collectif est toujours inférieur à celui de l'individu. Il ne se laisse pas de souligner le contraste entre le comportement de l'individu isolé et de l'individu dans la foule. Pris séparément, les gens ont des habitudes pasifiques. Réunis en foule, les mêmes gens n'hésitent pas à approuver les propositions les plus féroces, à envoyer à la guillotine les individus les plus manifestement innocents; et contrairement à tous leurs intérêts, à renoncer à leur inviolabilité et à se décimer eux-mémes. Les foules qui sont le jouet de toutes les excitations extérieures, reflètent leur variabilité incessante. Elles passent en un instant de la férocité la plus sanguinaire à la générosité ou à l'héroïsme le plus absolu. La foule étant ainsi une puissance irresistible, selon LE BON, ne tolère aucun sursis, aucun obstacle entre ses désirs et leur satisfaction. Partant de cette hypothèse, il se prononce, ce qui est plus grave et important pour notre étude, sur les défaillances qui se produisent dans le domaine de la moralité. En effet, nous pouvons arriver ici à l'explication de la fréquence des délits dans la foule. C'est seulement par le fait que 
les instincts de la férocité destructive sont des résidus des âges primitifs qui dorment au fond de chacun de nous. Dans la vie de l'individu isolé; il lui serait dangereux de les satisfaire, tandis que son absorption dans une foule irresponsable et où, par conséquent, l'impunité est assurée, lui donne toute liberté pour les suivre.

On voit bien que, LE BON, analyse l'individu dans la foule. D'après lui, la foule a son mode de pensée qui lui est propre, c'est-à-dire de pensée en images. C'est celle aussị des primitifs et des enfants, et qui s'oppose à la pensée s'exprimant sous la forme de concepts. Ces idées-images ont une vivacité excessive. Quant à l'excessive suggestibilité de la foule, elle représente un de ses traits dominants. Les foules n'étant capables ni de réflexion ni de raisonnement ne connaissent par l'invraisemblable. Elles sont trop impulsives, trop mobiles. Il faut signaler une fois de plus que, selon LE BON, un commencement d'antipathie ou de désapprobation qui, chez l'individu isolé, ne s'accentuerait pas, devient aussitôt haine féroce chez l'individu en foule. Tous les individus en foule suivent les meneurs. Les hommes réunis en foule perdent toute volonté et se tournent d'instinct vers celui qui en possède une. Tandis que ces meneurs ne sont pas, le plus souvent, des hommes de pensée, mais des hommes d'action. Ils se recrutent surtout parmi les névrosés, les excités, les demi-aliénés qui côtoient les bords de la folie. En d'autres termes, ils se distinguent de la foule par une affectivité suraiguë, souvent maladive.

Ces idées ont sans doute contribué beaucoup à la psychologie. Mais, au point de vue de la culpabilité, nous ne pouvons pas trouver une pensée claire chez LE BON. Car, il importe de ne pas oublier qu'il ne fut pas criminaliste, juriste, mais médecin.

\section{Théorie de MAC DOUGALL:}

MAC DOUGALL était un grand psychologue anglais ${ }^{27}$. A l'opposé de LE BON, il établit nettement le contraste entre la masse organisée et la masse inorganisée. La masse organisée présente bien des phénomènes élémentaires de la psychologie collective sous des formes relativement simples; plus le niveau de l'organisation est élevé, plus la psychologie devient complexe.

Ce qui est important pour MAC DOUGALL, c'est l'affectivité de la foule qui la caractérise essentiellement. L'excitation ou intensification de l'excitation est le résultat le plus frappant de la formation d'une foule et une des raisons principales de sa force attractive. Les membres d'une foule sont, pour ainsi dire, détachés d'eux-mêmes. Ils se sentent saisis d'une

17 Reiwald, De l'esprit des masses, Paris, 1949, pp. 04-101. 
grande vague d'excitation. Ils perdent la conscience de leur individualité. Une quantité de personnes réunies d'une manière ordinaire emprunte le caractère d'une foule au sens psychologique, si toutes subissent la même excitation, si leur attention est dirigée vers le même objet et si l'état d'esprit de chacune d'elles est déterminé dans une certaine mesure par l'état mental de celles qui l'entourent. C'est la condition fondamentale de la vie collective.

L'individu dans une foule est, dans une certaine mesure, dépersonnalité. C'est par cela que la foule peut se laisser entrainer à des excès de brutalité résultant de la personnalisation des individus qui la composent et d'une carence du sens des responsabilités. MAC DOUGALL signale que l'excitabilité particulière de la foule contribue à abaisser son niveau intellectuel, de même que l'absence du sens des responsabilités.

Quant à la formation de la volonté, elle s'est produite de façon différente dans les foules primitives et dans les foules organisées. Lec actes d'une foule primitive sont plutôt comparables à ceux d'un animal qu'à ceux d'un être humain. Ils ne sont le résultat ni d'une volonté collective, ni de la volonté de tous les membres; étant primitifs, ces actes ne sont pas volitifs au sens propre du mot, mais plutôt instintifs.

Comme nous l'avons déjà expliqué; MAC DOUGALL a bien examiné la différence entre les foules primitives et les masses organisées. Selon lui, par ex€mple, l'armée représente une masse organisée dans laquelle une volonté déterminée se manifeste. Il est naturel que cette masse organisée nous intéresse plutôt au point de vue des bandes. A côté de cela, d'après MAC DOUGALL, dans n'importe quel groupe, il y a un sentiment de groupe qui suscite des excitations et des impulsions d'où résultent des actes intéressants.

Il résulte facilement de ses observations que MAC DOUGALL ne s'interesse pas au problème de la responsabilité et, naturellement, de la criminalité.

\section{E. Théorie de FREUD:}

FREUD, créateur de la psychanalyse, a publié sur ce sujet deux ouvrages principaux: "Psychologie collective et analyse du moi" et "Totem et Tabou"18.

D'après FREUD, la psychologie est la science fondamentale. La sociologie ne saurait étudier le comportement humain sans recourir aux explications psychologiques. Selon lui, la psychologie a rarement affaire à

${ }_{18}$ Freud, Psychologie collective et analyse du moi, Paris, 1824; Totem ve tabu Ankara, 1949. 
l'individu isolé, mais plutôt à l'individu en contact avec ses semblables, sauf dans le cas du narcissisme comme stade prédominant de la première enfance.

Nous savons que FREUD voit dans la libido (l'amour) la force qui cimente les rapports entre les gens. Le processus, dont TARDE voit l'origine dans l'imitation, LE BON dans la suggestion et MAC DOUGALL dans l'induction affective primitive, est ramené par cet éminent biologiste et psychologue à une orientation particulière de la libido, à une identification. De méme que les frères et soeurs s'identifient dans leurs aspirations communes, les membres d'une foule s'identifient les uns aux autres. Cette identification mutlelle est un des éléments de sa formation. Cependant, à l'opposé de ses prédécesseurs, FREUD part, non pas de la foule primitive, mais de deux masses supérieures, organisées, permanentes, artificielles: l'Eglise et l'Armée. Il examine le chef, la horde primitive, enfin les rapports entre la horde primitive et le père. Selon lui, ces rapports donnent une image' exacte de ce qui existe entre la foule et le chef. Il résulte de ses recherches que les conclusions ci-dessous apparaissent: la foule nous apparait ainsi comme une résurrection de la horde primitive. De même que l'homme primitif survit virtuellement dans chaque individu, de même la foule humaine est capable de reconstituer la horde primitive. La psychologie de la foule, telle que nous la connaissons, c'est-à-dire impliquant la disparition de la personnalité consciente, l'orientation des idées et sentiments de tous dans une seule et même direction, la prédominance de l'affectivité et la vie psychique inconsciente, la tendance à la réalisation immédiate des intentions qui peuvent surgir, cette psychologie correspond à une régression vers une activité psychique primitive, telle qu'elle existe précisément dans la horde primitive.

Mais, nous ne pouvons pas trouver la motivation de la criminalité dans une foule organisée ou non organisée chez FREUD, qui ne s'est interessé qu'à la structure libidineuse de la foule, c'est-à-dire à la structure relative à la libido de la foule. C'était naturel. Pourtant, FREUD s'est contenté d'expliquer la force contagieuse du délit dans la collectivité. Mais, il a eu tort de baser la structure de la masse uniquement sur la libido. Peut-être serait-il plus exact de parler d'une structure affective de la masse, ce qui aurait l'avantage d'impliquer non seulement la libido, mais ‘.ussi l'instinct agressif.

\section{F. Théorie de Gustave JUNG:}

Chez JUNG, grand psychologue suisse, nous pouvons trouver beaucoup d'hypothèses au point de vue de la criminalitét ${ }^{6}$.

19 Cité par Reiwald, op. cit., pp. 116-126. 
Selon lui, les foules sont des bêtes aveugles. En effet, l'irruption des forces collectives cause chez les membres qui les composent d'étonnantes modifications du psychisme. C'est ainsi qu'un être doux et raisonnable peut se muer en une bête sauvage.

On peut signaler que SIGHELE, TARDE et LE BON ont porté exactement le même jugement. LE BON signale l'existence de ces forces chez l'enfant, le primitif et la femme. JUNG ajoute à cette liste intéressante et importante pour notre étude l'aliéné qu'il considère comme envahi par son inconscient. Selon JUNG, si vous réunissez une centaine d'hommes, même choisis parmi les plus intelligents, ils ne formeront bientôt plus qu'un agrégat stupide. Parce que, avant tout, chacun est doté de toutes soŕtes de traits vicieux du primitif.

La psychologie de JUNG attribue une grande importance à l'exploration de l'inconscient collectif et également du psychisme collectif. En même temps, il reprend la notion de suggestion pour expliquer la cohésion de la foule. Il ajoute ainsi:

'Si, en tant que membre d'un groupe, j'éprouve ce qu'on appelle des sonsations collectives, celles-ci se produisent sur un echelon plus bas de la conscience que s'il s'agissait de sensations individuelles. L'jndividu en foule est extremement suggestible".

Les apports existant entre la société et l'individu sont décrits pàr JUNG à l'aide de la notion d'inflation de la personnalité. A son avis, l'individu ne subit nulle part mieux que dans la foule un tel gonflement de sa personnalité. C'est alors que, s'identifiant entièrement avec la collectivité, il acquiert ce sentiment de toute puissance en vertu duquel il s'arroge toutes les capacités et tous les droits.

Il importe de signaler que personne n'a évoqué jusqu'ici' aussi vigoureusement que JUNG la puissance dynamique de l'inconscient et son rapport avec les forces archaïques. Il s'agit, selon lui, d'une lutte ininterrompue du conscient et de l'inconscient, lutte au cours de laquelle les forces opposées ne cessent de se déplacer. Les résultats d'un déséquilibre peuvent être différents; d'une part, chez l'individu, ils se manifestent par des névroses, l'inadaptation, une scission grave entre l'individualité et le rôle collectif, d'autre part, dans la société, la collectivité, la communauté, par la décadence ou des explosions collectives, il y a toujours un risque à provoquer la réaction des forces inconscientes. A partir de cela, le phénomène de foule doit être considéré comme la conséquence et l'expression d'un grave déséquilibre collectif, comme la parole silmultanée de l'inconscient collectif chez une multitude d'individus.

JUNG, qui a examiné l'Allemagne hitlérienne, s'est intéressé à la 
question de la nature de la responsabilité et également de la culpabilité collective. A son avis, l'homme collectif menace d'étouffer, d'engloutir l'individu, l'être humain pris à part, sur la responsabilité duquel repose pourtant toute l'oeuvre édifiée par la main de l'homme. La masse est toujours anonyme et irresponsable.

En ce qui concerne la culpabilité collective, à ce propos, JUNG s'est contenté de reprendre la théorie que FREUD a développée sur la force contagieuse du crime. En résumé, la culpabilité collective est une fatalité tragique s'abattant sur tous ceux, innocents et coupables, qui se trouvaient à proximité du crime. Cette culpabilité demeure une arme brandie sur la foule des coupables et des non coupables.

\section{G. Théorie d'ADLER:}

ADLER, fondateur de la psychologie individuelle, a étudié le complexe d'infériorité. Ses idées se sont avérées fécondes dans le domaine de la pédagogie, de léducation et de la criminologie ${ }^{20}$.

A notre avis, chez ADLER, nous ne pouvons pas trouver'quelque chose de suffisant en matière de psychologie collective. Car, comme nous l'avons écrit plus haut, il était le fondateur de la psychologie individuelle. Mais, malgré tout, ADLER a attribué une importance capitale au sentiment de la communauté et a voulu montrer le rôle que joue ce sentiment dans le phénomène collectif. De plus, il a insisté sur les forces productrices de la masse, c'est-à-dire, sur l'aspect positif de la foule. Selon lui, LE BON, malgré toutes ses tentatives pour jeter quelque lumière sur ce problème (c'est-à-dire psychologie de la masse) s'est borné à constater que le psychisme collectif représente davantage que la somme des psychismes individuels dont il se compose et qu'un mouvement collectif peut poursuivre aussi bien de bons que de mauvais objectifs. Quant à la timide tentative de FREUD (comme on le sait ADLER était d'abord un disciple de FREUD dont il ne se sépara que plus tard) en vue d'expliquer la soumission de la foule au chef par la libido et de la rattacher aux sentiments de l'enfant pour le père, nous pouvons la négliger.

Il a prétendu que, les expériences qu'on a faites dans le domaine de la psychologie individuelle permettent de conclure que dans toute génération un style de vie presque identique, celui du groupe le plus actif, traduit l'état d'esprit de la foule, de la masse. Il en est ainsi pour tous les domaines de la vie sociale, en art aussi bien qu'en politique et en philosophie. Ce style de vie s'établit au cours des trois premières années de l'enfance et ne peut être modifié dans un sens favorable que par des

20 Cité par Reiwald, op. cit., pp. 127-136. 
méthodes scientifiques. L'état d'esprit des masses d'une génération reflète, dans un sens négatif ou positif, les impressions suscitées au cours de l'enfance par la vie sociale.

Selon ADLER, il importe d'examiner dans quelle mesure et dans quel sens les velléités de l'individu trouvent leur expression dans la masse. Il faut certainement considérer la psychologie collective du même point de vue que la psychologie de l'individu. Car, en elle se rejoignent les désirs des individus. Premièrement, on doit donc se préoccuper de la tendance à surmonter une situation d'infériorité, tendance provoquée par la force impétueuse de l'évolution. D'ailleurs, l'aspiration à une valeur réelle, qu'elle se développe durant l'enfance ou ultérieurement, n'est pas seulement l'objectif de l'individu, mais, également celui de la foule, de la masse. A côté de cela, les vues toujours individuelles sur le sens de la vie constituent la base de tout désir de valeur auquel l'individu, aussi bien que la masse, doit obéir inexorablement.

Cependant, les idées d'ADLER paraissent simples en matière de phénomène de foule. Selon ce grand psychologue, l'individu qui se voit ou se croit défavorisé ne trouve nulle part ailleurs que dans la foule d'aussi grandes possibilités de compensation et de surcompensation. Le sentiement de toute omnipuissance qu'éprouve l'individu en foule annihile, ne fût-ce qu'un moment, tous les sentiments d'infériorité, la force des autres membres de la foule devient sa propre force. L'identification avec la foule procure à l'individu un sentiment d'exaltation qu'il ne serait nullement capable d'éprouver dans d'autres circonstances.

On voit que l'existence du sentiment de la communauté chez ADLER, bien qu'il soit postulé au centre même de sa théorie, demeure fort équivoque. ADLER ne nous donne pas une réponse définitive aux problèmes du phénomène de la foule et aux motivations des délits collectifs commis dans la foule, dans la masse, en d'autres termes et en bref, dans les groupes.

\section{H. Théorie d'ESPINAS:}

ESPINAS a expliqué ses idées en matière de phénomène de foule dans son ouvrage "Des sociétés animales" et a exercé une grande influence sur TARDE $^{21}$.

Selon ESPINAS, l'homme isolé ne sent ni ne pense comme le même homme transporté au sein d'une foule. Il est suffisant d'examiner et d'observer, pour prouver cette idée, ce qui se passe dans une assemblée devant laquelle parle un orateur. Il dit, en cette matière, de même:

31 Espinas, Des sociétés animales, Paris, 1878. 
"Je suppose que l'émotion ressentie par, lui puisse ètre représentée par: le chiffre 10 èt qu'aux premières paroles, au premier éclat de son éloquence, il en communique au moins la moitié à chacun de ses auditeurs qui seront 300 , si vous voulez bien. Chacun réagirà par sez applaudissements ou par un redoublement d'attention".

D'après l'observation d'ESPINAS, l'individu qui se trouve dans une assemblée ou bien dans une foule n'a qu'une faible conscience du mécanisme de contagion collective. Une autre observation de ce grand savant met en évidence une première manifestation du psychisme de la masse: c'est l'amour fraternel.

Même chez ESPINAS, nous ne pouvons pas trouver les réponses de la motivation des délits commis dans une foule. Cependant, il est incontestable qu'ESPINAS a inspiré de nombreux auteurs, même parmi ceux qui ne partageaient pas ses opinions. C'est pourquoi, nous nous contentons brièvement de citer ses idées dans notre étude modeste.

\section{Théorie de REIWALD:}

Selon ce criminaliste ${ }^{22}$, c'est dans le phénomène de foule, lors de mouvements collectifs - guerres, guerres civiles, révolutions - que l'agressivité atteint son point culminant. Dans un Etat, il a falu que l'impulsion agressive soit sublimée, pour qu'une société puisse se constituer. Une réglementation peut diriger l'aggressivité collective de même que la procédure pénale moderne s'est substituée à la vendetta, à la guerre privée et à la justice du lynchage.

Nous savons tous bien que, d'une part, le mouvement collectif ne révèle qu'un seul aspect de l'instinct d'agression; il implique le désir de violence et de destruction, d'autre part, le processus d'identification de l'individu avec la masse a son origine de même que l'agressivité, dans la première enfance. Cependant, cet instinct d'agression est susceptible d'être sublimé. Car, l'évolution du droit pénal (il vise ici le droit pénal international) nous fournit un exemple remarquable à l'appui de notre théorie. Il a été possible, en effet, de domestiquer l'aggressivité à l'intérieur de la communauté nationale, en particulier dans un mouvement de paix. Aussi, convient-il non pas de chercher à éliminer les forces affectives de la masse, puisqu'il s'agit d'un élément fondamental de la vie psychique, mais de les mettre au service d'un but, de les canaliser, de les sublimer.

On voit que REIWALD examine le phénomène de la foule au point de vue de la sublimation. Selon lui, une société peut être parvenue à

$2 \approx$ Reiwald, op. cit., pp. 139-148. 
maitriser, d'une façon presque générale, un mouvement collectif d'une ampleur considérable. On peut punir les coupables présumés ou réels.

Cependant, les mouvements collectifs ne cessent pas de nos jours malgré des sanctions très sévères. Comme notre écrivain l'a reconnu, de nombreux lynchages se produisent aussi en temps de paix. D'ailleurs, même le droit pénal doit son origine, pour une part, à un phénomène de foule, qui n'a pas complètement disparu, la justice de lynchage. Mais les violentes psychoses collectives, dont nous avons été les témoins et les victimes, montrent que le crime, la névrose et la folie sont autre chose que des phénomènes pathologiques de dégénérescence dont seuls quelques individus sont atteints. Il est hors de doute que le crime et la folie habitent au sein même de la sociétê humaine et moderne, malgré tous les efforts que l'on faits pour les combattre dans la mesure du possible.

\section{J. Théories sociologiques:}

Plusieurs sociologues ont examiné directement ou indirectement le phénomène de foule ${ }^{23}$.

GEIGER, sociologue allemand, définit l'organisme collectif comme une unité autonome, qui a son existence propre, relativement indépendante de celles des membres dont il se compose. Selon lui, la masse est exclusivement révolutionnaire et a un caractère anonyme et anti-individuel.

Aux yeux de KAUTSKY, un disciple de MARX, l'individu, au sein d'une foule, développe des forces qui dépassent de loin la mesure de ce dont il serait capable comme être isolé.

LIPPMANN, un écrivain américain mondialement connu, rejette l'hypothèse d'une âme collective. L'unité de la casse est assurée par l'existence d'une sur-âme. La masse ne saurait constituer un arganisme, car, elle subit continuellement les effets de la suggestion. C'est pourquoi, elle est incapable de juger logiquement.

Selon DEWEY, un des représentants le plus important de la doctrine du béhaviorisme, tout comportement doit être ramené à un processus de stimulations et de réactions. Car,le béhaviorisme doit un essort particulier. à la doctrine de PAVLOV sur le réflexe conditionné. D'après ALLPORT, également un représentant du béhaviorisme, une foule est une agglomération d'individus dont l'attention est dirigée vers un objectif commun, qui provoque chez eux une réaction. Ces réactions revêtent généralement un caractère simple et sont accompagnées d'une forte émotion. C'est ainsi que la foule sedistingue d'un groupe qui se livre à des actions communes,

${ }^{23}$ Cité par Réiwald, pp. 150-229. 
car, dans ce dernier, l'attention de chaque individu est habituellement concentrée sur sa propre tâche. La foule, comme l'a dit Cymbal YOUNG, implique une action commune du type correspondant à l'échelon le plus bas des réactions collectives. Car, elle est caractérisée, la plupart du temps, par une attitude de haine et d'intolérance. La haine est elle-même un mélange de peur et de rage vis-à-vis d'un objet. D'autre part, au point de vue dynamique, la foule est, dans une large mesure, un phénomène de suggestion qui rappelle les réflexes conditionnés de PAVLOV. Les foules sont des groupes de combat d'un caractère élémentaire et violent. A l'exception de quelques cas particuliers, peu nombreux, tels que les cas de panique et les mouvements religieux, leurs mouvements sont caractérisés par des réactions combattives, querelleuses et destructives. Ces réactions ne sont pas dûes à une aggressivité originaire ni à une sorte de sentiment primitif de communauté. Mais, au danger qui menace les tendances d'un grand nombre d'individus, les pousse à se réunir et les incite en même temps à une action commune. Les membres d'une populace cherchent des victimes, non pas simplement par cruauté sanguinaire, mais pour établir le fonctionnement normal de leurs réactions entravées. L'acte en question, le coup de feu et l'assassinat, normalement sujet à la désapprobation la plus rigoureuse devient ici, tout au contraire, l'objet de l'approbation la plus enthousiaste. La sociéte désapprobatrice est abstraite. C'est ainsi que l'inhibition de la violence est remplacée non seulement par la désinhibition, mais par l'impulsion à la violence.

Quant à DURKHEIM, grand sociologue français, il a nettement pris parti contre l'école psychologique, en particulier, contre la théorie de TARDE. Le phénomène collectif, comme on en voit la manifestation par excellence dans une masse, doit pouvoir être reconnaissable à des caractéristiques extérieures. Il doit se présenter à l'individu comme une puissance qui lui est étrangère, extérieure et dont l'effet est irrésistible. Par exemple, dans une assemblée, les grands mouvements d'enthousiasme, d'indignation, de pitié qui se produisent n'ont pour lien d'origine aucune conscience particulière. Ils viennent à chacun de nous du dehors et sont susceptibles de nous entraîner malgré nous. Nous nous apercevons alors que nous les avions subis beaucoup plus que nous ne les avions engendrés. Il arrive même qu'ils nous fassent horreur, tant ils étaient contraire à notre nature même. C'est ainsi que des individus parfaitement inoffensifs pour la plupart, réunis en foule, se laissent entraîner à des actes d'atrocités. Or, ce que nous disons de ces explosions passagères s'applique d'une manière identique à ces mouvements d'opinion durables qui se produisent sans cesse autour de nous.

Il est temps d'expliquer que la plupart des grands écrivains et poètes, 
comme ZOLA, TAINE, MALRAUX, TOLSTOI, ZWEIG, ont décrit le phénomène de la masse ainsi que ces psychologues et sociologues.

\section{K. Théorie de MM. ROBERT et LASCOUMES:}

Ces deux écrivains ont examiné les bandes, qui, comme nous l'avons déjà dit, sont des regroupëments plus petits et surtout mieux organisés (voir, II. Terminologie) ${ }^{24}$

Quant à la question des manifestations délinquantielles dans le phénomène des bandes, selon eux, elle n'est pas une caractéristique déterminante, mais une conséquence presque nécessaire. Autrement dit, la délinquance ne peut servir de critère sufissamment compréhensif pour distinguer en profondeur les bandes d'autres groupes. Mais, la bande, dans sa nature, dans son attitude dégrégative, est normalement entraînée dans un processus criminogène. Cependant, pour admettre ce point de vue, il faut prendre du processus criminogène une vue plus large qu'on ne le fait généralement encore maintenant. La démarche criminelle doit être comprise comme un mouvement sociologique parmi d'autres, aux répercussions plus larges que le simple acte délinquantiel qu'atteint le Code pénal.

D'après ces auteurs, il résulte des recherches que, en premier lieu, la délinquance n'est pas le critère désicif de la bande. Il est intéressant d'examiner les modalités d'exécution des délits pour vérifier ce premier raisonnement. En effet, une bande qui prépare soigneusement ses manifestations criminelles serait essentiellement délinquante. Autrement dit; on pourrait la caractériser par l'accomplissement de tels actes. Mais, selon les pourcentages d'infractions, la bande ne semble pas constituée dans un but délinquant. Bien au contraire, c'est l'attitude de ce groupe qui crée une disponibilité à l'action antisociale, une impulsion en faveur de ces agressions contre l'out-groupe. Certes, une telle déduction ne saurait être absolue. On souligne l'hétérogénéité des formes de bande. Il est antiscientifique de vouloir ici les réduire à un seul schéma. D'ailleurs, certaines bandes sont constituées en vue de la délinquance. Néanmoins, ce cas est assez rare statistiquement. Les bagares notamment entre bandes rivales forment une modalité délinquantielle très particulière. En résumé, la délinquance n'est pas la caractéristique première et la raison d'être des bandes.

En deuxième lieu, il faut examiner la liaison entre l'attitude des bandes et le processus criminel. D'après les statistiques, la délinquance des jeunes en groupe ne diffère pas sensiblement de l'ensemble de la délinquance

24 Robert-Lascoumes, op. cit., pp. 243-271. 
juvénile, encore que les infractions contre les biens y occupent une place un peu plus prééminente.

Ces sortes d'infractions ne semblent donc pas spécifiques des manifestations délinquantielles des bandes. Cependant, il faut remarquer que les catégories retenues sont vagues et trop générales. Dans cette mesure, on pourrait penser que certaines modalités d'infractions sont propres aux bandes en ce qu'elles demandent la réunion des co-auteurs ou de complices. Tels sont les viols collectifs, les actes de vandalisme ou de violence en groupe. Mais, il faut noter qu'un simple agglomérat ou une réunion temporaire peut commettre les mêmes actes. D'ailleurs, les procédés statistiques ne permettent pas toujours de distinguer les bandes aussi peu structurées soient-elles des foules rassemblées accidentellement. Cependant, il importe de bien distinguer deux modalités criminogènes; les manifestations délinquantielles de bandes et "les crimes de foules". selon l'expression classique. TARDE définit ainsi les crimes de foules:

"Action en commun et en masse sous l'impulsion d'entraînement auxquels tous participent et où se dégagent des forces, des virtualités qui, à l'état d'isolement, resteraient engourdies".

Le premier caractère, action en commun et en masse, constitue une première différence. TARDE étudie pêle-mêle la criminalité des groupes et celle des foules, mais des travaux plus récents ont permis de distinguer, d'après la dimension dont la considération atteint ici l'ordre qualitatif.

L'impulsion collective est le second caractère: le crime des foules a un aspect justicier ou pseudo-justicier, comme on le voit dans les lynchages, par exemple. Quant au troisième, il est constitué par la libération des tendances qui se manifeste notamment par le passage à l'acte.

Comme on le sait, SIGHELE le résumait ainsi: "L'occasion a dans la foule le terrible de l'irréparable". En résumé, la délinquance des bandes ne peut être assimilée au crime des foules essentiellement. Ce n'est pas la sorte de délit qui fait la spécificité, mais bien l'action du groupe sur le processus criminel.

Il importe de signaler que le double mouvement de valorisation de l'in-groupe et de dévalorisation de l'out-group est directement criminogène: Rappelons que tout sentiment de sympathie envers l'out-group s'éteint par suite d'une action réciproque du groupe et du milieu. La plupart du temps, la bande possède une idéologie propre caractérisée par l'indifférence aux conséquences de l'acte délictueux. Malgré tout, la délinquance joue un rôle dans la situation psycho-sociologique du groupe. Elle remplit une fonction dans la vie de la bande. C'est par cela que le délit n'est pas 
perçu comme un non-droit, mais, au contraire, comme un moyen d'expression normalisé.

L'action criminogène de la bande n'apparaît pas seulement dans le processus précurseur. Elle semble bien favoriser la récidive, la réitération et l'aggravation du processus de guerre à l'environnement. Car, tous les travaux s'accordent sur la liaison bande-récidive. La récidive est plus élevée dans la délinquance des bandes que dans celle d'autres groupes. Surtout les bandes sont un facteur de réitération. C'est cette potentialité délinquante qui constitue l'état dangereux dans notre matière. De toute manière, notre groupe est dangereux. Car, il maintient ses membres en état permanent de prédélinquance collective. Ainsi, il ne faut pas dire que la bande est caractérisée par la délinquance, constituée pour la délinquance. Mais, en ce sens, elle est un groupe criminel, même si les circonstances font qu'il n'y a jamais commission d'infractions au sens du Code pénal, elle est criminelle à la suite de son processus de ségrégation.

En particulier, les bandes d'adolescents peuvent pratiquer des sortes très diverses d'infractions. Néanmoins, certaines sont plus répandues. D'autre part, la signification des actes délictueux peut être variable ou, au moins plus ou moins visible. On sait que les bandes se rendent essentiellement coupables d'infractions contre les biens. Il faut préciser encore qu'il y a peu d'infractions astucieuses, du type escroquerie ou abus de confiance. Dans les bandes, l'activité délinquante reste à un niveau plus primaire. Les infractions contre les biens recouvrent donc essentiellement les vols (surtout vol de voitures) et les actes de vandalisme.

Une certaine différence se fait jour quand on passe aux agressions contre les personnes. Certes, il reste deux buts: promotion du groupe et dans le groupe et affirmation de la ségrégation hostile envers l'environnement.

Le résultat est que, d'après ces écrivains, la délinquance n'est pas le trait caractéristique des bandes. Mais elle en donne toutefois un éclairage intéressant.

Après avoir examiné l'aspèct socio-psychologique de la question, nous pouvons aborder sa structure juridique.

\section{LES ASPECTS PARTICULIERS ET LA STRUCTURE JURIDIQUE DE L'INFRACTION COLLECTIVE EN FRANCE:}

On voit que tous les auteurs, dont nous avons examiné les idées, sont presque d'accord au sujet du caractère plus ou moins criminogène des groupes, soit foule, soit bande. D'ailleurs, la plupart du temps, on répartit. 
des tâches au sein du groupe. C'est ce qụi augmente les chances d'impunité et qui confère aux délinquants associés une puissance accrue. Ainsi, comme l'a dit un auteur, on peut considérer que l'infraction collective traduit le passage de la criminalité du stade'artisanal au stade industriel ${ }^{25}$.

Le législateur avait connu l'existence des entreprises collectives au siècle précédent. La pluralité d'auteurs aboutissait à l'aggravation de peines prévues par la loi pénale. L'intervention de plusieurs délinquants constituait parfois une circonstance aggravante, comme les infractions de vol, de proxénétisme, de rébellion ou de viol.Mais, l'influence des principes classiques imprégnés d'individualisme paraissait interdire le développement de solutions originales et nouvelles. Car, le sort de chaque prévenu était déterminé par son acte isolément envisagé.

De nouvelles théories ont renouvelés les termes des questions posées par les délits collectifs (ou bien l'infraction collective). La nouvelle doctrine a mis l'accent sur l'environnement du délinquant, a montré les causes concrètes de la commission de l'acte incriminé, a indiqué l'importance des circonstances qui ont entouré l'agissement illicite, le caractère dangereux du délinquant en groupe, enfin a conduit à souhaiter la création d'une cause générale d'aggravation de peine quand il s'agit d'une entreprise criminelle collective.

Par ailleurs, de nos jours, on constate le déclin de la délinquance dans l'ensemble du droit au sein duquel on voit d'anciennes notions s'adapter à la collectivisation des rapports sociaux. Ainsi, en droit pénal, il s'agit d'une dégradation des principes classiques. C'est ce qui atténue, les obstacles à l'adoption de solutions spécifiques à l'infraction collective. Ainsi, on est arrivé à la multiplication des hypothèses de la responsabilité, à la répression plus efficace, à l'amoindrissement du rôle de l'élément matériel de l'infraction et à l'importance croissante accordée à l'élément moral et enfin on a favorisé le développement des responsabilités pénales du fait d'autrui.

En effet, l'agissement de chaque participant est facilement masqué par celui des autres. Ces résultats que nous avons soulignés plus haut ont naturellement facilité l'adoption de solutions repressives originales en droit pénal. Aussi, pour faire face à de graves troubles issus d'agissements collectifs et pour éviter leur renouvellement, le législateur a incriminé certains actes collectifs et a modifié leur incrimination.

Par exemple, en France, parmi les textes les plus connus, on peut citer la loi du 18 décembre 1893 qui, visant les menées anarchistes, a

25 Dupeyron, L'infraction collective, Revue de science criminelle et de droit pénal comparé, 1973, pp. 357-381. 
remanié les articles 265 et suivants du Code pénal afin de faciliter la répression des faits projetés et commis par plusieurs personnes. La loi du 15 septembre 1948 a reprimé d'une façon brutale les crimes de guerre imputables aux formaticns occupantes et aussi a créé une responsabilité collective. Enfin, faut-il rappeler la loi du 8 juin 1970 dite "loi anti-casseur" qui tend à réprimer certains types de délinquance collective qualifiés par le législateur lui-même de nouvelles formes de délinquance, (voir, référence, n. 68).

Ce qui est important, c'est l'originalité de ces textes. Cette originalité découle du fait que ces textes incriminent tous comme délit autonome, un agissement commis, projeté ou tenté par plusieurs délinquants. Ils ne créent pas une juxtaposition d'infractions individuelles et indépendantes. Bien au contraire, ils constituent une catégorie originale d'incrimination tenant compte du groupe délictuel. Aussi, ces délits collectifs se différencient-ils d'autres types connus d'infraction. Premièrement, puisque l'infraction collective résulte de la 'violation d'un texte réprimant en particulier un fait commis, tenté ou projeté par plusieurs auteurs, elle ne saurait être confondue avec les infractions individuelles incitant à des agissements collectifs telles que les délits de provocation à la désobéissance ou les délits de formation et la reconstitution de groupes illicites. De telles infractions sont des infractions individuelles. En effet, lorsqu'un individu organise une manifestation illégale, l'agissement illicite incriminé est individuel. Ce qui est collectif, c'est l'effet qu'il recherche. En résumé, dans de telles conditions, l'ensemble du fait peut être collectif, mais non l'infraction.

Deuxièmement, il faut distinguer les infractions collectives des délits bilatéraux, comme l'adultère, la corruption. En effet, le législateur envisage deux participations individuelles et distinctes dans ces incriminations et non une participation de plusieurs auteurs comme dans les délits collectifs. C'est pourquoi, les questions posées par les délits collectifs se trouvent étrangères aux délits bilatéraux.

Trosièmement, les délits collectifs se différencient aussi des délits commis par une personne morale. En effet, dans ce cas-là, l'être moral est punissable, mais ici, il s'agit juridiquement d'une seule personne.

Enfin, l'infraction collective se distingue de l'infraction commise collectivement qui implique l'intervention d'une pluralité d'auteurs pour commettre une infraction (par exemple, la coaction, la complicité, le recel, etc...). Mais, lorsqu'il s'agit d'un délit collectif, cette pluralité d'agents, chiffrée ou non, est considérée comme un élément constitutif.

Cependant, cette infraction en question n'a pas encore été profondé- 
ment étudiée dans le domaine doctrinal. En cette matière, la pratique précède la théorie. En effet, le développement des textes nouveaux et la survivance de textes anciens réprimant des agissements collectifs illicites ont attiré l'attention de la doctrine contemporaine et ont suscité des études remarquables sur la responsabilité collective, surtout sur la responsabilité du fait d'autrui.

On voit que le délit collectif est un élément original du droit pénal de nos jours. L'intervention de plusieurs auteurs devient tantôt un indice révélateur de la culpabilité de chacun d'eux, tantôt un obstacle à sa détermination. Le législateur estime que cette infraction doit être considérée comme un fait global et autonome à la fois. C'est pourquoi, s'il s'agit d'un délit collectif, d'une part, les critéres individuels de la participation punissable sont modifiés et, d'autre part, l'imputation du résultat collectif à chaque participant est déformée. C'est pourquoi la question de la responsabilité collective vaut d'être examinée en cette matière ${ }^{25}$.

\section{A. Pensée criminelle collective et répréhensible:}

Selon le principe constamment affirmé par la Cour de cassation, "nul n'est passible de peine qu'à raison de faits personnels". Autrement dit, la première condition d'existence de la culpabilité est une relation matérielle entre l'infraction et la conduite personnelle de l'agent. A la suite de cela, on arrive à un autre principe, à une autre règle. La règle, souvent rappelée par la Cour de cassation est "la responsabilité pénale ne peut résulter que d'un fait personnel". Principe postulé par les exigences élémentaires de la justice rétributive. Car, il n'est par concevable que l'on puisse punir une personne dont la conduite est complètement étrangère à l'infraction poursuivie. C'est pourquoi, la répression pénale est subordonnée à l'accomplissement personnel d'un acte illicite.

Cependant, ce principe n'est pas strictement applicable en matière d'infraction collective. La plupart du temps, la simple pensée criminelle collective est punissable. Selon DUPEYRON, c'est la spiritualisation du fait personnel ${ }^{27}$. Lorsqu'il s'agit d'un délit projeté par plusieurs auteurs, le législateur ne prévoit pas toujours la répression de l'accomplissement de l'acte. Il punit et réprime seulement la simple résolution concertée d'agir en commun. Par exemple, c'est le cas des articles 87 et 94 du Code pénal qui punissent le complot "si le complot n'a pas été suivi d'un acte commis ou commencé pour en préparer l'exécution la peine sera celle de la détention criminelle à temps" ... "il y a complot dès que la résolution

26 Merle-Vitu, Traité de droit criminel, Paris, 1884, I, pp. 610-612; Pradel, op. cit.. n. 370 .

${ }^{27}$ Dupeyron, étude précitée, p. 362. 
d'agir est concertée et arrêtée entre deux ou plusieurs personnes". De même, les articles 123 et suivants du même code répriment la coalition de fonctionnaires. En effet, l'article 123 incrimine "tout concert de mesure contraire aux. lois, pratiqué soit par la réunion d'individus ou de corps dépositaires de quelque partie de l'autorité publique, soit par députation ou correspondance entre eux, sera puni..." Un autre exemple, c'est le cas des articles 265 et suivants qui concernent l'association de malfaiteurs. Selon l'article 265 (modifié par la loi no. 81-82 du 2 fevrier 1981): "Quiconque aura participé à une association ou à une entente établie en vue de la préparation, concrétisée par un ou plusieurs faits matériels, d'un ou de plusieurs crimes contre les personnes et les biens sera puni d'un emprisonnement de cinq à dix ans et pourra être interdit de séjour".

Comme on le sait, la simple pensée criminelle est exceptionnellement punissable en matière de délits individuels. Par contre, les délits collectifs envisagés ont un caractère si original que le critère de la participation punissable est constitué par l'entente. Or, un tel critère est propre à l'infraction collective ${ }^{28}$. Au cours de la réalisation et de la matérialisation d'un projet délictueux, on trouve un processus criminel qui est divisé en cinq étapes principales. Ces étapes successives conduisent à la consommation d'un délit et constituent ce que l'on appelle "le chemin du crime, (iter crimines), la trajectoire du crime; d'abord la pensée criminelle, ensuite le stade de l'extériorisation verbale ou manuscrite du projet délictueux, c'est-à-dire, la résolution d'agir extériorisée; puis le stade des actes préparatoires; après le stade du commencement d'exécution et enfin le stade de la consommation ${ }^{29}$. Mais il faut. ajouter une étape supplémentaire à ce chemin du crime, lorsque l'infraction est le fait de plusieurs agents. En effet, en matière d'infraction collective, il y a encore une étape qui apparaît avant le stade des actes préparatoires: c'est l'étape de l'entente qui se fait entre les divers délinquants. Puisque, l'entente suppose un accord de deux volontés au moins. C'est pourquoi, cette étape apparaît en matière d'infraction collective.

28 Ibid, p. 363 .

* On peut consuiter pour plus de détails sur l'iter criminis: Selçuk. Suç, suç yörüngesi ve kalkışmanın konumu. Adalet Dergisi, 1983, n. 5., pp. 801-807; Adornata, Il momento consumativo del reato, Milano, 1968; Antolisei, parte generale, p. 377; Battaglini, Dirito penale, Padova, 1949, p. 421; Bettiol-P. Mantovani, op. cit., pp. 607-611; Dönmezer-Erman, Nazari ve tatbiki ceza hukuku, Istanbul, 1981, $\mathrm{n}$. 547; Erem, Ümanist doktrin açısından Türk ceza hukuku, Ankara, 1984, I, p. 323; Mantovani, op. cit., p. 368; Merle-Vitu, op. cit., I, p. 579; Pradel, op. cit. n. 348; Rodriguez Dévesa (por Serrano Gomez), Derecho peral espanol, Madrid, 1936, pp. 773-778; Pannain, Manuale di diritto penale, parte generale, I, Torino, 1950, pp. 439, 440; Roux, Cours de droit criminel français, I, Droit penal, Paris, 1927, pp. 100-102, Varinard, Tentative, J.C. Pénal, 1979, $\mathrm{n}^{\circ \mathrm{s}}$. 10, 65. 
Certes, ladite étape n'est pas ignorée par le législateur. Car, certains textes incriminent l'association entre plusieurs personnes comme ceux punissant les atteintes à la sûreté de l'Etat. De plus, le Code pénal français augmente la peine au fur et à mesure que les délinquants sont près du stade de la consommation. A titre d'exemple, d'après les articles 86 et suivants, la loi réprime de peines correctionnelles (un an à dix ans d'emprisonnement) la proposition de former un complot. Bien au contraire, des peines criminelles (cinq à dix ans de détention) sanctionnent le complot, c'est-à-dire en termes textuels: "la résolution d'agir concertée et arrêtée entre deux ou plusieurs personnes" à condition qu'elle ait pour but de porter atteinte au régime constitutionnel. De plus, le législateur sanctionne plus fortement le complot aggravé, c'est-à-dire le complot en actes préparatoires (dix à vingt ans de détention). Enfin, on sanctionne la tentative ou le crime consommé de la détention criminelle à perpétuité. On voit que, cette gradation des peines met en lumière, d'une façon indiscutable, l'existence de la phase d'entente.

Lorsqu'il s'agit d'un "concert de mesures contraires aux lois" pratiqué par des fonctionnaires, il y a encore une entente en vue de s'opposer à l'exécution des lois ou aux ordres gouvernementaux.

D'une manière semblable, on punit les fonctionnaires "qui auront par délibération arrêté de donner des démissions" dont l'objet ou l'effet serait d'empêcher ou de suspendre soit l'administration de la justice, soit l'accomplissement d'un service quelconque “(art. 125 du Code pénal). De plus, les articles 265 et suivants, qui introduisent la notion de complot en droit commun, sanctionnent la simple association de malfaiteurs, en d'autres termes la participation "à' une association formée ou à une entente établie en vue de la préparation concrétisée par un ou plusieurs faits matériels, d'un ou de plusieurs crimes (délits)".

A côté de ces textes les plus significatifs, on peut voir d'autres incriminations d'association, en droit pénal français telles que celles résultant des articles 95 et 96 du Code pénal qui sont relatifs à l'organisation de bandes armées et à la participation à celles-ci. Pour qu'il y ait bande armée aù sens de ces textes, il est nécessaire que soient réunis les éléments suivants: premièrement l'existence d'une organisation, c'est-à-dire d'un groupe hiérarchisé ayant des chefs et des subordonnés; deuxièmement le fait que la bande soit armée, sans qu'il soit nécessaire pour autant que chacun de ses membres soit pourvu d'une arme; troisièmement, le but particulier poursuivi par la bande armée. Cette dernière condition distingue ces infractions de l'association de malfaiteurs prévue par les articles 265 et suivants du Code pénal français, comme du pillage prévu par l'article 
440 qui vise seulement les propriétés mobilières ${ }^{30}$. De même, on rapprochera l'incrimination de l'ordonnance du 30 juin 1945 sur les ententes prohibées. En effet, selon l'article 55 bis (rédac. ord. $n^{\circ}$ 67-835 du 28 septembre 1967) "les actions concertées, conventions, ententes expresses ou tacites ou coalitions ... ayant pour objet ou pouvant avoir pour effet ... de fausser le jeu de la concurrence ... sont prohibées ...".

Ces textes, qu'on a brièvement cités, montrent bien que le législateur français, non seulement n'ignore pas l'existence d'une entente punissable, mais il l'adapte et la réprime comme une infraction commune. C'est pourquoi, on constate que le législateur a été conduit à s'écarter des principes du droit pénal classique dans le but de prévenir les accomplissements des délits collectifs.

\section{B. La tentative et l'infraction collective:}

En effet, de telles incriminations, dont la justification paraît résulter de l'aggravation du trouble social issu de l'intervention de plusieurs délinquants, dérogent au principe d'après lequel il faut avoir entrepris l'exécution pour être punissable. Au fond, en raison de leur structure et de leur régime, de nombreuses institutions du Code pénal français subordonnent la répression à l'accomplissement d'un acte matériel. Mais, étant donné que la pensée criminelle, en d'autres termes l'entente, est répréhensible, le législateur provoque dans ces mêmes institutions des changements assez sensibles qui manifestent généralement une tendance répressive accrue. Ainsi les délits issus d'une entente changent la théorie et les principes de la tentative.

Comme on le sait, parfois l'infraction, quoique caractérisée par une manifestation extérieure de la volonté pénale, n'est pas consommée. En d'autres termes, la matérialisation du délit n'est pas complète. Il s'agit alors de l'infraction tentée.

De nos jours, presque toutes les législations incriminent la tentative. Cependant, elle ne doit pas être très éloignée de la consommation. En effet, "on ne peut équitablement punir la volonté criminelle qu'à partir du moment où elle s'est concrétisée par des actes impliquant son caractère irrévocable ou qui contiennent déjà en germe une certains potentialité dangéreuse",31.

\footnotetext{
${ }^{30}$ Goyet, (Rousselet, Arpaillange, Patin), Droit pénal spécial, Paris, 1972, p. 29; Vitu, op. cit., I, n. 87 et s. L'article 440 du Code pénal français est abrogé par la Loi du 2 février 1981.

${ }^{31}$ Merle-Vitu, op. cit., p. 579.
} 
Pour préciser la tentative punissable, il faut d'abord définir la notion de commencement d'exécution et la distinguer des actes préparatoires. L'article 2 du Code pénal français n'est pas univoque. Cependant, la jurisprudence, après avoir appliqué la conception objective dans l'ancien droit et la conception subjective sous l'empire du Code pénal de 1791, est actuellement à mi-chemin de l'une et de l'autre, c'est-à-dire elle adopte la conception mixte plutôt éclectique. Selon la jurisprudence la plus récente, le commencement d'exécution est "l'acte tendant directement au délit et accompli avec l'intention de le commettre". C'est-à-dire que cet acte ne doit laisser aucun doute à propos des intentions de son agent et doit converger directement à la réalisation du délit ${ }^{32}$.

Il déduit de ces données que le Code pénal français suppose l'accomplissement d'un acte matériel. Tandis que, comme nous l'avons indiqué ci-dessus, les incriminations d'entente ne nécessitent pas un tel acte. I importe donc même d'altérer la conception éclectique de la tentative pour appréhender certains comportements très dangereux qui apparaissent en matière de délits collectifs. Aussi, ne faut-il pas méconnaître que c'est le caractère collectif du comportement antisocial qui conduit lé législateur à ériger, dans les cas les plus fréquents, l'entente en infraction. Cependant, il n'y a pas lieu, a priori, de refuser l'application de l'article du Code pénal relatif à la tentative aux délits collectifs, en particulier aux délits d'association. En effet, lorsqu'il s'agit d'une résolution concertée d'agir en commun, la doctrine parait hésitante. Car, on peut dire qu'il est difficile de séparer exactement le simple projet criminel individuel de l'accord donné par une autre personne à ce projet. Mais, on peut aisément imaginer des actes tendant directement à l'infraction comme en matière d'atteinte à la sûreté de l'Etat. C'est ainsi que le moment de la répression est anticipé, précoce. Voilà une des caractéristiques des infractions de ce genre. A la suite de cela, il nous semble important d'aborder la question du désistement.

\section{Désistement et infraction collective:}

Il s'agit ici du désistement volontaire qui entraîne l'impunité du délinquant, quelle que soit la nature du mobile du désistement, l'agent échappe à la peine. Mais, d'une part, il doit être volontaire; d'autre part, le désistement volontaire doit se situer à la phase du commencement

32. Ibid., p. 583. On peut consulter pour plus de détails: Siniscalco, La Struttura del delitto tentato, éd.. Giuffré, Milano, 1981, p. 87 et s.; Devèze, le commencement d'exécution en jurisprudence, Rev. Sc. Crim, 1981, p. 777 et s:; Manzini, Trattato di diritto penale italiano, éd., Utet, Torino, 1981, II, p. 481 et s.; Varinard, étude précitée. 
d'exécution, en d'autres termes, doit consister à interrompre une activité délictueuse avant qu'elle n'ait produit les résultats prévus par la loi en tant que délit consommé.

Quant à l'infraction collective, elle doit être réprimée, la plupart du temps, au stade de la pensée criminelle qui précède la phase du commencement d'exécution. Dans ce cas-là, le profit du désistement sera effectivement réduit presque à néant. C'est sans doute le contraire de la politique criminelle concernant le désistement. Pourtant, en matière de délit collectif, il semble que cette dérogation aux principes soit moins importante qu'on pourrait le croire. D'une part, à cause de la pluralité d'agents, il apparaît que la perpétration du délit projetée est très probable sinon certaine. D'autre part, il est à remarquer qu'en pratique les, chances de désistement sont très réduites, puisque les différents participants à l'entente ne manqueront pas de convaincre à nouveau de l'intérêt de l'entreprise l'assosié qui tenterait de se retirer. Le législateur est probablement poussé par ces raisons à étendre au droit commun la notion de complot à cause de l'infraction d'association de malfaiteurs. Puisque, le désistement ou bien le retrait qui prend la forme d'un désistement ${ }^{33}$ n'est pas probable, que la certitude de la perpétration de l'infraction collective paraît établie et que, de toute façon, lé caractère collectif de l'entreprise criminelle engendre un danger social accru, il paraît souhaitable de réprimer les agissements tendant au délit avant le commencement d'exécution dès la phase de la résolution concertée d'agir ${ }^{34}$.

$\mathrm{Au}$ fond, toute la théorie classique de la tentative est élaborée en tenant compte du chemin du crime individuel selon lequel pour pouvoir punir, il faut avoir la certitude que l'individu va commettre l'infraction. Car, dans un système classique, la loi pénale réprime le choix d'un agissement antisocial, la punition n'est encourue que si le choix en question est définitif, surtout irréversible. Donc, la liberté individuelle, la possibilité de désistement interdit une répression dès le début du chemin du crime, c'est-à-dire le commencement d'exécution. Quelles que soient les discussions qui ont été suscitées par la notion de commencement d'exécution, c'est ce qui justifie l'impunité de celui qui s'est volontairement désisté.

Pourtant, lorsqu'il s'agit d'un délit collectif, à vrai dire d'une infraction d'entente, la conception de l'iter criminis (chemin du crime) est modifée. Car, comme nous avons déjà écrit, l'infraction collective est consommée dès qu'il y a une entente. Puisque, le désistement paraît devoir intervenir avant la consommation du délit, il faut analyser le retrait de l'association

$\$ 9$ Merle-Vitu, op. cit., II, p. 64.

34 Dupeyron, étude précitée, p. 367. 
ou bien de l'entente comme un état de repentir ${ }^{35}$. Mais, comme on le sait, le repentir intervient, au contraire du désistement, après la consommation de l'infraction, et est, la plupart du temps, inopérant, c'est-à-dire qu'il laisse subsister la responsablité pénale du délinquant. Ce repentir ne será donc pas apte à détruire toutes les conséquences de l'infraction, d'une part. D'autre part, la répression très précoce réduit considérablement la possibilité du désistement. De plus, cette solution est critiquable au point de vue de la politique criminelle. Car, les délinquants, qui n'ont pas entrepris la consommation proprement dite de l'infraction, seront incités à aller jusqu'au bout par cette solution sans avantage. Sous la lumière de cette politique criminelle, le législateur français a réprimé certains crimes contre la sûreté de l'Etat d'autant moins sévèrement que les délinquants étaient plus éloignés de la consommation du celui-là. Par contre, dans les autres infractions d'entente, cela n'est pas prévu. Mais le désistement peut être considéré comme une circonstance atténuante.

Cependant, si l'on recourt à la notion du retrait, on parvient à une autre conclusion. Car le retrait a un effet strictement individuel. Or, il convient de détruire l'association pour que la résolution concertée ne se manifeste pas par actes. Donc l'impunité doit être logiquement attạchée à la fois à un retrait de l'association et surtout à la disparition de cette association. Or, la dénonciation doit seule assurer l'impunité. Il s'agit ici de la dénonciation émanant des coupables eux-mêmes. Cette dénonciation est encouragée dans certains cas par le législateur qui assure aux dénonciateurs le bénéfice d'une excuse absolutoire ou atténuante. Par exemple, les articles 101 (infraction à la sûreté de l'Etat), 138 et 139 alinéa 5 (fauxmonnayage et contrefaçon du sceau de l'Etat), 247 alinéa 2 (évasion favorisée), 266 et 267 (association de malfaiteurs), ${ }^{35 a}$ et 435 du Code pénal français (destruction par explosifs). Cependant, ces textes ne manquent pas de cohérence. Parfois l'excuse n'existe que si la dénonciation a lieu avant la pérpétration de l'infraction (art. 247 al. 2), ou avant toute poursuite (art. 266 et 267); dans les autres cas, la dénonciation même postérieure aux poursuites est admise, mais alors le dénonciateur doit, en plus, procurer

35 tbid., p. 367.

35a L'article 266 du Code pénal français est d'abord modifié par la loi n. 81-82 du 2 février 1981. Mais, puis, il est abrogé par la loi n. 83-460 du 10 juin 1983 on raison de l'hostilité du législateur de 1883 a l'égard de textes adoptés en 1081. Cependant, ensuite, la loi n. 86-1019 du 9 septembre 1886 (Journal officiel, 10 septembre 1986 , p. 10954) a rétabli cet article qui incrimine l'association de malfaiteurs en vue de préparer l'un au moins des délits suivants : proxénétisme prévu par les articles 334-1 et 335 du Code pénal, vol aggravé de l'article 382, alinéa 1 ou 2, destruction ou détérioration aggravée de l'artıcle 435 ou extorsion de l'article 400 , alinéa 1, du Code pénal. Cette association est punissable d'un emprisonnement de un à cinq ans et d'une amende de 5000 à 100000 francs. 
l'arrestation des autres coupables. En outre, l'excuse est absolutoire en règle générale, par exception pour les infractions contre la sûreté de l'Etat, elle n'a cette valeur que si elle intervient avant la perpétration des crimes ou des délits; postérieure, l'excuse est seulement atténuante ${ }^{36}$.

Le désistement volontaire est à l'iter criminis individuel ce que cette notion de la dénonciation est à l'iter criminis collectif. Elle peut assurer l'impunité totale lorsque la dénonciation permet d'empêcher les autres délinquants d'aller jusqu'au bout. Au contraire, lorsque l'infraction est consommée, l'excuse parait changer de nature. Le caractère absolutoire ou atténuant dépend alors de la plus ou moins grande importance que l'on attache à l'arrestation des coupables. D'ailleurs, à cause de son apparition postérieure à l'entente (en d'autres termes, la consommation du délit), la dénonciation ne peut naturellement pas avoir pour effet de détruire le caractère délictueux de l'acte et, bien entendu, la culpabilité de l'auteur. En conséquence, en raison de la précocité de l'incrimination, la dénonciation devient une excuse absolutoire qui, sens supprimer la culpabilité du délinquant, lui assurera l'impunitée $e^{37}$.

On voit que, malgré l'anéantissement des possibilitès de désistement, si l'agent abandonne le projet criminel, il doit pouvoir échapper à la répression. En effet, en cas d'une infraction d'association, d'entente, l'excuse de dénonciation a un caractère général. Cependant, pour faire échapper à la répression le coupable ayant participé à un délit collectif, la loi est plus exigeante qu'elle ne l'est pour le délinquant agissant seul. Par contre, en cas d'un simple accord en vue de commettre une infraction, en fonction de la théorie de la tentative, l'activité des agents n'est répréhensible que dans un temps proche de la consommation. C'est pourquoi, une dénonciation antérieure à la consommation du délit a une valeur peu pratique. Car, avant la tentative, aucun acte n'est punissable, donc la dénonciation n'assure aucun itérêt ${ }^{38}$.

\section{Prescription et infraction collective:}

En matière pénale, la prescription est une des raisons de l'extinction de l'action publique. C'est pourquoi, il faut examiner la durée des infraction d'entente. En effet, l'association paraît tantôt durable, tantôt brève. Par exemple, selon l'article 265 du Code pénal, l'association de malfaiteurs est punissable qu'elle qu'en soit la durée ${ }^{39}$. Il en résulte, s'il s'agit d'une

\footnotetext{
${ }^{36}$ Merle-Vitu, op. cit., II, p. 248. Les articles 265, 266, 267 et 268 sont modifiés par la loi n. 81-82 du 2 février 1981.

${ }^{37}$ Dupeyron, étude précitée, p. 368.

38 ibid., p. 369.

${ }^{39}$ Goyet, op. cit., p. 214; Vitu, op. cit., I, n. 207 et s.
} 
infraction continue selon la doctrine qu'on ne peut imputer la continuité de l'infraction au délinquant que dans la mesure où celui-ci l'a provoquée par des actes de volonté réitérés ${ }^{40}$. La jurisprudence a une tendance positive à cet égard. Alors, le point de départ du délai de prescription de l'action publique deviendra le jour de la cessation de l'entente.

\section{E. Collectivisation de la responsabilité pénale au point de vue du fait matériel:}

Dans le droit contemporain, en principe, la responsabilité pénale pèse sur ceux qui ont joué un rôle, direct ou indirect, dans la réalisation de l'infraction. Tandis que la répression était fréquemment étendue dans les civilisations primitives à tous les proches du coupable d'un acte incriminé. La portée de la responsabilité s'élargissait alors jusqu'à prendre la forme d'une responsabilité collective. Cette conception révolte particulièrement la conscience moderne qui est attachée au principe de la responsabilité des peines. D'après ce principe, la justice impose de traiter chacun selon ses oeuvres. Pourtant, il faut bien reconnaitre que cette pratique primitive et impitoyable n'a pas été sans laisser certains vestiges qui persistent encore de nos jours.

En effet, le développement historique de la responsabilité pénale est intéressant. Car, à l'origine, la responsabilité s'est présentée historiquement sous une forme collective. On peut dire qu'elle est à l'aube du droit pénal ainsi que la propriété collective à l'aube du droit civil. Sous sa forme la plus absolue, la responsabilité en question est celle que supporte le groupe social auquel l'auteur appartient. Tandis que les autres membres de ce groupe n'ont pris aucune part directe dans l'infraction commise. Par exemple, l'appartenance à une race maudite suffit pour être amené à payer l'acte de l'un quelconque des siens. Tant que la peine ne poursuit qu'un but de vengeance ou d'intimidation, la responsabilité collective fait partie intégrante du système ${ }^{41}$. Car, dans la mise en oeuvre de la vengeance privée se manifeste une étroite solidarité active et passive du groupe. La vengeance cherche à atteindre non seulement le coupable, mais ses proches, son chef, les membres les plus importants du groupe ${ }^{42}$.

Autrefois, il y avait la responsabilité familiale dans presque toutes les sociétés primitives. Hors des limites de celle-là, quand on commet une infraction; certains éléments peuvent rester non identifiés parmi un groupe précis, par exemple, population d'un territoire, habitants d'une cité, mem-

\footnotetext{
${ }^{10}$ Merle-Vitu, op. cit., I, p. 574 et s.

41 Imbert-Levasseur, op. cit., pp. 193, 194, 219.

42 Stéfani-Levasseur-Bouloc, Droit pénal général, Paris, 1984, p. 400.
} 
bres d'une corporation, etc... Dans ce cas là, la responsabilité pénale s'étend généralement et automatiquement à l'ensemble du groupe, chez tous les peuples, dans l'état du pré-droit dominé surtout par les conceptions religieuses. De nombreux siècles, qui ont précédé la période historique ont connu des formes de responsabilité collective étendue et n'ont pas distingué entre participants et non-participants au crime, même entre coupables et innocents. On rencontre des exemples de ce genre dans le droit grec et dans le droit romain archaïques ${ }^{43}$.

En France, en 1789, la responsabilité collective a dû disparaitre. Mais ella reșurgi dans la loi du ler vendémiaire AN IV dont l'article 2 dispose que:

"Dans les cas où les habitants de la commune auraient pris part aux délits commis sur un territoire par des attroupements ou des rassemblements, cette commune sera tenue de payer à la République une amende d'un montant égal au montant de la réparation principale" ${ }^{\text {"44. }}$.

Le droit pénal contemporain considère sans aucun doute la responsabilité collective ou bien la responsabilité par contagion comme une institution surannée, abolie, propre aux époques barbares. En effet, la responsabilité morale de l'agent et la personnalité des peines sont des axiomes fondamentaux des législations modernes. Le progrès a consisté à rendre progressivement la responsabilité individuelle afin que chacun n'ait à répondre que de son propre fait $t^{45}$ et que nul ne doive supporter de peine du fait des agissements d'autrui.

Cependant, certaines formes attardées subsistent ou tendent à réapparaître à l'époque moderne, c'est-à-dire que la responsabilité collective est loin d'être un souvenir regrettable. $\mathrm{La}$ règle antique des luttes entre clans n'a pas complètement disparu à notre époque. Selon cette règle, les membres du groupe social auquel appartient le malfaiteur, pouvaient tous être appelés à supporter la responsabilité pénale de ses actes ${ }^{46}$. Pour préciser la question, il faut un peu étudier la théorie de la participation.

\section{a) La culpabilité et la participation au fait collectif:}

Comme on le sait, la culpabilité est une notion complexe dans le droit pénal, qui comporte un aspect matériel (participation physique à l'infraction) et un aspect moral (participation fautive). Autrement dit, la première condition d'existence de la culpabilité est une relation maté-

43 Lebigre, Quelques aspects de la responsabilité en droit romain classique, Pari.. 1967, pp. 11-13.

44 Imbert-Levasseur, op. cit., p. 220.

45 Stèfani-Levasseur-Bouloc, op. cit., pp. 397-399.

${ }^{4 \epsilon}$ Imbert-Levasseur, op. cit., p. 221. 
rielle entre l'infraction et la conduite personnelle de l'auteur. En d'autres termes, il faut établir avec certitude cette relation personnelle de criminalité qui a deux critères liés l'un à l'autre. Le premier critère est la relation de participation, le deuxième, la relation de causalité. Cette question de la relation de participation se complique lorsque l'infraction a été commise en coopération avec plusieurs personnes. Car, il s'agit alors de démarquer et d'individualiser le fait personnel qui est ainsi enchevêtré dans le fait d'autrui ou dans le fait collectif ${ }^{47}$.

En particulier, s'il s'agit des infractions collectives, de nouveaux problèmes juridiques surgissent sur ce point. A ce propos, l'une des deux oftions qui.viennent tout de suite à l'esprit est la responsabilité individuelle de chaque membre du groupe en fonction de la part qu'il a prise à l'action; l'autre, la responsabilité collective de tous les participants. Les pénalistes: classiques ont pris parti pour la première solution. Car, elle était compatible avec le principe de l'individualisation de la peine. De plus, la deuxième solution avait fourni trop de fâcheux exemples dans le processus historique de droit pénal. Cependant, sous la pression de la logique des faits, ce. principe n'a pas, résisté longtemps. En effet, au début du $\mathrm{XX}^{\circ}$ siècle, le penseur FAUCONNET disait que tous les efforts d'individualisation de la responsabilité consacraient, non pas un progrès, mais un affaiblissement extrême, de la responsabilité qui est collective et communiquable par nature. C'est pourquoi, la législation moderne apporte à l'heure actuelle, des brèches qui ont tendance à s'élargir, à cette conception individualiste et également et parallèlement les criminalistes contemporains paraissent sollicités par la tentation de tirer des conséquences plus étendues du caractère collectif de l'infraction ${ }^{48}$.

En résumé, quand une infraction est commise par plusieurs délinquants, selon la théorie de la complicité et de la coaction, on rechercheles personnes qui ont participé et la répression n'est plus subordonnée au seul accomplissement de l'acte illicite. Cette répression s'étend au delà de l'auteur principal. Selon la théorie dont il s'agit, il faut établir la distinction entre l'auteur, le complice et le comparse. De plus, comme il arrive le plus souvent, il est difficile d'identifier les personnes qui ont contribué à l'accomplissement de l'acte incriminé, en particulier lorsqu'il s'agit d'une infraction commise en groupe, la détermination des participants à l'acte incriminé est parfois impossible, difficile ou même inutile. Alors, il convient seulement de rechercher les participants au groupe. Aussi, afin de ne pas laisser impunies certaines infractions, la législation française tend à ne plus subordonner la pénalité, la répression à la manifestation de

${ }_{47}$ Merle-Vitu, op. cit., I, pp. 607-612.

48 Ibid., pp. 622-623. 
l'accomplissement. de l'acte matériel ou de la complicité. C'est-à-dire, en d'autres termes, que la participation est déplacée à cet égard. Donc, la participation à l'acte incriminé n'est plus répréhensible, mais la participation et l'appartenance au groupe ${ }^{49}$.

\section{b) L'appartenance à un groupe:}

En incriminant l'appartenance au groupe, auteur de l'infraction et non l'accomplissement des actes constitutifs de cette dernière, le législateur crée un critère de participation punissable. En effet, le fait d'être volontairement présent au sein d'un groupe lors d'une action infractionnelle provoque dans certains cas précis des conséquences pénales. Au fond, il s'agit ici d'une dégradation du fait matériel dans la théorie de la participation.

aa) L'appartenance d̀ un groupe constitue une infraction spéciale dans dertains cas:

Le fait de participer à un groupe délictueux constitue parfois une infraction distincte indépendamment des peines encourues à l'occasion de chaque délit commis au sein de cette organisation, pourvu que l'appartenance au groupe et la participation à l'infraction commise par ce groupe soient établies. Quand le législateur réprime spécialement un délit commis en groupe, cette tendance parait assez forte. Voici les infractions principales à ce sujet:

1 - Le complot:' Les complots dits simples ou bien aggravés sont prévus par les articies 87 et 94 du Code pénal français. Ces deux types de complots, qui précèdent l'attentat ont pour but certains crimes politiques dans la réalisation progressive d'une entreprise contre la sûreté de l'Etat.

Les éléments constitutifs sont au nombre de quatre: la résolution d'agir qui implique une volonté précise. Cette résolution doit être concertée entre deux ou plusieurs personnes, c'est-à-dire qu'il faut une réunion de volontés dans un même but. Cette résolution doit être arrêtée entre les conjurés et enfin le complot doit avoir un but particulier ${ }^{50}$.

2 - Formation de bandes armées: les articles 95, 96 et 101 al. 4 du Code pénal sont relatifs à l'organisation de bandes armées. Il s'agit, ici, d'une organisation hiérarchisée qui a un but particulier. En effet, ce but doit être de troubler l'Etat par l'un des moyens suivants: l'un des crimes prévus par les articles 86 et 93; l'envahissement, le pillage ou le partage des propriétés publiques ou privées; le fait de faire attaque ou résistance envers la force publique agissant contre les auteurs de ces crimes.

\footnotetext{
${ }^{49}$ Dupeyron, étude précitée, p. 372.

50 Goyet, op. cit., p. 25; Vitu, op. cit., $n^{\text {os }} 75$ et $s$.
} 
Le texte permet de réprimer des faits d'assistance à la bande armée en dehors des cas de complicité ordinaires, à la condition que les auteurs aient agi volontairement et en connaissance de cause. De plus, ce qui est important pour nous, les subalternes, qui n'ont exercé aucun commandement ni emploi dans la bande, sont punis.

Il faut noter que, dans un très récent passé, divers textes admettaient que les membres d'une bande ayant commis ou tenté certains crimes étaient punissables du seul fait qu'il appartenaient à la bande. Par exemple, l'article 97 (abrogé par l'ordonnance du 4 juin 1960) disposait que:

"la peine de mort sera appliquée sans distinction de grade à tous les individus faisant partie de la bande et qui auront été saisis sur le lieu de réunion séditieuse".

3 - Organisation de mouvements insurrectionnels: l'art. 99 du Code pénal français punit de la peine de mort ${ }^{50 a}$ ceux qui ont dirigé ou organisé un mouvement insurrectionncl ou qui lui ont sciemment et volontairement fourni ou procuré des armes, munitions et instruments de crime, ou envoyé des subsistances ou qui ont, de toute manière, pratiqué des intelligences avec les directeurs ou commandants de mouvement. Le législateur a voulu ainsi atteindre ceux qui apportent en connaissance de cause une aide quelconque à l'insurrection sans commettre d'actes de complicité caractérisés.

4 - Participation à l'attroupement: Aux termes de l'art. $105 \mathrm{du}$ Code pénal français, toute personne non armée faisant partie d'un attroupement armé ou non armé ne l'aura pas abandonné à la première sommation sera punie.

5 - Coalition de fonctionnaires: L'art. 123 du Code pénal français punit d'un emprisonnement de deux à six mois et, en outre, facultativement, de l'interdiction des droits civiques et de tout emploi public pendant dix ans, tout concert de mesures contraires aux lois, pratiqué soit par la réunion d'individus ou de corps dépositaires de quelque partie de l'autorité publique, soit par députation ou correspondance entre eux.

6 - Association de malfaiteurs: Le Code pénal français avait puni l'association de malfaiteurs afin d'atteindre les bandes organisées qui ré-

\footnotetext{
${ }^{30} \mathrm{~B}$ La peine de mort est supprimée, en France, par la Loi $\mathrm{n}^{\circ}$. 81-808 du 9 octobre 1981. Mais, le législateur français s'est contenté de la supprimer et n'a prévu aucune peine de substitution. Désormais, d'après. l'article 3 de la loi du 9 octobre 1981, dans les dispositions législatives en vigueur, toute référence a la peine capitale doit étre remplacée par la réclusion criminelle à perpétuita pour les crimes de droit commun, et par détention criminelle à perpétuité pous: les crimes de nature politique.
} 
pandaient la terreur dans les campagnes à la fin de la Révolution. A la suite de cette répression, ces bandes avaient rapidement disparu. Cependant, il s'était formé des sortes d'associations anarchistes ayant pour but la propagande par le fait. Le législateur, pour les réprimer, a modifié le texte des anciens articles 265 à 268 qui ne répondaient plus aux nécessités actuelles de la défense sociale, le 18 décembre 1893. Le nouveau texte des articles 265 à 267 punit l'association même non organisée, la simple entente qui ont pour but de commettre ou de préparer des crimes contre les biens ou les personnes.

Le nombre des affiliés et également la durée fixée à l'association ou l'entente ne sont pas importants. Le concours de deux personnes suffit pourvu qu'on démontre la résolution d'agir en commun, l'accord pour passer à l'action extérieure par la commission d'infraction ${ }^{51}$.

bb) La participation à une activité collective constitue une circonstance aggravante dans certains cas:

Afin de réprimer certaines infractions, le législateur a eu une tendance à aggraver les responsabilités personnelles de ceux qui participent à une activité collective. D'ailleurs, les positivistes préconisaient la généralisation de cette solution à tous les cas de complicité $e^{52}$.

A première vue, les considérations les plus éclatantes de cette tendance sont les suivantes:

1 - Rébellion: Le Code pénal français punit la rébellion en vue d'assurer le respect dû aux fonotionnaires et agents de la force publique lorsqu'ils exécutent les ordres de la loi de l'autorité (art. 209). Si cette rébellion est commise par une réunion de 3 à 10 personnes ou plus de 20 personnes, cela constituera une circonstance aggravante (art. 210, 211 et 214).

On voit bien qu'ici, le trouble social issu de l'agissement collectif est entièrement imputé à chaque individu. Cela apparaît avec une netteté particulière. Car, lorsque l'intensité des participations individuelles à l'infraction collective est connue, le droit positif français n'en tient, en principe, aucun compte. C'est pourquoi, selon les articles 209 et 214 , les individus non armés encourrent la même peine que s'ils avaient été armés. Il est donc caractéristique que la criminalité propre des membres du groupe est détérminée collectivement en fonction de la criminalité du groupe.

2 - Mendicité: La mendicité consiste à solliciter du public, dans un intérêt personnel, des secours gratuits. Selon la loi pénale, la mendicité en réunion constitue une circonstance aggravante (art. 276).

51 Goyet, op. cit., p. 214; Vitu, op. cit., I., n ${ }^{\text {os } . ~ 208, ~} 209$.

52 Merle-Vitu, op. cit., I, p. 624. 
3 - Viol: Le viol est un acte exercé directement sur une personne et de naturé à porter atteinte à sa pudeur, sans qu'il y ait à distinguer s'il est commis publiquement ou non. Si cette infraction est commise, ou en co-activité ou bien en complicité, cette situation conștituera une circonstance aggravante (art. $332 \mathrm{du}$ Code pénal, modifié par la loi $\mathrm{n}^{\circ}$ 80-1041 du 23 décembre 1980).

4 - Vol: Le vol est la soustraction frauduleuse de la chose d'autrui (art. 379 du Code pénal). Les éléments constitutifs communs de tous les vols sont au nombre de quatre: il doit y avoir eu soustraction; cette soustraction doit avoir été frauduleuse; elle a dû avoir pour objet une chose mobilière; la chose soustraite devait appartenir à autrui.

Comme on le sait, il y a plusieurs circonstances aggravantes relatives au mode d'exécution du vol. Une de celles-ci est sans doute le vol commis en activité. Cependant, la circonstance que le vol a été commis par deux ou plusieurs personnes n'aggrave l'infraction que si elle est accompagnée de la réunion de trois circonstances suivantes; effraction intérieure ou extérieure dans un local d'habitation ou un lieu où sont conservés des fonds, valeurs, marchandises ou matériels, ou bien nuit, ou bien violence. Il faut que le vol même ait été exécuté par plusieurs auteurs; il ne suffirait pas que l'auteur unique eût des complices (art. 382, modifié par les lois $n^{\circ} 81-82$ du 2 férrier 1981 et 10 juin 1983$)^{53}$.

5 - Pillage: Malgré l'abrogation de l'ancien article 97 dont nous avons parlé plus haut (abrogé par l'ordonnance du 4 juin 1960), il existe encore des cas dans lesquels le droit positif français incrimine gravement la participation à un groupe générateur d'une infraction. C'est ainsi que selon l'article 440:

"Tout pillage ...... commis en réunion ou bande et à force ouverte sera puni de la réclusion".

Or, la doctrine considère que le seul fait d'avoir fait partie de la bande est un acte de complicité dans les actes commis par celle-ci.

Le pillage signifie la dévastation accompagnée de vol. Il faut signaler que le dégât se distingue du pillage. Car le dégât constitue une destruction sans profit pour personne. Avant la modification par la loi $n^{\circ} 70-480 \mathrm{du}$ 8 juin 1970, larticle 440 du Code pénal punissait même le dégât. Les dégâts causés aux biens dạns. les conditions mêmes de l'article 440, en d'autres termes, en réunion ou en bande et à force ouverte, se trouvent visés par l'article 314, (abrogé en 1981), tel qu'il résulte de la loi susvisée du 8 juin 1970. Car l'article 5 de cette loi a supprimé du texte de l'article

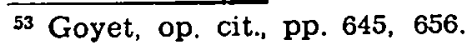


440 les mots "tout dégât" réduisant ainsi le champ d'application de ce dernier au pillage proprement dit $^{54}$. D'aileurs cet article est aborgé par la Loi $\mathrm{n}^{\circ} 81-82$ du 2 février 1981.

Le pillage d'objets mobiliers, quels qu'ils soient, est le premier élément de ce crime. Deuxièmement, il faut que l'infraction ait été commise par plusieurs personnes réunies et usant de moyens violents. Cependant, peu importe que les inculpés aient été armés et aient exercé des voies de fait sur les personnes.

On voit de plus que l'article 440 expose tous les participants à une peine de dix à vingt ans de réclusion criminelle. Il est remarquable que c'est la peine attachée à tout acte de violence ${ }^{55}$.

cc) L'appartenance active à un groupe entraîne une responsabilité des agissements collectifs dans certains cas:

De nos jours, certains textes permettent d'imputer aux membres d'un groupe les conséquences pénales des agissements collectifs. En effet, l'obligation de démontrer la participation effective de chacun aux faits qui font l'objet de la poursuite n'est pas nécessaire. Le législateur a utilisé une technique particulière de deux sortes pour imposer cette solution. Le législateur a voulu établir, en premier lieu, une présomption de participation déduite de l'appartenance au groupe; en deuxième lieu, assimiler l'appartenance au groupe à la participation à l'infraction ${ }^{56}$.

1 - La participation présumée: crimes de guerre: l'art ler de la loi du 15 septembre 1948 utilisait le premier, c'est-à-dire le système de la présomption de participation en vue de réprimer les crimes de'guerre.

En effet, un retour vers la collectivisation de la responsabilité pénale avait été introduit en France par cette loi. Elle était destinée à faciliter la répression des abominables massacres dont les troupes nazies s'étaient rendues coupables à Ascq, à Tulle, à Oradour-sur-Glane, etc... Selon l'article ler de la loi du 15 septembre 1948:

\begin{abstract}
"Lorsqu'un des crimes de guerre est imputable à l'action collective d'uns formation ou d'un groupe faisant partie d'une orgánisation déclarée criminelle (tel était le cas, par exemple, pour les Waffen SS) par le Tribunal militaire international (Tribunal de Nuremberg) agissant en vertu de l'acte du 8 aoút 1945, tous les individus appartenant à cette formation ou à ce groupe peuvent être considéés comme co-auteurs à moins qu'ils n'apportent la preuve de lour incorporation forcée et de leur non-participation au crime".
\end{abstract}

54 Itid., p. 906. Imbert-Levasseur, op. cit., p. 223; voir, référence n. 30.

ss Stéfani-Levasseur-Bouloc, op. cit., p. 398; voir, référence n. 30.

36 Merle-Vitu, op. cit., I, p. 625. 
Et également, l'article 2 précisait et disposait encore:

\begin{abstract}
“Pour l'application de l'article précédent, sont considérés comme coupables de l'action collective de la formation ou du groupe envisagés, les crimes de guerre commis par ses membres dans la même région, même isolément ou de leur propre initiative, lorsque, par leur importance, leur gravité, leur répétition ou par le nombre des victimes, ces actes constituent les éléments d'une action d'ensemble".
\end{abstract}

Ces dispositions furent abrogées par la loi du 20 janvier 1953 pendant que le procès du massacre d'Oradour était en cours. Car, elles avaient été vivement critiquées en doctrine, d'une part; la jurisprudence se montra, à juste titre, très réticente pour ses applications, d'autre part ${ }^{37}$. Cependant certains écrivains (en particulier, IMBERT et LEVASSEUR) même actuellement estiment qu'elles étaient peut-être moins insolites qu'elles ne le paraissaient au premier abord, car, chaque fois qu'elles mettent en cause le maintient de l'ordre public, le principe de la responsabilité individuelle est quelque peu malmenés ${ }^{58}$.

Ce qui est remarquable ici c'est la technique que l'on a utilisée. Elle était très originale. Car la participation à l'infraction était présumée du fait de l'appartenance au groupe. D'ailleurs, il s'agissait ici d'un groupe constitué dont les membres étaient connus et identifiés à l'avance (ainsi une unité de l'armée). Dans de telles hypothèses, le rattachement au groupe n'a pas à être effectué, mais est plutôt préćtabli. Lorsqu'une ou plusieurs infractions sont commises par un tel groupe ou par certains de ses membres, à cause de diverses difficultés ou de la solidarité des membres du groupe, le législateur tente de sanctionner tous les membres du groupe. Il désire que la responsabilité pénale soit simplifiée et collective et que tous les agissements jugés particulièrement intolérables soient réprimés beaucoup plus facilement ${ }^{59}$.

On voit bien, au point de vue de l'imputation matérielle du résultat de l'infraction collective, que la loi n'hésite guère lorsque le degré de participation paraît a priori difficile à connaître ou a fortiori ne peut être déterminé. En d'autres termes, lorsque le degré de participation est indéterminable, cette tendance s'impose. Car, il va de soi qu'on ne peut tenir compte de leur intensité. Le droit positif français manifeste alors une tendance très nette à ne tenir aucun compte du degré de participation de chacun à l'agissement illicite et à imputer le fait illicite du groupe à ses membres. C'est-à-dire que, dans toutes les hypothèses envisagées, la loi ou la jurisprudence françaises répriment la participation au groupe

57 Ibid, p. 625; Imbert-Levasseur, op. cit., p. 222; Dupeyron, etude précitee, p. 376.

Imbert-Levasseur, op. cit., p. 222.

s Dupeyron, étude précitée, p. 378. 
sans tenir compte de l'irtensité des participations individuelleś à l'infraction commise. Pour bien synthétiser en peu de mots et en une phrase célèbre, il est possible de dire de l'infraction collective que chacun en a sa part et que tous l'ont toute entière ${ }^{60}$. C'est pour cela que la loi du 15 septembre 1948 déclarait:

"tous les individus appartenant à cette formation ou a ce groupe peuvent être considérés comme co-auteurs".

D'ailleurs, en matière de pillage, l'article 440 du Code pénal ${ }^{60 a}$ prévoit une disposition analogue ainsi que les anciens articles 76 et 97.

Pourtant, l'article 2 de cette loi avait dû restreindre les limites du groupe dont les membres étaient punissables de peur que la répression de méfaits commis par quelques uns ne s'abatte sur une foule d'individus. En effet, lorsque les membres du groupe ne sont pas connus à l'avance pour réprimer, il y a licu de rechercher qui a participé au groupe; ainsi le lien de participation n'a pas démesurément relâché. Au contraire, quand cette appartenance est préétablie, il convient de restreindre les dimensions du groupe si l'on ne veut pas punir des individus absolument étrangers à l'infraction. A cause de cela les activités individuelles devaient apparaître comme faisant partie de l'action de l'ensemble du groupe répréhensible ${ }^{61}$.

En revanche, il faut étudier le problème au point de vue de l'acte fautif. Il est hors de doute que, lorsque la participation à l'acte illicite est déduite de l'appartenance à un groupe constitué, il est difficile de trouver une faute apte à fonder la sanction. Aussi, ne trouve-t-on plus en droit positif de texte consacrant une telle forme de responsabilité. Mais, le législateur a créé ce type de responsabilité à l'occasion de crimes particulièrement odieux, comme les crimes de guerre. Cependant, il l'a partiellement atténuée. En effet, la loi du 15 septembre 1948 avait insisté surtout sur le terrain de la preuve, non sur le terrain du fond. Selon la loi, les membres du groupe qui ont participé aux crimes commis par celui-ci étaient considérés come auteur. Mais la sanction n'était pas étendue par la loi à des membres du groupe prouvant être étrangers aux faits illicites, à la condition qu'on ne peut pas trouver dans leur adhésion au groupe une faute véritable ou tout au moins à la condition que leur appartenance au groupe fut exempte de toute faute ${ }^{62}$. D'autre part, s'il est admis que la participation au groupe légitime la répression, la démonstration de l'absence de participation (en tant qu'auteur ou complice) à l'agissement illicite du groupe doit demeurer sans effet sur l'xistence de la culpa-

66 .tbid, pp. 384, 385, 387.

60 Voir, référence n. 30.

61 Ibid., pp. 378, 379.

62 tbid., p. 379 . 
bilité. Cependant, dans des hypothèses particulières, une telle preuve est susceptible d'entraîner l'impunité. En d'autres termes, il peut en être ainsi en l'absence de faute résultant de la participation au groupe lorsque la participation à l'acte illicite est seulement présumée. C'est pourquoi la loi de 1948 a admis que la preuve de l'absence de participation à l'infraction a pour effet d'écarter la responsabilité des membres du groupe lorsque leur incorporation avait été forcée ${ }^{63}$.

Cependant, cette loi était, à juste titre, vivement critiquée, parce qu'elle allait dans certains cas beaucoup plus loin en ce sens qu'elle imputait à la fois à tous les membres du groupe les faits illicites' de ce dernier et à l'action collective de la formation ou du groupe envisagé les crimes de guerre commis par ses membres dans une même région même isolément ou de leur propre initiative.

2 - L'assimilation entre l'appartenance au groupe et la participation:

Le régime le plus interessant et éclatant est, à ce sujet, sans doute le cas d'actions commises en groupe et en bande prévues par les articles 313 et 314 du Code pénal français. C'est pourquoi, ces articles valent d'être étudiés, en particulier le dernier.

\section{a - Crimes et délits commis en bande:}

Lorsque les infractions prévues par les articles 295 à 312 (meurtre, assassinat, parricide, infanticide, empoisonnement, menaces, blessures et coups volontaires non qualifiés meurtres) sont commises en réunion séditieuse, avec rébellion ou pillage, les chefs, auteurs, instigateurs ou provocateurs de la réunion sont punis comme coupables de ces crimes et délits selon l'article 313 du Code pénal. Peu importe qu'ils n'aient pas pris part personnellement aux actes commis, ou même qu'ils n'aient pas poussé les auteurs à les commettre. Le législateur apporte ici nettement une dérogation au principe de la responsabilité pénale et aux règles de la complicité pour assurer le maintien de l'ordre ${ }^{\text {th }}$.

En effet, cet article est à cet égard significatif. Car, le législateur va plus loin, puisqu'il impute à chaque membre du groupe non seulement les agissements de ce groupe, mais, à notre avis, encore des faits individuels dont les agissements du groupe n'ont été que l'occasion. L'article susdit impute "aux chefs, auteurs, instigateurs et provocateurs" des réunions

\footnotetext{
63 Ibid., pp. 381, 382 .
}

84 Imbert-Levasseur, op. cit., p. 222; Merle-Vitu, op. cit., I, p. 625; Goyøt, op. cit., p. 478 . Vitu, op. cit., I, n. 146, II, n. 1747. Les articles 305, 308, 309, 310, 311 et 312 sont modifiés et les articles 307 et 308 sont abrogẹs par la loi $n^{\circ} 81-82$ du 2 février 1981. 
séditieuses accompagnées de rébellion ou pillage, les crimes et délits commis au cours de ces réunions, rébellions ou pillages. Il n'est alors plus tenu compte de la part personnelle prise dans la réalisation de ces crimes. C'est-à-dire que, d'après l'article, les chefs de la foule en rébellion sont ainsi rendus personnellement responsables des excès auxquels cette foule se livrera ${ }^{65}$.

C'est ainsi que l'article apporte encore une dérogation aux règles de la complicité. Car, il assimile aux auteurs matériels des coups et blessures, par exemple, les provoçateurs ou les instigateurs, qui n'auraient été que , des complices en application de l'article 60 du Code pénal français ${ }^{66}$.

A noter que, plus le lien entre la faute de participation et les faits licites est étroit, moins les solutions sont critiquables. Ainsi, lorsque cette faute traduit une véritable adhésion aux agissements du groupe et une aide morale à celui-ci, ellès ne paraissent pas, en principe, exorbitantes (outrancières). Par exemple, ce lien paraît être, a priori, moins relâché dans les infractions qui sont commises par une association, une bande ou à la suite d'une entente que dans celles qui sont le fruit d'une réunion. Mais, au contraire, elles ne semblent pas défendables lorsque ce lien est trop ténu et faible comme dans le cas prévu par l'article $313^{67}$.

\section{b - Actions commises en groupe (loi anti-casseurs):}

Le projet gouvernemental qui est devenu "la loi tendant à réprimer certaines formes nouvelles de délinquance" (la loi $n^{\circ} 70-480$ du 8 juin 1970 , plus connue sous la nom de loi anti-casseurs dans le public) sovleva une grande émotion lorsqu'il apparût qu'il risquait d'instituer certains cas de responsabilité collective. En effet, l'art. 314 du Code pénal, issu de ladite loi, prévoit, des assimilations de moindre portée, soit à l'égard des instigateurs ou organisateurs de certaines actions collectives, soit même à l'égard des simples memibres du groupe ${ }^{68}$.

65 Dupeyron, étude précitée, p. 285; Vitu, op. cit., I, n. 146, II, n. 1747.

66 Stéfani-Levasseur-Bouloc, op. cit., $\mathrm{n}^{\text {os }}$. 250-253; Vitu, loc. cit.

67 Dupeyron, étude précitée, p. 380; Vitu, loc cit.

6 On peut consulter pour plus de détails : Blin, Commentaire de la loi $n^{\circ} 70-480$ du 8 juin 1970 tendant à réprimer certaines formes nouvelles de délinquance. Semaine juridique, 1970, I, Doctrine, p. 2348 et s.; Bouzat, La loi du 8 juin 1970 tendant à réprimer certaines formes nouvelles de délinquance, (dite loi "anti-casseurs"), En hommage à Jean Constant (Mélanges Constant), Faculté de Droit de Liège, Belgique, 1971, pp. 51-67; Chavanne, Revue de Science Criminelle et de droit pénal comparé, 1970, pp. 889-881: Colliard,'Libertés, publiques, Paris, 1972, pp. 602-606; Doll, La loi "anti-casseurs", Gazette di Palais, 1970, 2 ème sem., pp. 54-60, Duffar, La loi "anti-casseurs," Revue de droit public et de science politique, janv/fév., 1972, pp. 49-104; Imbert-Levasseur, op. 
Au fond, la loi du 8 juin 1970 ne comporte que six articles créant, modifiant ou complétant des incriminations qui, n'ayant d'autre lien entre eux que le but poursuivi par le législateur, s'insèrent dans le Code pénal français, à l'exception du dernier article. On peut toutefois dire que la disposition fondamentale de cette loi est dans son article ler. Cet article donne une vie nouvelle à l'article 314 du Code pénal, abrogé depuis 1939 et resté vacant, qui vise la répression des violences et dégradations ou destructions commises, soit à la suite d'actions dites de commando, soit du fait d'un rassemblement illicite ou interdit et qui institue une responsabilité pécuniaire à l'encontre des auteurs de ces violences ou destructions. D'ailleurs, c'est seulement autour de cet article ler (en d'autres termes autour de l'article 314 du Code pénal) que se sont produites toutes les polémiques, tant dans l'opinion publique qu'au parlement. Tandis que les autres articles, qui n'intéressent pas notre exposé, ont été votés sans discussion. C'est pourquoi, nous bornerons cette étude assez détaillée à cet article ler, c'est-à-dire l'article 314 du Code pénal et nous ferons allusion aux controverses, aux hésitations qui témoignent d'inquiétudes juridiques, dans la mesure où elles apparaîtront utiles et nécessaires pour éclairer notre exposé.

Cétte loi est sans doute, en premier lieu, destinée à réprimer les actions violentes, trop fréquentes, menées par des individus sous l'anonymat d'un

cit., pp. 63, 223; Delmas-Marty, Les chemins de la répression,Paris, 1880, pp. 43-48; Lambert, Revue de la police nationale, oc/nov., 1970, pp. 7-2\%; Merle-Vitu, op. cit., I, p. 625; Goyet. op. cit., pp. 478-488; Stéfani-Levasseur, op. cit., p. 250 et s.; Semaine juridique, 1972, Gazette du Palais, 1872; Vitu, op. cit., I, nos. 157 et s. : Delmas-Marty, op. cit., pp. 43-44. L'article 314 du Code pénal français est abrogé par la Loi du 23 décembre 1981 ( $n^{\circ}$. 81-1134). Cependant, il est utile $ə t$ méme nécessaire de l'étudier de plus près, d'une part, en vue de bien montrer l'évolution et la dimension de I'infraction collective dans un pays civilisé et. d'autre part; en vue de mettre en lumière la tendance des législateurs portant atteinte au principe de la responsabilité pénale individuelle qui, en effet, est un axiome fondamental du droit pénal moderne. Tandis que la responsabilite collective est considérée comme une institution surannée, propre aux époques barbares. C'est la loi "anti- casseurs" qui avait tenté d'introduire cette notion" etrangère à la tradition juridique française. C'est pourquoi, elle avait été vivement critiquée par les juristes à cette epoque - là et mème ne connaissait pas une utilisation maximale. Les magistrats français peuvent penser, peutêtre d'ailleurs, comme l'a dit M. Colliard (op. cit., pp. 605, 603), qu'existe un 3 sorte de tendance à se "défausser" sur eux des problèmes du maintien do l'ordre. Il existait, à n'en pas douter, à cette ápoque-lâ un malaise profond, dont la responsabilité ' collective, qui était un écho, en quelque sorte, des idées barbares et donc paraissait mettre le droit pénal en contradiction avio lui -méme- était la cause primordiale. En tenat compte de ce processus et surtout de ce qui s'était passé, le législateur du 1881 a abrogé cette loi et donc. larticle 314 du Code pénal français. 
groupe du type "commando" ainsi que les exactions commisès lors de certains rassemblements. Leurs agents bénéficiaient d'une quasi certitude d'impunité et' ne supportaient pas les conséquences pécuniaires de leurs agissements, suites qui auraient pu et dû être lourdes et qui incombent définitivement à l'Etat et aux collectivités.

En effet, certains groupes voulant prolonger les événéments de mai 1968 auraient pris l'habitude de mener des actions violentes contre les bâtiments universitaires ou autres bâtiments publics. Ils saccageaient, cassaient les vitres, faisaient de graves dégâts, molestaient les fonctionnaires, occupaient les locaux, etc... Plus les sanctions semblaient incertaines, plus l'opinion publique était excédée et émue de ces comportements. C'est pourquoi, le. Garde des Sceaux l'a déclaré, le but essentiel de la loi a été "d'assurer une répression plus efficace des actes de violence et de destruction et de permettre plus aisément le dédommagement des victimes" en faisant payer ceux qu'on appelle les "casseurs". Car, d'après le slogan, en ce moment là, il convenait que les casseurs fussent aussi les payeurs.

Toutefois, rarement le dépôt d'un projet de loi a suscité autant de polémiques. Le texte gouvernemental a dû reconnaître de multiples amendements lors des navettes successives̀ entre les deux assemblés. Il a même fallu recourir aux bons offices d'une commission mixte paritaire. On reprocha, tout d'abord, au gouvernement d'avoir voulu créer de nouvelles incriminations pénales. Tandis que celles-ci existaient dans le Code pénal pour réprimer l'ensemble des faits collectifs et individuels qu'il se proposait d'atteindre. Ensuite, on lui reprocha d'avoir introduit dans la législation française la notion d'une responsabilité collective contraire aux principes certains du droit qui ne connaît guère d'exception que celle prévue par l'article 313 du Code pénal français (sauf la loi du 15 septembre 1948, abrogée par la loi du 30 janvier 1953). Puis, d'aucuns firent encore au gouvernement grief de porter atteinte par les dispositions nouvelles aux libertés publiques et spécialement syndicales, au droit de grève, au droit du travail et au droit de réunion. En particulier, DUVERGER alla méme jusqu'à écrire dans les pages du journal "Le Monde" que ces textes "risquaient de menacer un jour les appareils de partis ou de mouvements d'opposition sans lesquels la démocratie ne peut vivre". Rien ne serait plus facile que de provoquer des violences ou des destructions sans que les chefs et les organisateurs de la manifestation y soient pour quelque chose et sans qu'ils aient la possibilité matérielle ou morale de donner l'ordre de dislocation... Par les emprisonnements et les préparations civiles, un ministre de l'intérieur et des juges décidés pourraient réduire à l'impuissance syndicats ou partis d'opposition" (22 mai 1970). Enfin, d'autres ont qualifié ce texte de loi ambiguë, dangereuse, même scélérate. Ils pré- 
tendaient que l'ensemble du texte tient au "camouflage" de la présentation "formes nouvelles de délinquance". Depuis le premier communiqué du. gouvernement et pendant toute la discussion du projet, les partisans du texte ont tenté de démontrer que les libertés individuelles des citoyens étaient menacées par le vandalisme aveugle de petits groupes de jeunes comme si le pays était traversé par une vague de délinquance juvénile (halbstarken, teddy-boys, hooligans, blousons noirs, etc...). Le texte est devenu lá loi dans cette atmosphère. De plus, ils estiment qu'à l'instar des lois qui, dans le passé, ont réprimé les attroupements, cette loi "anticasseurs" intervient après une période de troubles politiques (agitation de mai 1968 et ses séquelles). L'objet essentiel qu'elle poursuit est également de prévenir et de réprimer les mouvements d'effervescence sur la voie publique. On invoque, pour la justifier, le prétexte toujours renouvelé de délinquance nouvelle et de circonstances particulières. Enfin, comme la loi de 1848, elle se superpose à la législation existante sans la modifier ni l'abroger. C'est pourquoi:

"la loi est d'abord ambiguë, présentée aux juristes comme un perfectionnement du droit pénal et à l'opinion comme un texte d'indemnisation, le but de la loi est d'abord de restaurer l'ordre menacé par une délinquance idéologique".

La loi est, d'autre part, dangereuse: le laxisme de la rédaction entretient le justiciable dans une insécurité qu'aggrave encore l'incertitude de l'interprétation judiciaire. Enfin, les conditions de constitution du délit, les règles de la responsabilité pénale et civile ont paru à certains si rigoureuses qu'ils ont retenu le qualificatif "scélérate" pour caractériser la loi en question ${ }^{69}$.

Cepenciant, la loi "anti-casseurs" a été, d'une manière générale, assez bien accueillie à cette époque-là par l'opinion publique. D'ailleurs, toutes les critiques avaient été, d'une façon satisfaisante, réfutées par le gouvernement. D'abord, les textes existants dans le Code pénal français étaient à la fois insuffisants et surtout d'un maniement très lourd pour assurer une répression efficace et rapide des faits de violence et de-destructions. En effet, dans la plupart des cas, la mise en oeuvre de la procédure de la cour d'assises, en particulier, n'est pas rapide. Tandis que ce texte nouveau se présentait "pour une grande partie, comme une véritable mesure de correctionnalisation des poursuites qui pouvaient être exercées devant le

${ }^{69}$ Blin, étude précitée, p. 2348; Bouzat, étude précitée, pp. 51-57; Chavanne. étude précitée, p. 889; Colliard, op. cit., p. 605; Duverger, Le premier pas, Lo Monde, 22 mai 1970; Duffar, étude précitée, pp. 52-54; Floriot, Le projet de loi sur "certaines formes nouvelles de délinquance" élargit la notion de responsabilité pénale collective, Le Monde, 21 avril 1970; Vitu, op. cit., I, n. 157. 
cour d'assises" mais qui, en fait apparaissaient "si lourdes que le ministère public ne peut jamais que répugner à en requérir le prunoncé" (Journal officiel - Débats, Assemblée nationale 1970, p. 1384). C'est-à-dire qu'on avait voulu correctionnaliser certains faits incriminés aux fins de parvenir à une répression rapide et assurée, plutôt que de s'en tenir à des peines criminelles d'un effet dissuasif et incertain. En deuxième lieu, la conception de la responsabilité collective adoptée par le texte n'était pas contraire à la législation française. Car, selon le Garde,des Sceaux, la loi, en obligeant les auteurs des faits incriminés à réparer les dommages que ces faits avaient occasionnés, ne faisait rien d'autre que d'appliquer à une hypothèse particulière, les principes régissant l'exercice de l'action civile, tels qu'ils découlent des articles 2 et du Code de procédure pénale.

En troisième lieu, le Garde des Sceaux multiplia les arguments et donna l'assurance que le projet ne portait atteinte ni à la liberté de réunion, ni au droit de grève, ni aux libertés syndicales même ni à aucune de nos libertés individuelles. En résumé, cette loi ne compromettrait pas l'équilibre nécessaire entre les exigences de la répression et les libertés essentielles des citoyens. Car, le souci du libéralisme avait influé sur les rédactions successives et différentes de cette $\operatorname{loi}^{70}$.

Nour bornerons notre exposé à l'article ler de la loi du 8 juin 1970 (c'est-à-dire, le nouvel article 314 du Code pénal), comme nous l'avons dit supra, et nous étudierons successivement, d'abord les trois infractions dans une première partie, ensuite les modalités de la répression dans une deuxième partie, enfin les dispositions communes, c'est-à-dire la responsabilité civile et la solidarité dans une troisième par‘ie.

aa - Infractions (art. 314 du Code pénal)

aaa - Violences ou dommages matériels commis en groupe lors d'action à force ouverte:

Aux termes de l'alinéa ler de l'article 314 du Code pénal:

"Lorsque, du fait d'une action concertée, menee \& force ouverte par un groupe, des violences ou voies de fait auront été commises contre les personnes ou que des destructions ou dégradations auront été causées aux biens, les instigateurs at les organisateurs de cette action, ainsi que ceux qui y auront participé, volontairement, seront punis, sans préjudice de l'application des peines plus fortes prévues par la loi, d'un emprisonne. ment de un à cinq ans".

- Eléments constitutifs du délit:

:0 Blin. étude précitée; Bouzat, étude précitée, pp. 51-54. 
L'existence des quatre éléments suivants est indispensable pour constituer cette infraction.

En premier lieu, il faut qu'on se trouve en présence d'une "action concertée, menée à force ouverte par un groupe".

"L'action concertée". doit "être ménée à force ouverte" ce qui suppose l'emploi public et flagrant de la violence. Cependant les expressions "à force ouverte" et "à mains armées" ne sont pas équivalentes. Jusqu'ici, l'article 440, actuellement abrogé, du Code pénal ne citait que ce premier terme que l'on trouve dans le Code de l'Administration communale, à propos des pillages, dégâts de denrées ou de marchandises, effets, propriétés mobilières, commis en réunion ou bandes. En 1771, il était défini ainsi par un conseiller;

"La force ouverte est celle qui se fait avec armes ou avec les seules défenses naturelles, telles que les pieds et les mains, les pierres, les branches d'arbres, etc...".

Par conséquent, le délit serait constitué, bien que ses auteurs n'aient pas été armés ou qu'armés, ils n'aient pas fait usage de leurs armes.

En effet, pendant la discussion du projet, un sénateur avait bien proposé un amendement tendant à demander que les participants à l'action fussent "porteurs d'armes apparentes ou cachées ou d'objets quelconques apparents ou cachés apportés pour servir d'armes". Mais le Garde des Sceaux put facilement faire repousser cette demande. Il remarque avoir pertinence que si cet amendement était adopté, le texte proposé serait vidé de sa substance et naturellement de son pouvoir. Puisqu'aussi bien, la force ouverte peut résulter de l'usage des seules défenses naturelles de l'homme.

L'utilisation de la force ouverte consiste évidemment en violences publiques et manifestes exercées à la manière des commandos, c'est-à-dire que les actions appelées "opération de commando" sont des actions à force ouverte par un groupe. Ces violences peuvent n'être que morales. Alors il s'agira de menaces. Les violences peuvent n'être exercées que sur les choses.

Quant à la notion de groupe, dont ni les travaux préparatoires ni la loi elle-même n'ont donné sa définiton, il semble qu'on doive entendre par là la réunion d'un certain nombre d'individus animés des mêmes intentions, sans qu'on puisse, a priori, fixer le nombre de participants. Pourtant, il appartiendra aux magistrats d'apprécier souverainement dans chaque espèce, si l'on se trouve en présence d'un groupe tant au point de vue des effectifs que du degré de cohésion des membres. Cependant, il est à noter que certains écrivains ont vivement critiqué cette notion. Selon 
eux, l'appréciation de celle-ci sera très difficile et produira les imputations hasardeuses ${ }^{71}$.

L'existence de violences ou de voises de fait contre les personnes ou de destructions ou dégradations causées aux biens est le second élément du délit. Peu importe la nature, la gravité et le résultat des violences exercées ou des voies de fait commises contre les personnes. En d'autres termes, il n'y a pas lieu, notamment, de tenir compte de la distinction établie par le Code pénal français en matière de coups et blessures, selon que ceux-ci ont entraîné une incapacité totale de travail personnel pendant plus de huit jours (art. 309 C.P.) ou inférieur à huit jours (art. $R 401$ C.P.). L'infraction est constituée même si les blessures ont été légères et dès que les autres éléments de l'infraction prévue par l'article 314 du C.P. sont réunis sous réserve de l'application de peines plus élevées en cas de cumul d'application.

Or, selon la jurisprudence:

"l'un des éléments constitutifs de cette infraction (art. 314 C.P.) est donc que l'action ait eté menèe à force ouverte".

qui implique l'emploi de la force, de la violence. Cette condition n'est pas remplie lorsque l'on se trouve en présence d'une manifestation pour laquelle il est seulement établi - dans le cadre de cet élément constitutif qu'est "à force ouverte" - que des jeunes gens se sont réunis à une heure déterminée devant un immeuble pour scander des slogans et distribuer des tracts $^{72}$.

"Lorsque des blessures ont été faites volontairement par plusieurs prévenus au cours d'une scène unique de violences, l'infraction peit ètre appréciée dans son ensemble, sans qu'il soit nécessaire, pour les juges du fond, de préciser la nature des coups portés par chacun des prévenus à chacune des victimes"'73.

Il suffit pour que le délit de l'article 314 soit caractérisé qu'au cours d'une action concertée, menée à force ouverte par un groupe, des violences aient été exercées même celles-ci n'étaient pas préméditées ${ }^{74}$.

Quant aux destructions et dégradations, elles impliquent toutes 1 es atteintes portées aux biens. Peu importe la nature, mobilière ou immobilière des biens et l'importance des dégâts qu'ils ont subis.

Le troisième élément du délit est caractérisé par une relation de cause à effet entre l'action, telle qu'elle a été ci-dessus expliquée, et les violences

71 Duffar, étude précitée, pp. 93-95; Vitu, op. cit., I, n. 158.

72 Colmar, Ch. correct. 12 nov. 1971, Semaine juridique, 1972, IV, p. 85.

73 Crim., 13 juin 1972, Ibid., p. 17.

74 Trib. grande instance de Caen, Gazette du Palais, 1972, 2ème sem., p. 888. 
exercées contre les personnes, d'une part, ou les dégradations causées aux biens, d'autre part. En d'autres termes, les violences ou les dégradations en question doivent être survenues lors de l'action même, c'est-à-dire résulter de celles-ci (art. 309, modifié par la loi 2 février 1981, R. 40-1. 445, abrogé par la même loi, C.P.).

L'existence de l'intention délictueuse est le quatrième élément du délit. En effet, il résulte non seulement des termes mêmes de la loi, mais encore de l'application des règles du droit commun que le délit en question est une infraction intentionnelle. C'est ce que le législateur explique clairement, en vue de faire apparaître, sans équivoque posșible, le caractère intentionnel de ce délit. C'est pourquoi, il précise que l'action du groupe, four être punissable, doit avoir été "concertée" et la participation de chacun de ceux qui ont contribué à cette action doit être prêtée "volontairement".

Le projet gouvernemental ne parlait que "d'action à force ouverte" et même le texte voté par l'Assemblée nationale en première lecture n'incriminait que "l'action menée à force ouverte". Sur l'initiative du rapporteur au Sénat, en ajoutant à ces termes le mot "concertée", le législateur a voulu retenir expréssément le critère intentionnel. Il s'agit de l'action de ceux qui se réunissent en groupe, dans l'intention délibérée de commettre des violences sur les personnes ou des dégradations sur les biens, en mettant l'accent sur le caractère intentionnel des faits incriminés. En d'autres termes, le qualificatif "concertée" doit mettre en relief l'intention délibérée de commettre des violences ou des dégradations, le caractère prémédité de l'action ${ }^{75}$.

Or, la jurisprudence aussi a insisté sur ce caractère du délit "l'importance des peines prévues (en ce cas) démontre que le législateur a voulu punir une action grave telle que la préparation concertée pour la violence" (Cour de Grenoble, 22 oct. 1971) ${ }^{76}$. Constitue le délit prévu et réprimé par l'article 314 , al. 1 du Code pénal, le fait pour plusieurs jeunes gens de s'être trouvés à une heure donnée en un lieu déterminé, ce qui caractérise l'action concertée, d'avoir alors constitué un groupe, c'est-à-dire la réunion de plusieurs personnes animées des mêmes intentions, en commettant des violences ou voies de fait contre des personnes, alors qu'ils constituaient un commando de protection de leurs camarades, distributeurs de tracts ${ }^{77}$.

75 Blin, étude précitée; Doll, étude précitée, p. 55; Duffar, étude précitée, pp. 70-72; Goyet, op. cit., p. 480; Vitu, op. cit., I, n. 158.

76 Duffar, étude précitée; p. 70.

77 Trib. gr. Instance de Paris, 16ème Chambre correctionnelle, 14 fév. 1972, Semaine juridique, 1973, IV, p. 31. 
L'infraction est bien entendu constituée dès l'instant qu'il y a intention délictueuse, quel que soit le mobile de cette infraction comme l'a dit l'arrêt suivant:

"L'action concertée menée à force ouverte par un groupe ou au cours de laquelle des violences ont été exercées sur les personnes et deg dommages causés aux biens, constitue, quel que soit le mobile qui ait animé ses auteurs, une infraction de droit commun, justifiant $\mathrm{l}$ ' application de la contrainte par corps"'78.

En outre, pour éviter toute équivoque, le législateur a tenu à préciser que seule la participation volontaire à l'action concertée est répréhensible. Elle doit être "personnelle et délibérée" et s'extérioriser par une présence active exprimant une intention de coopération et d'assistance ${ }^{79}$.

\section{Personnes punissables:}

L'article incrimine tout d'abord les "instigateurs" et les "organisateurs" de l'action. Le projet initial utilisait le mot "chef" au lieu d'instigateur. En raison de l'imprécision du mot "chef", on a préféré le mot "instigateur". D'ailleurs le mot "chef" ne visait que les organisateurs immédiats d'un groupe alors que le terme "instigateur" permet d'atteindre les véritables responsables, même lorsqu'ils n'apparaissent pas, en raison des formes essentiellement mouvantes de ces actions. Car, l'instigateur d'une infraction est celui qui, sans participer physiquement à l'infraction, a suggéré à l'auteur matériel de la commettre. Il est en réalité l'une des causes génératrices de l'infraction et il peut être considéré comme l'auteur moral ou intellectuei $i^{80}$.

Avec le Président BLIN, on peut penser que les instigateurs de l'action sont ceux qui en ont conçu l'idée qui l'ont fomentée et que les organisateurs sont ceux qui ont transformé le projet en réalité concrète et donné les instructions pour l'exécuter. Le législateur a préféré, sans aucun doute dans un but comminatoire, retenir expréssément leur culpabilité et il n'est pas exigé que les instigateurs et organisateurs aient personnellement participé aux actes repréhensibles. Une fois que leur appel à la violence a été suivi d'effet, ils tombent sous le coup de la loi. Celle-ci frappe tous les membres du groupe, sans qu'il soit nécessaire de démontrer le rôle exact joué par chacun d'eux ${ }^{81}$.

Selon la loi, les personnes punissables sont ensuite "les participants à

78 Crim. 9 décembre 1971, Semaine juridique, 1972, IV, p. 17.

79 Duffar, étude précitée, p. 74; Trib. Grande instance de Caen a insisté sur co caractère dans une décision, Gaz. Palais, 1972, (2ème sem.), p. 888.

80 Merle-Vitu, op. cit., I., p. 640.

$\$ 1$ Blin, étude précitée, p. 2348; Bouzat, étude précitée, p. 58; Doll, étude précitée, p 55; Goyet, op. cit., p. 479; Vitu, op. cit., I, n. 159. 
l'action", en d'autres termes, ceux qui auront participé vỏontairement à l'action. Cette action doit, d'après le texte même avoir été volontaire et. suivant l'expression du Garde des Sceaux, à la fois personnelle et délibérée. C'est pourquoi il n'est pas question de poursuivre les simples passants. qui, flânant dans la rue ou sortant d'une bouche de métro, se trouvent pris inopinément dans un groupe de manifestants. Cependant, on peut critiquer l'adverbe "volontairement" au point de vue de style juridique. Mais il exprime le souci du législateur qui désire que la loi ne frappe que les. vrais coupables ${ }^{82}$.

bbb - Violences ou dommages matériels commis au cours de rassemblements illicites ou interdits (art. 314 al. 2 C.P.):

Après avoir réprimé les violences ou dommages matériels commis lors d'actions à force ouverte, en d'autres termes, d'actions de commando, lelégislateur français punit les violences et les dégradations ou destructions commises lors de rassemblements illicites ou interdits. En effet, selon l'article 314, al. 2 du Code pénal:

"Lorsque, du fait d'un ressemblement illicite ou légalement interdit par l'autorité administrative, des violences, voies de fait, destructions ou dégradations qualifiées crimes ou délits auront été commises, seront punis :

$1^{\circ}$ ) Les instigateurs et les organisateurs de ce rassemblement qui n'auront pas donné l'ordre de dislocation dès qu'ils auront eu connaissance. de ces violences, voies de fait, destructions ou dégradations, d'un. emprisonnement de six mois à trois ans.

$2^{\circ}$ ) Ceux qui auront continué de participer activement à ce rassemblement après le commencement et en connaissance des violences, voies de fait, destructions ou dégradations, d'un: emprisonnement de trois. mois à deux ans".

On voit bien que le délit prévu par l'alinéa 2 de l'article 314 vise des actes de violences ou de désordre se produisant dans le cadre de certains. rassemblements qui n'ont pas été spécialement constitués dans le but de les commettre ou de les provoquer ${ }^{33}$. Tandis que, l'infraction prévue par l'alinéa premier du même article supposait l'existence d'une action concertée dans le dessein de commettre des violences ou de causer des destructions.

\section{Eléments constitutifs du délit:}

Pour que les juridictions de répression puissent entrer en voie de condamnation, les éléments suivants sont exigés:

82 Blin, étude précitée, p. 2348; Bouzat, étude précité, pp. 57, 59.

${ }_{8 \varepsilon}$ Blin, loc. cit., Bouzat, étude précitée, pp. 57, 59; Duffar, étude pnécitée, p. 76; Goyet, op. cit., pp. 481-483; Vitu, op. cit., I, n. 160. 
Il doit, en premier lieu, s'agir d'un rassemblement illicite ou légalement interdit par l'autorité administrative. Si les violences ont lieu lors d'un rassemblement déclaré ou non interdit, l'article ne s'applique pas. S'il s'agit d'une interdiction du rassemblement, les tribunaux apprécieront certainement ce caractère de celui-ci. Car le terme "interdit" se trouve précédé, à la suite d'un amendement du mot "légalement". D'ailleurs, cette interdiction ne doit être prononcée que par l'autorité administrative, comme nous l'avons déjà dit, c'est-à-dire sous un contrôle juridictionnel. Parce que, en France, les manifestations sont soumises à déclaration préalable aux termes de l'article ler du décret-loi du 23 octobre 1935.

Pourtant le Garde des Sceaux a affirmé que l'article 314 ne modifie en rien ce décret-loi ni en ce qui concerne le régime juridique des manifestations ni en ce qui concerne les sanctions contre les organisateurs de manifestations illicites, c'est-à-dire non déclarées ou interdites après déclaration. La loi prévoit tout bonnement des sanctions plus graves lorsque la manifestation illicite dégénère en violence et que les organisateurs n'ont pas donné l'ordre de dislocation. Il a déclaré clairement que "ce texte exigera, en cas de poursuites, que le parquet démontre que l'intéressé a voulu participer au rassemblement, qu'il a eu connaissance du début des violences".

'La jurisprudence aussi estime qu'un rassemblement autorisé ou toléré devient illégal s'il s'organise et se poursuit dans des conditions contraires à la loi et, notamment, lorsque des violences sont commises. La seule circonstance que le défilé se soit déroulé avec la participation de manifestants armés, dont la présensence n'a pas échappé et ne pouvait échapper aux organisateurs, suffit à lui conférer un caractère illicite" ${ }^{" 84}$.

En deuxième lieu, l'élement requis de cette infraction est l'existence de "violences", voies de fait, destructions ou dégradations qualifiées crimes et délits. Selon ces répressions, les contraventions se trouvent exclues et à la différence du texte de l'alinéa ler, celui de l'alinéa 2 de l'article 314 du Code pénal n'incrimine donc pas n'importe quelles violences ou dégradations. Il faut que celles-ci soient assez graves pour être qualifièes crimes ou délits. C'est pourquoi, une bousculade, des violences légères, le bris d'une vitre ne permettront pas de retenir ces incriminations.

En trosième lieu, il doit s'agir de l'élément intentionnel à côté d'autres que nous avons examinés plus haut. Car cette infraction aussi, comme les autres délits institués par l'article 314 du Code pénal, est un délit intentionnel, comme le montrent clairement les dispositions de la loi que nous examinerons plus loin au sujet des personnes punissables.

a Trib. correc. Dinan, 3 fév. 1972, Semaine juridique, 1972, p. 85. 


\section{Personnes punissables:}

L'article punit, d'abord, les instigateurs et les organisateurs du rassemblement. Cependant, il ne sont punissables, aux termes de l'alinéa 2 du texte qu'autant “qu'ils n'auront pas donné l'ordre de dislocation, dès qu'ils auront eu connaissance des violences, voies de fait, destructions et dégradations".

Le projet initial n'avait nullement prévu cette possibilité d'échapper à la responsabilité pénale. C'est pourquoi l'ordre de dislocation n'aurait pu n'être qu'une circonstance atténuante laissée à l'appréciation du juge. Mais, sur la proposition de la Commission des lois de l'Assemblée, cette échappatoire a été adopté par les parlementaires qui ont été mus par des considérations juridiques et politiques. Car, ils ont estimé qu'il était bon pour l'ordre public d'inciter les organisateurs de rassemblements illicites à donner l'ordre de dislocation, d'une part, et d'autre part, qu'il pouvait être injuste de poursuivre les responsables d'une manifestation qui n'avaient pas prévu initialement que des violences pourraient se commettre, mais qui, dès qu'ils ont eu connaissance de l'existence desdites violences, ont cherché à mettre fin en ordonnant la dislocation. Ils ont désiré également répondre aux soucis, en matière de liberié de réunion et des droits syndicaux dont les organisateurs sont souvent ses dirigeants. C'est ainsi que l'élément de l'intention délictueuse découle de la connaissance de violences perpétrées et se manifeste pour les instigateurs et organisateurs du rassemblement, par l'absence d'ordre de dislocation de celui-ci: on voit bien qu'il s'agit là d'une notion nouvelle: on devient coupable par la seule connaissance des infractions commises par les autres. En d'autres termes, une fois que les instigateurs et organisateurs ont été informés des violences ou destructions commises-c'est à partir du moment où débute leur responsabilité pénale et civile - il leur appartient d'ordonner immédiatement la dislocation du rassemblement.

La loi incrimine ensuite les participats au rassemblement, mais non seulement dans la mesure où "ils auront continué à participer activement à ce rassemblement après le commencement et en connaissance des violences, voies de fait, destructions ou dégradations".

Le projet initial s'était contenté d'énoncer "ceux qui auront fait partie du rassemblement". L'adverbe "activement" a été ajouté à l'initiative d'un député et le Garde des Sceaux a précisé "qu'agir activement, en s'inspirant du Litré, c'est déployer une grande activité avec beaucoup d'ardeur".

Ces précisions montrent la volonté du législateur d'éviter tout risque d'erreur et de méprise et le souci de revêtir le délit d'un caractère essen- 
tiellement volontaire et encore le souci de protéger les droits civiques. C'est pourquoi, la seule présence d'une personne sur les lieux où se déroule un rassemblement violent ne saurait suffire à entrer en voie de condamnation contre elle. On ne sanctionnera que si, activement, en connaissance de cause, l'intéressé est demeuré au sein de l'attroupement qui a mal tourné. En effet, le délit est une infraction intentionnelle. D'ailleurs, l'élément de l'intention délictueuse de cette infraction découle de la connaissance des violences perpétrées et se manifestera, pour les participants, par la volonté délibérée de se manifester dans la manifestation après que des désordres et les violences ont commencé.

A première vue, l'adjonction du terme "activement", à la suite du verbe "participer" peut paraitre superflue et inutile tant au point de vue grammatical et sémantique que de la technique de la loi, Mais, au point de vue juridique et surtout pratique, cet adverbe amène le ministère public et les juges à agir minutieusement. C'est pourquoi, il est bien certain que des participants à un rassemblement non déclaré ou interdit, mais paisible, ne seraient pas punissables si certains groupes s'étant séparés du rassemblement pour aller commettre des désordres, ces participants s'abstenaient de les suivre et abandonnaient le mouvement.

Quant à la charge de la preuve, elle revienț au ministère public. Probablement, en dehors du cas cle flagrant délit, ce sera parfois bien difficile, pour le parquet, de rapporter la preuve qui lui incombe, soit que les organisateurs d'un rassemblement qui a dégénéré en désordres n'ont pas donné l'ordre de dislocation en temps utile, soit du caractère volontaire de la participation à ce rassemblement des personnes interpellées à cette occasion. Le Garde des Sceaux l'a déclaré clairement à la tribune de l'Assemblée lors de la discussion.

\section{ccc - Répression des actions de provocateurs:}

L'alinéa 3 de l'article $31 \_$du Code pénal français incrimine les provocations commises dans les rassemblements même illicites:

"Seront punis d'un emprisonnement de un cinq ans ceux qui se seront introduits dans un rassemblement, mème licite, en vue d'y commettre ou de faire commettre par les autres participañts, des violences, voies de fait, destructions ou dégradations".

Cet alinéa a été ajouté et inséré par le Parlement, s'inspirant d'une proposition sénatoriale, au projet initial, pour répondre aux objections formulées, pendant la discussion de ce projet, par certains parlementaires qui avaient exprimé la crainte que des provocateurs, s'étant glissé dans 
une manifestation ou un rassemblement, ne les fissent dégénérer en violences ou en desordres ${ }^{85}$.

Il est remarquable que l'action des provocateurs, redoutée par tous les organisateurs sérieux de réunions ou de manifestations, particulièrement dans les milieux syndicaux, est réprimé, par cet article, avec la même sévérité que celle des groupes amenant une action à force ouverte.

\section{Eléments constitutifs d'infraction:}

Le législateur a donné clairement et suffisamment une définition du provocateur, selon laquelle celui qui s'introduit dans un rassemblement, même licite, en vue d'y commettre ou de faire commettre par les autres participants des violences, voies de fait, destructions ou dégradations est un provocateur. C'est ainsi qu'elle est applicable, aussi bien à l'individu qui, dans le but indiqué par la loi, s'introduit dans une manifestation ou un rassemblement interdits ou illicites, qu'à celui qui, dans le même but, se glisse dans un rassemblement dûment autorisé (BLIN). En d'autres termes, la seule introduction est punie même si le provocateur n'a pu susciter aucun trouble et désordre, aucune violence.

Le délit prévu par l'alinéa 3 de l'article 314 suppose la réunion de trois éléments. Premièrement, un rassemblement licite ou non; deuxièmement, l'existence de violences, voies de fait, destructions et dégradations, suns qu'il soit nécessaire - comme pour l'infraction prévue par l'alinéa 2 de l'article 314 -qu'il s'agisse de faits qualifiés crimes ou délits, troisièmement l'intention délictueuse.

Ce dernier élément est même nettement précisé par la loi qui dispose:

"en vue d'y commettre ou de faire commettre par les autres participan's des violences, voies de fait, destructions ou dégradations".

dans un rassemblement. Il importe de signaler qu'il s'agit là d'un des cas assez rares où le législateur fait entrer le mobile parmi les éléments constitutifs du délit où d'après l'expression consacrée, il ne se contente pas d'un "dolus generalis", c'est-à-dire d'un élément moral, en d'autrès termes, d'une intention criminelle (l'intention de violer la loi pénale) de droit commun; mais il exige un "dolus specialis" c'est-à-dire, une intention plus caractérisée qui n'est requise par la loi que pour la répression de certains délits déterminés ${ }^{88}$.

65 Blin, étude précitée, loc. cit.; Bouzat, étude précitée, pp. 57-60; Goyet, op. cit., p. 485; Vitu, op. cit., I., n. 162.

${ }^{86}$ Merle-Vitu, op. cit., p. 678 et s. 


\section{Personnes punissables:}

La loi punit les provocateurs et donne clairement la définition de ceux-ci. C'est pourquoi il est superflu d'insister en cette matière. Pourtant il importe de formuler deux remarques.

Premièrement le "provocateur" visé par cet alinéa, n'est pas exactement le provocateur tel que le droit pénal français le connait généralement. Car, au fond "la provocation n'est un acte de complicité punissable que dans la mesure où elle a été accompagnée des circonstances décrites par l'article 60 du Code pénal français, qui sont destinées à la renforcer et à la rendre plus suggestive: dons, promesses, menaces, abus d'autorité, machinations ou artifices coupables" ${ }^{\prime 87}$. Tandis qu'il ne s'agit pas là d'un instigateur à un rassemblement, mais "d'un individu qui profite d'un rassemblement déjà organisé, pour s'y glisser en vue de commettre ou de faire commettre par.d'autres, diverses infractions".

Deuxièmement, la provocation est ici érigée en infraction distincte, ce qui ne manque pas d'entraîner des conséquences importantes au regard de la complicité.

\section{bb. Les modalités de la répression aaa - Les pénalités.}

La peine prévue pour la première infraction est un emprisonnement de un à cinq ans. En ce qui concerne la deuxième infraction, le législateur s'est montré, à juste titre d'ailleurs, plus sévère pour les instigateurs ou organisateurs d'un rassemblement illicite ou interdit qui encourent un -emprissonnement de six mois à trois ans tandis que les simples participants à un tel rassemblement n'encourrent qu'un emprisonnement de trois mois à deux ans. Pour la troisième infraction, comme pour la première, la peine prévue et encourue est un emprisonnement de un à cinq ans.

\section{bbb - Tentative}

La tentative, au point de vue classique, n'est punissable dans aucun délit qu'institue l'article 314 du Code pénal français. Cependant en étudiant l'infraction prévue par cet article, il importe de se rappeler tout ce que nous avons déjà écrit supra $(\S I V, B, c)$. En effet, lorsque la loi punit la simple "introduction dans un rassemblement même licite ...", même si les violences et destructions n'ont pas été commises, elle incrimine en luimême un acte qui peut en outre être considéré comme le commencement 
d'exécution d'autres actes coupables. Il est bien certain que c'est une sorte de tentative ${ }^{88}$.

\section{ccc - Complicité}

La complicité est évidemment punissable d'après les principes du droit commun pour tous les délits qu'institue l'article en question. Par exemple, une complicité par aide et assistance (conduire des provocateurs à proximité du rassemblement sans s'y introduire soi-même) ou par fourniture de moyens (procurer aux provocateurs des armes).

Cependant, comme nous l'avons dit plus haut, la provocation étant érigée en délit distinct au troisième alinéa de l'article 314 , la loi permet ainsi de punir la complicité de provocation. Tandis que la complicité de ce genre ne pourrait pas être sanctionnée vis-à-vis des règles classiques de droit commun, selon lesquelles la complicité de complicité n'est pas punissable ${ }^{89}$.

\section{ddd - Circonstances atténuantes et sursis.}

Puisqu'il s'agit d'un délit de droit commun, les circonstances atténuantes, le sursis simple et même le sursis avec mise à l'épreuve ont applicables, comme l’a souligné la jurisprudence:

"Doivent bénéficier des circonstances atténuentes, les prévenus auxquels ne peut être imputé un acte de violence quelconque non plus que d'avoir pris des initiatives dans le déroulement des faits. Car il ne leur reste plus que leur qualité, de participants volontaires". ${ }^{90}$

\section{eee - Cumul d'infractions.}

Première infraction (art. 314, al. 1 C.P.). La loi de 1970 a pris soin, comme elle le fait chaque fois qu'elle crée une incrimination de réserver. le cas où les peines plus fortes seraient encourues, en d'autres termes, elle l'a précisé expréssément: "sans préjudice de l'application des peines plus fortes prévues par la loi" (art. 314 al. 1, in fine).

C'est ainsi que, si quelqu'un ayant commis cette première infraction tombe en même temps sous le coup d'une autre disposition pénale plus sévère, on appliquera même cette seconde disposition. En bref, s'il s'agit d'un cumul'réel d'infraction, elle l'appliquera en sus de la première, ou bien, si le fait plus grave puni par la seconde disposition contient le même fait puni par la première, c'est-à-dire, en termes juridiques, s'il s'agit d'un

88 Bouzat, étude précitée, p. 61.

$9 \theta$ Ibid., loc. cit.

90 Trib. Gr. Instance de Caen, Gaz. Pal.; 1972, 2ème sem.; p. 888. 
cumul idéal d'infractions, elle l'appliquera seule à l'exclusion de la première.

Les cas de cumul risquent d'être nombreux. C'est ce qui se produirait, par exemple, en cas de vol, lorsque celui-ci s'accompagne de certaines circonstances, telles que la violence, nuit, effraction qui le transforment en crime (art. 382 C.P.). Il en serait de même dans le cas prévu par l'article 303 du Code pénal en cas de violences sur les personnes ayant entraîné la mutilation, l'amputation ou-la privation de l'usage d'un membre, la cécité, la perte d'un oeil ou autres infirmités permanentes ou encore ayant causé la mort, sans intention de la donner, étant observé que les instigateurs ou organisateurs de l'action pourraient, dans ces cas, être atteints en vertu de l'article 313 du Codé pénal. De même pourraient être poursuivis, en vertu de l'article 434 du Code pénal (modifié par la loi du 2 février 1981), les participants à l'action, coupables d'incendie volontaire; en vertu de l'article 435 (modifié par les lois du 2 février 1981 et du 10 juin 1983), ceux qui auraient causé des destructions à l'aide d'explosifs; en vertu de l'article 437, ceux qui auraient détruit ou détérioré un objet mobilier ou un bien immobilier appartenant à autrui; en vertu de l'article 439 , ceux qui auraient brûlé ou détruit des registres, minutes ou actes originaux de l'autorité publique, ou des effets de commerce ou de banque, etc... étant précisé que, dans ces hypothèses comme dans celle d'un vol qualifié, les instigateurs ou organisateurs ne pourraient être poursuivis que comme complices et si les éléments constitutifs de la complicité étaient établi à leur encontre.

Nous savons bien que l'article 314 du Code pénal est la consécration la plus éclatante de la responsabilité collective, comme le disent les commentateurs de la loi du 8 juin 1970. Mais, il s'agit ici d'une application tempérée, nuancée, de la responsabilité de ce genre. Car, la sanction applicable n'est pas celle qui est prévue par les lois compétentes pour chaque type d'infraction commise ${ }^{91}$.

En ce qui concerne la seconde infraction (art. 314, al. 2. C.P.), la loi ne réserve pas expressément à son propos "l'application de peines plus fortes". Il est bien certain que, dans de nombreux cas, le délit que nous examinions se cumulera avec d'autres infractions. Par conséquent, on appliquera les peines ordinaires du cumul d'infractions qui permettront la poursuite des crimes et délits, voire des simples contraventions commises lors des rassemblements.' C'est-à-dire que rien ne s'opposerait non plus à ce que les simples contraventions qui ne peuvent justifier l'application de l'article 314 alinéa 2 du Code pénal soient réprimées séparément

91 Merle-Vitu, op. cit., 1973, I, p. 520. 
selon les règles qui leur sont propres. Mais les règles du cumul des peines ne jouent pas naturellement pour les contraventions.

Tout d'abord, la loi nouvelle ne modifie pas le décret-loi du 23 octobre 1935, ni en ce qui concerne le régime juridique des manifestations ni en ce qui regarde les sanctions contre les organisateurs de rassemblements illicites, c'est-à-dire non déclarés ou interdits après leur déclaration.

Deuxièmement, selon la déclaration du Garde des Sceaux, l'article en question laisse subsister intacte la répression des attroupements, telle qu'elle résulte des articles 104 à 108 du Code pénal modifiés par l'ordonnance du 4 juin 1960 et par la loi du 23 décembre 1981 (n. 81-1134) et qui conserve son champs d'application particulier.

Troisième infraction (art. 314 , al. 3 C.P.): En ce qui concerne la troisième infraction, si le provocateur ne s'est pas contenté de s'introduire dans le rassemblement, dans le dessein défini par la loi et a participé effectivement aux violences, voies de fait ou dégradations, le cas échéant, il y aura lieu à l'égard de ce provocateur, d'appliquer des règles sur le cumul d'infractions.

\section{eee - Excuse absolutoire}

Selon la doctrine, l'excuse absolutoire fait disparaître la responsabilité juridique de l'intéréssé bien que sa culpabilité soit établie. Dans ce cas là, le prévenu est absous. En cas d'absolution, l'auteur de l'infraction est exempt des peines prévues normalement, pour des motifs qui ne tiennent pas à une absence de faute, mais plutôt à des considérations de politique criminelle et d'utilité sociale ${ }^{92}$.

Nous constatons qu'il s'agit d'une excuse absolutoire qui, bienveillance assez originale, facultative pour le juge, a été instituée par l'alinéa 3 de l'article 314 au profit des instigateurs, organisateurs et participants d'un rassembiement, lorsque des individus ont été condamnés effectivement pour s'être introduits dans ce rassemblement afin d'y commettre ou y faire commettre des violences, des destructions ou dégradations.

Ce texte interéssant n'est applicable, en premier lieu, que lorsqu'il s'agit d'un rassemblement illicite ou interdit, puisque lorsqu'il s'agit d'un rassemblenient autorisé, les sanctions prévues par les alinéas 2 et 3 de l'article 314 ne peuvent être prononcées que contre les participants aux seuls rassemblements et non à ceux des groupes violents visés par l'alinéa ler de l'article 314. En dehors de tous cela, il ne suffit pas aux organisateurs, instigateurs ou participants à un rassemblement qui a dégénéré

Stéfani-Levasseur-Bouloc, op. cit., n. 320 et s., 537 et s. 
en violences, pour bénéficier de l'excuse absolutoire, d'alléguer ou même d'établir l'existence et l'action de provocateurs, lors de ce rassemblement, il faut que les provocateurs, ou tout au moins l'un d'eux, aient été découverts et qu'une condamnation ait été prononcée à l'encontre d'un ou plusieurs de ceux-ci.

En outre, nous constatons que cette excuse absolutoire, n'est pas automatique, mais, au contraire, facultative, tandis que, selon la règle généralement admise, l'exemption de peines apportée par les excuses 'absolutoires est obligatoire. Mais, ceci, non obligatoire, comme l'indique le verbe "peut" dans la phrase.

Certes, comme toutes les excuses absolutoires, cette excuse aussi fait disparaître seulement la peine, mais non la responsabilité et, dès lors, ne dispose pas le prévenue absous de sa responabilité civile ${ }^{03}$.

\section{ggg - Procédure de flagrant délit:}

L'alinéa 2 de l'article 108 du Code pénal était complété par l'alinéa 3 de l'article 5 de la loi du 8 juin 1970. Cet article diposait que "les dispositions des articles 393 et suivants (du flagrant délit) du Code de procédure pénale sont applicables ... ainsi qu'aux délits prévus et punis par l'article $314 " 94$.

Comme l'on sait, le délit flagrant est celui qui est en train de se commettre ou qui vient de se commettre (art. $53 \mathrm{CPP}$ ). Cette procédure s'appuie sur une répression le plus souvent expéditive et énergique et a pour objet une sanction rapide, donc plus exemplaire. Parce que la personne a été prise sur le fait et que sa participation au fait est.certaine. Cependant, certains écrivains estiment que cette procédure est assez sévère pour l'application de l'article 314 du Code pénal ${ }^{95}$.

\section{cc - Dispositions communes: Responsabilité civile et solidarité aaà - Responsabilité civile}

La responsabilité civile qui tient toute entière dans la première phrase de l'alinéa 4 de l'article 314 du Code pénal est une justification officielle de la loi dernière:

"Los personnes reconnues coupables des délits définis au présent article sont responsables des dommages corporels et matériels".99

\footnotetext{
${ }^{93}$ Blin, étude précitée, loc. cit.: Bouzat, étude précitée, p. 63; Goyet, op. cit., p. 484; Vitu, op. cit., I, n. 162.

94 Crim, 8 déc. 1971, Semaine juridique, 1972, IV, p. 17.

${ }^{55}$ Duffar, étude précitée, pp. 97-100; Vitu, op. cit., I., n. 163.

B Blin, loc. cit.; Bouzat, étude précitée, pp. 63-67; Doll, étude précitée, pp. 58, 59; Duffar, étude précitée, pp. 100-102; Goyet, op. cit., pp. 486-487; Vitu, op. cit, I, n. 164 .
} 
On constate que ce principe met à la charge des personnes poursuivies une présomption de responsabilité du fait d'autrui. En effet, comme nous l'avons déjà dit, bien que la Cour de cassation affirme en principe que "nul n'est punissable qu'à raison de son fait personnel", la responsabilité pénale et civile peut résulter exceptionnellement du fait d'autrui, en France, soit dans des cas de forme de responsabilité collective soit dans le cas du chef d'entreprise ${ }^{97}$. Certes, cette exception que nous avons examinée est une de celles des plus rigides. Car, l'ensemble des délinquants visés par l'article 314 du Code pénal est responsable des dommages corporels ou matériels causés. Selon la formule du Premier Ministre "les casseurs seront les payeurs". L'exposé des motifs de la loi a exprimé les raisons de cette disposition, qui a suscité des débats fort animés, comme suit:

"Cette responsabilité, tant pénale que civile, ne se justifie pas seulement par le souci de mettre fin à l'impunité avec les tentations et les encourgements qui en découlent, dont bénéficient ceux qui șe réfugient dans le cadre d'une action commise en réunion pour échapper aux conséquences de leurs agissements. Elle se fonde aussi sur le fait que la participation plus ou moins active à un rassemblement illicite ou interdit par l'autorité responsable et plus encore à l'action d'un goupe menée à force ouverte, implique, de la part de son auteur, l'acceptation cónsciente d'un certain nombre de risques, notamment dans le cas où des violences ou dommages viendraient à ètre causés".

En vertu de cet article, les personnes suivantes sont civilement responsables de la réparation des dommages causés aux personnes et aux biens. En premier lieu, les organisateurs et instigateurs d'une action dite de commando prévue par l'alinéa ler de l'article 314 ainsi que les participants à cette action; en second lieu, les instigateurs et organisateurs d'un rassemblement illicite ou également interdit, au cours duquel des violences auront été exercées sur des personnes ou des dégradations causées aux biens et les participants à un tel rassemblement, dans les conditions indiquées aux alinéas 2 de l'article en question; en troisième lieu, les provocateurs qui se seront introduits dans un rassemblement quelconque dans le but précisé dans l'alinéa 3 du même article.

On voit facilement que l'article 314 contient une rigueur certaine, car il institue une responsabilité civile à l'égard de tous les auteurs des délits qu'il prévoit. Cette disposition rend responsables des dommages aussi bien ceux qui n'ont fait que rester indûment dans le rassemblement du fait duquel les dommages ont été réalisés que ceux qui les ont réalisés euxmêmes. Cependant, bien que cet alinéa paraisse sévère dans la mesure où il permettra bien souvent de mettre à la charge de certaines personnes,

97 Delmas-Marty, Droit pénal des affaires, 1973, Paris, pp. 427-434; Merle-Vitu. op. cit., I, pp. 613-622; Stéfani-Levasseur-Bouloc, op. cit., p. 297 et s. 
telles que les organisateurs d'un rassemblement, la réparation des dommages causés par d'autres, il ne constitue pas une innovation dans le droit français. Car on rencontre une institution analogue notamment dans l'ar-. ticle 108 in fine:

"Toute personne qui aura continué à faire partie d'un attroupement après la deuxième sommation faite par un représentant de l'autorité publique être condamnée à la réparation pécuniaire des dommages causés par cet attroupement".

Pourtant, il faut ajouter que les deux dispositions ne sont pas entièrement semblables. Car l'application de l'alinéa 3 est facultative pour les coupables visés par l'article 108. En d'autres termes, les juges répressifs ont un très large pouvoir d'appréciation, puisqu'ils ne sont pas tenus de prononcer la responsabilité prévue par ce texte. Tandis que la condamnation aux réparations civiles de tous les individus condamnés pour l'une des infractions prévues par l'article 314 est légalement obligatoire. C'est pourquoi, pour tempérer cette sévérité le législateur a inséré dans le texte deux dispositions bienveillantes suivantes qui constituent des innovations en même temps qu'elles consacrent des dérogations importantes à des principes constants du droit français: la limitation de la réparation et l'atténuation facultative de la règle de la solidarité.

\section{bbb - Limitation de la réparation}

En effet, selon l'alinéa en question:

"Lo juge pourra limiter la réparation à une partie seulement de ces dommages et fixer la part imputable à chaque condamné".

En principe, selon la jurisprudence bien établie de la Cambre criminelle, il n'appartient pas aux tribunaux de procéder au partage de la responsabilité civile entre les coauteurs d'un même dommage. Tandis que la loi du 8 juin 1970 permet de l'effectuer en donnant au juge la faculté de limiter la réparation des dommages corporels ou matériels à une partie seulement de ces dommages et de fixer la part incombant à chaque condamné. Cependant, la victime des dommages a droit à la réparation du préjudice qu'elle a subi et ne peut se voir opposer la limitation prononcée par le juge, laquelle s'exprime aux termes de l'alinéa 4 de l'article 314:

"Cette limitation de la responsabilité est sans effet sur l'action en réparation ouverte à la victime en'application des articles 116 à $122 \mathrm{du}$ Code de l'administration communale".

En outre, en vertu de cet alinéa, les victimes, en cas de l'éventuelle insolvabilité des prévenus, peuvent exercer un recours contre les communes. Car elles sont civilement responsables selon l'article $115 \mathrm{du}$ Code 
de l'administration communale des dégâts et dommages résultant des "crimes et délits commis à force ouverte ou par violence sur leur territoire par des attroupements ou rassemblement armés ou non armés, soit envers des passants soit contre les propriétés publiques et privées". L'Etat contribue pour moitié à "ce risque social". Les indemnités sont réparties entre tous les contribuables, sauf les victimes, proportionnellement au principal de leurs contributions directes (art. 117 du même Code de l'administration communale).

Cependant, le Président BLIN estime que les victimes des dommages ne peuvent exercer leurs recours contre les communes que dans la mesure où les auteurs ou responsables de ces dommages n'ont pas âté condamnés à la réparation intégrale du préjudice subi. Mais, il faut ajouter que ce point de vue peut prêter à controverse.

\section{ccc - Atténuation facultative de la règle de solidarité}

En vertu de l'alinéa final de l'article 314:

"Il (le juge) pourra dispenser de la solidarité prévue à l'article 55 du Code pénal".

Comme l'on sait, l'article 55 suscité rend solidairement responsable tous les individus condamnés pour un même crime ou pour un même délit des restitutions et dommages-intérêts. Par contre, la loi de 1970 autorise le juge à dispenser de cette solidarité. Cette exception apportée à la règle consacrée depuis longtemps se justifie sans doute par la crainte que la condamnation à la réparation civile de l'ensemble du préjudice causé soit hors de proportion avec l'infraction reprochée d'une part, et par la volonté de répondre aux critiques de ceux qui reprochaient au gouvernement d'introduire dans le droit français la notion de responsabilité collective, d'autre part. Car, les juristes n'ont cessé, le plus souvent, d'y marquer leur hostilité. C'est pourquoi, la Cour de cassation avait déjà admis, dès avant cette loi, la possibilité, pour les juridictions répressives de limiter, pour certains prévenus, compte tenu des circonstances de fait. l'étendue de la solidaritép

\section{c - Solutions jurisprudentielles}

En effet, d'après la jurisprudence bien établie et concernant le tapage nocturne ou injurieux causé par un attroupement, les memibres du groupe sont punissables, aussitôt que leur appartenance au groupe bruyant est prouvée. Il n'est pas nécessaire de démontrer qu'ils ont pris part eil tant. qu'auteur ou complice aux faits incriminés. La seule appartenance au

${ }_{98}$ Crim. 24 avril 1894, 4 juin 1910, 9 déc. 1812, 21 oct. 1965, Goyet, op. cit., p. 488. 
groupé est suffisante à constituer la complicité punissable ainsi que le déclarait la Chambre criminelle, le 23 août 1894:

"A supposer qu'il n'eût pas personnellement chanté, il était tout au moins complice du tapage causé à raison de sa présence au milieu d'eux et de l'aide et de l'assistance qu'il leur avait ainsi sciemment prêtés pour la perpétration de la contravention".

Lorsqu'il s'agit de réprimer le dommage causé par une personne non identifiée au sein d'un groupe, cette tendance jurisprudentielle est assez significative au sujet de l'application des articles 319 et 320 du Code pénal. Cette application est subordonnée à la démonstration d'une faute involontaire, d'un dommage subi par la victime et d'un lien de causalité entre la faute et le préjudice. C'est-à-dire que s'il s'agit des cas dans lesquels il n'est pas possible de rattacher le résultat à l'oeuvre d'un participant déterminé. La Cour de cassation décide que le résultat est indivisiblement imputable dans la totalité à chaqun des participants, à condition que chacun ait pris une "part active à l'action commune". On voit bien que cette solution est un vestige rénové de la vieille théorie de la complicité corespective. Car, au fond, cette théorie comportait l'application à tous les co-auteurs d'une peine moyenne, c'est-à-dire inférieure à celle méritée par l'auteur et supérieure à celle de complices.

Mais, s'il s'agit des cas dans lesquels le résultat n'a pu être l'oeuvre que d'un seul participant dont l'identité est indéterminée, à première vue, la situation paraît asses compliquée. Par exemple, plusieurs chasseurs tirent des projectiles en même temps et dans la même direction. La victime est blessée par un seul indéterminé d'entre eux. La Cour de cassation a adopté même ici les principes de la complicité co-respective en matière de blessures volontaires. Elle estime que le fait étant unique, chacun des prévenus ayant pris une part active et personnelle à l'envoi des projectiles, la circonstance aggravante résultant des conséquences matérielles de ce fait implique nécessairement tous les auteurs.

En ce qui concerne les infractions involontaires, la jurisprudence ne paraît pas bien établie, à notre avis. Car la Cour suprême a refusé de condamner du chef d'incendie involontaire (art. $R$ 38,4') quatre jeunes gens qui avaient fumé dans une grange sur ce motif "qu'à défaut de pouvoir établir une faute personnelle à la charge de l'un quelconque des prévenus, le doute devait bénéficier à tous" (Ch. cr. 22 mars 1966). Par contre, dans un arrêt du 7 mars 1968, en matière de blessures involontaires, elle a approuvé la condamnation de deux enfants qui avaient blessé un de leurs camarades en envoyant des clous dans sa direction alors qu'il était établi qu'un seul projectile avait atteint la victime, en considérant qu'en l'état des faits énoncés, il résultait que les jeunes prévenus avaient 
tous les deux participé à une action essentiellement dangereuse et créée par leur commune imprudence un risque grave auquel leur camarade n'a pu échapper. La Cour était en droit de décider que l'un et l'autre se trouvaient également en faute au sens des articles 319 et 320 du Code pénal. et qu'ils devaient répondre des conséquences tant pénales que civiles qui en étaient directement ou indirectement résultées ${ }^{99}$. Le résultat est significatif. En 1966, la relaxe se fondait sur l'absence de faute à la charge des prévenus tandis qu'en 1968, deux ans plus tard, cette faute était établie. Il résulte de la dernière décision que la Cour suprême considère l'existence d'une causalité matériellc entre chaque faute et le dommage. Evidemment, un des deux enfants n'avait pas été l'auteur du tir dommageable. Mais ils ont commis une imprudence fautive en participant à une action dangereuse et commune.

En bref, on voit bien que la jurisprudence n'exige pas la démonstration directe d'une participaticn au dommage. La répression n'est plus subordonnée qu'à la preuve de la participation à l'action collective. C'est. ainsi que les participants à l'agissement collectif sont punissables sans qu'il soit nécessaire de démuntre. que leur agissement est la cause du dommage. ${ }^{100}$.

\section{d) Les effets de l'atténuation du critère de la participation}

Cette participation punissable paraît riche d'effets comme nous l'avons constaté.

En premier lieu, cette incrimination particulière par l'intermédiaire du groupe est source de cumul de delits, dans certains cas. En effet, si une personne est punissable pour avoir participé à une action commise en groupe, elle peut aussi l'être pour les délits particuliers commis lors dè l'action collective selon l'article 314 al. ler et 2 et l'article 97 précédemment étudiés. C'est-à-dire que si les membres d'un groupe ont personnellement. violé un intérêt protégé par la loi, on voir surgir un concours de délits. $\mathrm{Au}$ délit individuel se superpose ou s'ajoute le délit collectif.

En second lieu, la théorie de la complicité, c'est-à-dire la participation indirecte est assez modifiée. Car, à côté des participants au groupe, la lơ incrimine aussi ceux qui ont organisé le groupe, provoqué une manifestation ou dirigé la réunion. Ce qui est caractéristique, c'est que de tels actes n'ont pas leur répression subordonnée, en général, à la présence dans le groupe au cours de l'agissement illicite.

99 Crim. 7 mars 1966, Gaz. Pal. 1968, p. 319.

${ }^{100}$ Dupeyron, étude précitée, pp. 277, 278; Merle-Vitu, op. cit., p. 656. 
En troisième lieu, la loi incrimine le plus souvent les personnes qui n'ont fait que favoriser la perpétration du délit par le groupe, soit en le constituant soit en poussant ses membres à l'action. C'est pourquoi, la théorie de complicité est inadaptable aux délits collectifs. De plus, parfois, la loi va beaucoup plus loin, crée une participation présumée ét punit non seulement des complices, mais encore des tiers à l'infraction ${ }^{101}$.

\section{f) Faute, imputation et infraction collective:}

Il s'agit, d'ans l'infraction collective, d'une responsabilité. pénale du fait d'autrui, dont le fondement s'explique de deux façons différentes l'une de l'autre. La première est tirée de la théorie du risque, selon laquelle la société attend du droit pénal sa prutection. Celle-ci manquerait si on devait imputer les délits seulement à ceux qui les ont matériellement commis. Mais, cette notion du risque est incompatible avec les principes genéraux du droit pénal.

Quant à la notion de faute, elle explique la responsabilité patronale et tous les cas similaires. Si l'infraction est commise, c'est dire qu'il y a une faute du patron, par exemple, de surveiller son préposé de veiller à l'observation des réglements ${ }^{102}$.

Cependant la situation est un peu différente si la participation à l'acte illicite est déduire de l'appartenance à un groupe constitué, organisé et précis. Il faut bien convenir qu'il est difficile de trouver une faute apte à fonder la sanction. Pourtant, à l'occasion de crimes considérés particulièrement diangereux et odieux (comme, par exemple dans la loi du 15 septembre 1948), le législateur n'a pas hésité à faire revivre ce type de responsabilité, mais en l'atténuant partiellement.

Par contre, dans d'autres cas envisagés, les individus punissables ne font pas partie des groupes seulement en raison de leur état, mais en raison d'une véritable adhésion. C'est pourquoi, ils sont responsables des agissements du groupe. La responsabilité s'appuie ici sur la participation personnelle au groupe. Tandis que, dans le cas précédent, cette participation était préétablie. Il apparait que l'adhésion à ces groupes est elle-même fautive, puisque l'activité, le but ou même l'existence de ces groupes sont illicites.

Par exemple, il en est ainsi en matière d'infraction volontaire, car il s'agit d'une faute résultant de la participation à une action commune et

101 Dupeyron, ètude précitée, pp. 277, 278.

102 Delmas-Marty, op. cit., pp. 427-434; Merle-Vitu, op. cit., I., pp. 617, 618; StéfaniLevasseur-Bouloc, op. cit., pp. 293-297. 
dangereuse, comme l'a dít la jurisprudence que nous avons déjà examinée. En matière d'infraction collective volontaire, l'appartenance au groupe est aussi presque toujours fautive. Par exemple, l'adhésion à une bande ou à un groupe d'individus qui perpètrent un pillage à force ouverte est naturellement ilicite et donc fautive même si aucune part n'est prise matériellement au pillage. Il y a encoit la faute antérieure d'adhésion au groupe, à côté de la faute concemant l'appartenance du groupe au cours de son activité illicite (voir, par exemple, les articles 76, 313 et 314). En bref, la sanction est subordonnée à une faute; il s'agit tantôt d'une faute concernant l'appartenance au groupe au cours de l'action illicite, tantôt d'une faute antérieure concernant l'organisation d'un groupe (illicite par son but) ou l'adhésion de celui-ci.

Nous avons dit que la participation au groupe légitime la répression. Cependant, dans les hypothèses particulières, la démonstration de l'absence de participation au groupe est susceptible d'entraîner l'impunité. Il en est ainsi en cas de participation présumée. Par exemple, la loi du 15 septembre 1948 a admis qu'une preuve de cette sorte aura pour effet d'écarter la responsabilité des membres du groupe lorsque leur incorporation a été forcée.

En outre, d'une part, si une faute est nécessaire, la seule appartenance au groupe ne sera pas suffisante quand elle n'est pas fautive et, d'autre part, la seule présence au milieu du groupe ne peut pas constituer nécessairement une activité répréhensible s'il est démontré qu'il n'y a pas eu une véritable association aux actes de ce dernier.

En ce qui concerne l'imputation matérielle, le droit positif français tend à imputer le résultat global à tous les délinquants et la jurisprudence considère que la peine est indivisible, lorsque l'infraction résulte de 'activité d'un groupe ou est projetée par plusieurs personnes. On néglige de tenir compte de l'intensité des participants individuels. En effet, le montant des dommages et intérêts peut étre divisé entre les divers protagonistes. Mais la peine, au contraire, paraît, par essence, rebelle à un tel partage. Car, en raison de la nature et des finalités de la sanction, il n'est pas possible de fractionner la peine entre les divers participants à l'infraction.

Pourtant, il paraît a priori logique de doser la répression en fonction de l'importance de la participation aux actes incriminés. Mais le droit positif français n'adopte pas cette solution. La répression est la même, en principe, quelle que soit l'intensité de la participation. Il importe peu que le degré de participation soit déterminé ou inversement. Telle est la solution, par exemple, en matière de rébellion. Mais cette solution est compatible avec l'article 59 du Code pénal selon lequel le complice est 
passible des mêmes peines que l'auteur principal et avec la doctrine contemporaine d'après laquelle la répression des faits de complicité doit être calquée sur celle de l'auteur principal. Parce que l'acte de complicité est un acte dépendant. Donc le délit de complicité est un "délit cadre conditionné" par l'action principale. Cela permet évidemment de comprendre que la loi ou la jurisprudence n'hésite guère lorsque le degré de participation paraît a priori difficile à connaître ou a fortiori ne peut être déterminé. Car, lorsque le degré de participation est indéterminable, cette tendance très nette, qui ne tient aucun compte du degré de participation de chacun à l'agissement illicite s'impose. Telle est la solution, en matière de pillage, de la loi de 1948, de brande, de la loi anti-casseurs. De plus, ici, le caractère causal des agissements individuels est méconnu. Donc, à chacun est imputée l'action du groupe.

Cependant, certaines législations étrangères adoptent une autre solution assez nuancée surtout en matière de complicité corespective que nous avons examinée plus haut. Lorsque le degré de participation est indéterminé, la conception de la complicité corespective permet alors de punir les coparticipants à une infraction d'une peine inférieure à celle encourue par les co-auteurs et supérieure à celle prévue pour les complices (par exemple, l'article 463 du Code pénal turc). Mais la loi anti-casseurs paraît arriver à un résultat semblable. Car, cette loi prévoit une peine moyenne pour la présence active au sein du groupe, en vue d'éviter d'exiger la preuve d'une participation personnelle aux violences, d'une part, et en raison de l'absence de faute très apte à entraîner une répression sévère et de l'indétermination de la nature des violences, d'autre part. Or, dans un tel cas, puisqu'il n'est pas possible d'imputer un résultat précis, il est nécessaire de réprimer moyennement. La même tendance apparaît en matière d'association de malfaiteurs. Car l'entente en vue de commettre des crimes est sanctionnée d'une peine moyenne, en cette matière.

De telles solutions sont adoptées le plus souvent pour faire face à des dangers particulièrement graves. Plus le critère de la participation punissable est strict, moins elles paraissent critiquables ${ }^{103}$.

\section{g) Psychologie du délinquant et infraction collective:}

De nombreux écrivains attirent l'attention sur le caractère criminogène des groupes. Parce qu'il s'agit d'un affaiblissement de la personnalité individuelle dans les groupes, et, en particulier, dans la foule. Nous avons essayé d'expliquer cette question au début de notre modeste exposé.

${ }^{403}$ Dupeyron, étude précitée, pp. 379-387; Merle-Vitu, op. cit., I, pp. 627-657. 
Aussi, certaines législations (par exemple le Code pénal italien, art. 62/3) prévoient-elles une circonstance atténuante en faveur de celui qui a commis un délit par suggestion de la foule en tumulte, sauf dans l'hypothèse où la réunion était interdite et si le coupable est un délinquant d'habitude, de profession ou par tendance. C'est sans doute une circonstante subjective ${ }^{104}$.

Mais le droit français n'a pas prévu ce cas. Cependant, les tribunaux font, en général, application des circonstances atténuantes. Ils considèrent que les individus commettent tout de même des "infractions de contagion".

Cependant, on doit mettre l'accent sur la culpabilité individuelle et psychologique pour bien doser la criminalité de chacun. Sans doute, les plus coupables de l'infraction collective sont ceux qui ont pris les initiatives. Donc, la responsabilité de "meneur", (chefs) doit étre totale, mais celle des "menés" (simples participants ou subalternes) qui se sont laissés entraîner par la surexcitation collective et irréfléchie doit être envisagée avec une certaine indulgence. Cette conception a été mise en oeuvre en droit positif.

De nombreux textes qui incriminent plus sévèrement les chefs, auteurs instigateurs et provocateurs (art. 313), auteurs, directeurs de l'association, commandants en chef ou en sousordre (anciens art. 265 et suivant C.P.) peuvent être rattachés à cette tendance. De même, l'article 314 du Code pénal prévoit une peine de six mois à trois ans d'emprisonnement pour les instigateurs et organisateurs de rassemblements illicites ayant entraîné des violences; tandis que les participants aux rassemblements n'encourent qu'une peine de trois mois à deux ans. Par là, on voit apparaître à côté

${ }^{104}$ Comme nous l'avons indiqué au début de notre étude, le problème du délit commis par la suggestion de foule est étudié par les positivistes italiens, en particulier par Sighele et Florian, au point vue de la responsabilité. On peut consulter pour plus de détails à ce sujet: Antolisei, parte générale, p. 364; Battaglini, op. cit., p. 407; Bettiol-P. Mantovani, op. cit., pp. 595-595; Boscarelli, Compendio di diritto penale, parte generale. Milano. 1982, p. 197; Erem, op. cit., pp. 603-612; Erem, Adalet psikolojisi, Ankara, 1988, pp. 244-248; Stéfani-LevasseurJambu-Merlin, Criminologie et science pénitentiaire, Paris, 1968, $\mathrm{n}^{\mathrm{os}}$. 224-225; Manzini, (Pisapia-Nuvolone) op. cit., II. pp. 280, 281; Mantovani, op. cit., pp. 536, 537; Guadagno, Sull'attenuante dell'art. 62 n. 3 C P. in Foro penale, 1949, p. 32;; Guarneri, Concorso di persone nel reato e delitto di folla, Scuola positiva. 1962, 525; Ranieri, op. cit., p. 475; Santoro, Rilievi critico-costruttivi sulla circonstanze in attenuante della suggestione di folla tumultante, in Giustizia penale, 1962, II, 545; Colacci. La suggestione della folla in tumulto, In Scuola positiva, 1968, 231; Pradel, L'avant-projet de révision du Code pénal, Recueil Dalloz, Siney, chronique, 1977, p. 117. Bayraktar, Suç işlemeğe tahrik cürmú, Istanbul, 1977, p. 141 et s.; Yarsuvat, Toplantı ve gösteri yürüyüşleri hürriyeti ve ilgili ceza hükümleri, İstanbul, 1968, pp. 43-46. 
de l'accroissement des peines encourues pour les chefs la tendance à diminuer les pénalités applicables aux simples participants.

En outre, une autre tendance inverse apparait. Par exemple, l'article 441 du Code pénal français réduit la peine applicable à "ceux qui prouveront avoir été entraînés par des provocations ou sollicitations à prendre part aux pillages". De même "les individus faisant partie de bandes, sans exercer aucun commandement ni emploi seront punis de la détention criminelle à temps de dix à vingt ans" (art. 96 C.P.), tandis que "les chefs de bandes seront punis de mort" (art. 95 C.P.). Le législateur s'est inspiré du même souci dans les articles 213 et 214 alinéa 3 qui prévoient une excuse absolutoire sous certaines conditions que nous avons déjà examinées.

En résumé, on voit facilement que le législateur français traduit une technique nouvelle et originale de dosage de la criminalité en matière d'infraction collective. Ce dosage, en premier lieu, se fait par rapport au groupe, mais non par rapport au délit concernant les agissements du. groupe. En second lieu, il s'appuie surtout sur des données subjectives; l'activité matérielle reste au second plan, parce que, ceux qui ont physiquement participé aux actes délictieux (incriminés) ne sont pas nécessairement les individus les plus répréhensibles et punissables. C'est pourquoi, les tribunaux s'attachent, la plupart du temps, aux données objectives sans toujours donner la primauté à l'activité matérielle propre à chaque participant ${ }^{105}$.

\section{v. CONCLUSION}

Nous allon essayer de terminer notre modeste exposé par une conclusion aussi brève que possible. Car nous avons déjà examiné les aspects particuliers de l'infraction collective.

On peut dire que dans le processus historique, jamais les démocraties contemporaines ne se sont trouvées face à un aussi grand et aussi énigmatique défi que celui que constitue l'augmentation spectaculaire de la criminalité collective qui est devennue la caractéristique des sociétés urbaines industrialisées ${ }^{106}$. Face à cette criminalité multiforme qui, d'une part, "se trouve être fréquemment en symbiose avec la criminalité ordinaire"107, et qui, d'autre part, dispose des moyens d'action les plus puissants et "nous est corrélativement offerte par les nombreux épisodes de violence

105 Duffar, étude précitée, p. 75; D́upeyron, étude précitée, pp. 387-389; Merle-Vitu, op. cit., 1973, I, p. 518.

100 Bassiouni, étude précitée, p. 486.

197 Nuvolone, étude précitée, p. 749. 
gratuite, de destruction pour la destruction, de vandalisme, triste spécialisation de certaines bandes de jeunes voyous, dans un contexte politique ou en dehors de tout contexte politique" ${ }^{108}$, et donc, qui provoque une réaction profonde et.émotionnelle; toute l'humanité se demande: "Que faire pour arrêter ce flot toujours montant? Quelle doit être notre réaction? Quelles stratégies et quélles priorités devons-nous adopter?"1t. Voilà dans tout le monde, d'un bout à l'autre, le cri unanime qui est le meilleur indice du malaise que l'on éprouve devant l'impuissance de la loi pénale à protéger la sécurité publique, et voilà la preuve de l'inefficacité de la répression ${ }^{110}$.

Actuellement ces questions hantent la plupart des penseurs qui soulignent toujours la nécessité de trouver les moyens les plus éfficaces de la lutte contre la criminalité. Cette lutte "comporte sans doute, comme l'a dit $M$. Nuvolone, des programmes à brève échéance ainsi que des programmes à long terme. La réalisation des seconds n'importe aucunement de négliger les premiers, mais les prémiers seraient quelque chose de bien éphémère sans une sérieuse considération des possibilités de-résolution des seconds, qui impliquent une régénération foncière et une meilleure discipline des individus dans le cadre de la société civile""11.

Certes, il faut reprendre d'un regard toujours neuf les grandes questions relatives à l'organisation rationnelle de la réaction contre la délinquance et l'insécurité sociale. A cette délinquance et à cette insécurité, la communauté doit sans doute répondre par la prévention et la répression. Il importe plus de prévenir les crimes que de réprimer les criminels. C'est pourquoi, d'abord la prévention qui peut atteindre la racine du mal. Ensuite la répression qui est une chose nécessaire. Mais, il importe aussi de ne pas se trompèr. Il est certain que si un Pasteur invente un vaccin miraculeux contre l'infraction, nous l'espérons tous, à partir de ce jour-là, la police, les prisons, les menottes serviront seulement pour les musées ${ }^{112}$. Mais, pas encore aujourd'hui. Car, "l'infraction oppose en effet un individu au corps social tout entier; contre lui, pour le punir, la société a le droit de se dresser tout entière". Pourvu qu'on trouve de nouvelles techniques modernes pour ajuster au corps social les punitions et en adopter les effets et qu'on pose de nombreux principes pour régulariser, affirmer, universaliser l'art de châtier" ${ }^{\prime 13}$.

\footnotetext{
108 Nuvolone, étude précitée, p. 750.

109 Brown, étude précitée, p. 943.

110 Roux, Répression et prévention, Paris, 1822, p. 10.

11 Nuvolone, étude précitée, p. 750.

11 Carnelutti. Teoria generale del reato, Padova, 1933, p. 2.

21s Foucault, Surveiller et punir, Paris, 1884, p. 82.
} 
On voit qu'à ce sujet, les doctrines actuelles sont en train de rechercher les solutions satisfaisantes.

Quant aux solutions législatives, elles varient selon les pays bien que les législateurs quasi unanimes aient une tendance à réprimer ces agissements dans le monde moderne. En effet, dans chaque pays, le législateur ne veut pas que les libertés individuelles des citoyens soient menacées par le vandalisme aveugle de petits groupes de jeunes, comme si le pays était traversé par une vague de formes nouvelles de délinquance dite collective et souvent juvénile (halbstarken, teddy-boys, hooligans, blousons noirs, etc... ${ }^{114}$. D'ailleurs, nous voyons de manière cinglante cette tendance dans le communiqué de la loi du 8 juin 1970:

\begin{abstract}
"Depuis plusieurs mois, des formes nouvelles de délinquance se sont manifestées telles que les actions de petits groupes utilisent la violence pour entraver le fonctionnement normal des différentes activités qu'implique l'existence mème de la société et par là mème, pour atteindre les libertés individuelles de chacun. Il est apparu que les textes répressifs en vigueur n'épousaient pas ces formes nouvelles de délinquance et qu'il convenait de leur assurer la parade légale par l'intervention régulière et normale des tribunaux, parade qui est une véritable forme de défense de vie en société et donc des libertes. C'est

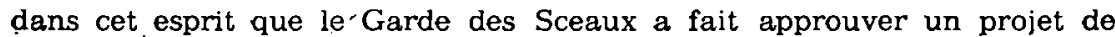
loi élaboré après consultation du Conseil d'Etat et qui apporte, en effet, un certain nombre d'innovations. Il s'agit de réprimer les rassemblements illicites ou interdits et les actions menées à force ouverte par des groupes lorsque des violences ont été commises contre les personnes et lorsque des destructions et dégrédations ont été causèes aux biens".
\end{abstract}

Dans ces circonstances, le législateur français, comme les autres, a agi plus sévèrement. L'article 314 dernier du Code pénal est un exemple remarquable en cette matière. On lit, dans l'exposé des motifs de cette loi que son objet général tend “à assurer avec la célérité et la fermeté désirables le maintien de la paix publique et le châtiment de ceux qui s'acharnent à la troubler par des actions violentes que réprouve l'immense majorité des citoyєns". D'ailleurs, le Garde des Sceaux a déclaré, à la tribune du Sénat, que le but essentiel du projet de loi a été "d'assurer une répression plus efficace des actes de violence"115.

Mais, on sait bien que le phénomène de délinquance depuis SIGHELE, s'attache en quelque sorte au processus d'imitation, de contagion et de suggestion dans les groupes. Car le psychisme particulier de l'individu se, modifie lorsqu'il se trouve entouré d'une multitude d'autres individus.

"14 La délinquance des jeunes en groupe, Centre de formation et deRecherche des

l'Education surveillee Vaucresson, 1963, chap., III, IV.

115 Journal officiel-Débats parlementaires, Sénat, 1970, p. 470. 
L'in'dividu et par voie de conséquence le groupe est électrisé par une étincelle de passion. C'est la raison pour laquelle le législateur italien, qui s'est inspiré des positivistes ${ }^{116}$, a considéré ce phénomène comme une circonstance atténuante subjective. Par contre, même dans ces conditions, en incriminant l'infraction collective, de façon générale et en la réprimant de manière spécifique, le législateur français a créé des cas de responsabilité collective et a voulu éteindre cette étincelle avant qu'elle s'enflamme, comme l'a dit, en la matière, le projet de loi du 8 juin 1970:

"...... un texte de dissuasion, destiné à faire prendre conscience des risques qu'il encourent à ceux qui seraient tentés de se laisser entrainer par la vague de violence".

En effet, dans le but de réprimer plusieurs vagues de banditisme qui ont déferlé sur toute la France depuis la fin du siècle dernier, un décret institue au Ministère de l'Intérieur un Office central pour la répression du banditisme - Décret $\mathrm{n}^{\circ} 73-952$ du 11 octobre 1973 - $^{117}$.

En résumé, s'il s'agit d'une infraction collective, la participation à une action collective est incriminée de telle sorte que la répression prend un caractère collectif. Par conséquent, on s'écarte des principes classiques. Les textes incriminent un état d'esprit, ron un acte. L'accent est mis sur les éléments subjectifs de l'infraction collective dans les tendances actuelles $\mathrm{du}$ droit français. Cette constatation est très importante. Car, puisque la conscience populaire veut que les auteurs de ces infractions qui soulèvent le plus la réprobation de l'opinion publique, soient sanctionnés par des peines graves et que ces infractions soient prévenues, on peut et on doit créer la collectivisaiton de la responsabilité pénale. Ce n'est pas remonter à l'époque ancienne et primitive, bien au contraire, c'est l'expression de la volonté générale dans les régimes démocratiques.

Partant de cela, à notre modeste avis, le législateur français a pour but de prévenir les perpétrations des infractions collectives. Aussi agit-il, d'une part, en fonction du but dissuasif et du caractère préventif de la peine et, d'autre part, en fonction de la vieille maxima attribuée au philosophe Sénèque "Vox populi, vox Dei".

116 Voir, référence $\mathrm{n}^{\circ} .104$.

117 Journal officiel, 13 octobre 1970, p. 11-43. 


\section{TÜRKÇE ÖZET:}

Yüzyılımızın başında Durkheim, suçun doğal bir toplum olgusu olduğundan söz etmişti. Ancak, günümüzde bu ,olgu, zaman zaman kamuoyunu sarsan boyutlara ulaştı. Özełlikle, örgütlü çeteler, düzene başkaldıran insan kümecikleri, bir sözcükle toplu suçlar tüm dünyayı düşündürmeye başlad.

Toplu suç teriminin anlamı konusunda birlik yoktur. Ancak, ansizın ya da önceden doğmuş bir iradeyle oluşan her insan kümesi genellikle bu terimin içine sokulmaktadır. Aslında bunlar arasındaki çizgiyi belirlemek de güçtür. Ancak, örgütlü bir topluluğun bu özelliği de göz ardı edilmemelidir.

$\mathrm{Bu}$ tür insan topluluklarnyla, yalnızca suç açısından hukukçular ilgilenmemişlerdir. Ruhbilimciler, toplumbilimciler, suçbilimciler, yazın adamları da ilgilenmişlerdir. Bu da konunun çok boyutlu ve çok disiplinli oldugunun kanıtıdır. Bu incelemeciler, ceza hukukuna elbette ışı tutmuşlardir. Bunlar arasinda özellikle Sighele, Tarde, Le Bon, Mac Dougall, Freud, Jung, Adler, Espinas'nın katkıları büyüktür.

Bu düşünürler, topluluk içinde insanın nasıl kolaylıkla suça itilen yeni bir kişiliğe büründügünü vurgulamaya çalışmışlardır. Bu düşünce yalnızca kuramsal alanda kalmamıştır. Örneğin, 1930 tarihli İtalyan Ceza Yasasının 62. maddesinin 3. bendi, bu tür bir toplulukta suç işlemek durumunda kalan suçlunun cezasının indirileceğini belirtmiştir. Yeter ki, fail, suçu alışkanlık ve mèslek edinmemiş ve toplantı da yasaklanmamış olsun.

Ancak son yılliarda, bu tür suçlardaki artış karşısında, yasa koyucular daha sert önlemler almak eğilimi göstermişlerdir. Gerçi, ceza yasalarının hemen tümünde, toplu halde suç işleme (komplo, toplu irza geçme, toplu hursızlık gibi) ağırlaştırıc neden olarak benimsenmiştir. Ancak, son yıllarda, bunlarla yetinilmemiş, özellikle kişilere ve malvarlıklarına yöneldiklerinde ağır sonuçlar doğuran, ülkenin bir ucundan öteki ucuna tüm kamuoyunu tedirgin eden ve bu özellikleriyle hemen her ülkede gündemde bulunan terorizme ve toplu suçlara karşı yasa koyucular, ceza hukukunun temel ilkelerini. zorlayan normlan benimsemek durumunda kalmıslardır. Özellikle incelememizin odağını oluşturan Fransa'da da, Mayıs 1968 ayaklanmalarının etkisi ile bu tür yasalaşmalara tanık olunmuştur. $8 \mathrm{Ha}$ ziran 1970 tarihli olup, kamuoyunda "kırıcılara karşı yasa" adıyla yaygınlaşan ve resmen "suçluluğun kimi yeni biçimlerini cezalandırmaya yönelik yasa" diye anılan yasa, bunun en çarpıcı örneğidir. Düşünürlerin şiddetle eleştirdikleri bu yasa, bireysel cezaî sorumluluk ilkesinin yerine 
ortak sorumluluk ve başkasinın eyleminden sorumlựuk anlayışını getirmiştir. Dayandığı temel gerekçe de, ceza hukukunun toplumu korumakla yükümlü olduğudur. Bireyselciliğin beşiği olan bir ülkede bu gerekçenin benimsenmesi, hem ilginçtir ve hem de dünyanm bu konuda hangi çizgilerde bulunduğunun çarpıcı bir göstergesidir. Bu konuda, suça katılma, kusur ve suçlanabilirlik (isnadiyet) kavramlarının da bu akımdan etkilendiği açıktır.

Toplu suç konusunda şimdilik ulaşılan noktalar bunlardır. Ancak kesin çözümler için, insanlığın kuram ve yasama alanlarında yeterli deneyimi olmadığınđan, zamanın erken olduğunu belirtmek gerekir. Bütün dünyada bu konudaki arayışlar sürmektedir. Denilebilir ki, toplumsal yarar ile bireysel yarar değerleri arasındaki çatışma, belki de tarihin hiç bir döneminde bu denli çarpıcı olmamıştır. Dünya, her iki değere de yeterince pay ayırıcı ve bunları uzlaştırıcı bir çözümün henüz çok uzağında görünmektedir. Kısa ve uzun vadeli planlamalarda ulaşılacak optimal bir çözüm, kuşkusuz _nsanlığın ortak dileğidir. Biz de bu dileğe katılmaktayiz. 